NASA Technical Memorandum 105417

AIAA-92-3916

\title{
Flow Quality Studies of the NASA Lewis Research Center 8- by 6-Foot Supersonic/9- by 15 -Foot Low Speed Wind Tunnel
}

E. Allen Arrington

Sverdrup Technology, Inc.

Lewis Research Center Group

Brook Park, Ohio

and

Mark T. Pickett

National Aeronautics and Space Administration

Lewis Research Center

Cleveland, Ohio

Prepared for the

17th Aerospace Ground Testing Conference

sponsored by the American Institute of Aeronautics and Astronautics

Nashville, Tennessee, July 6-8, 1992 
9- BY 15-FOOT LOW SPEED WIND TUNNEL

\author{
E. Allen Arrington \\ Sverdrup Technology, Inc. \\ Lewis Research Center Group \\ Brook Park, Ohio 44142 \\ and \\ Mark T. Pickett \\ National Aeronautics and Space Administration \\ Lewis Research Center \\ Cleveland, Ohio 44135
}

\begin{abstract}
$\underline{\text { Abstract }}$
A series of studies has been conducted to determine the existing flow quality in the NASA Lewis 8- by 6-Foot Supersonic/ 9-by 15-Foot Low Speed Wind Tunnel. The information gathered from these studies was used to determine the types and designs of flow manipulators which can be installed to improve overall tunnel flow quality and efficiency. Such manipulators include honeycomb flow straighteners, turbulence reduction screens, corner turning vanes, and acoustic treatments.
\end{abstract}

The flow quality studies were conducted at several locations around the tunnel loop. Pressure, flow angularity, temperature, and turbulence measurements were made with both fixed and translating probes. Flow visualization techniques using both video (smoke and tufts) and still photography (oil flow patterns) were also used in these studies. A large portion of the study focused on the flow entering and exiting the seven-stage axial flow compressor. The flow entering both the 8- by 6 - $\mathrm{ft}$ and the 9 - by 15 - $\mathrm{ft}$ test sections was also examined in detail. Dynamic pressure measurements were made to determine the operating conditions within the compressor.

Previous measurements in the tunnel indicated possible flow disturbances originating in the compressor. To examine this possibility the flow both entering and leaving the compressor was surveyed. Flow visualization at the compressor inlet showed that the north side of the compressor is receiving less flow than the south side. However, since velocity and flow angularity surveys at the compressor exit showed that the flow is evenly distributed at the compressor exit, there is no apparent discontinuity feeding through the compressor due to the nonsymmetric inlet flow. Dynamic pressure transducers in the compressor casing showed no indication of rotating stall.
Flow visualization and pressure measurements revealed a large separation region on the north side of the compressor exit tailcone when the tunnel is operating at conditions producing Mach numbers greater than 1.6 in the 8 - by $6-\mathrm{ft}$ test section. The flow visualization (tufts) showed separation off the entire downstream third of the north side of the tailcone, and reversed flow areas on the cone surface. Velocity surveys downstream of the tailcone also showed a velocity deficit along the north side of the tunnel coinciding with the separation off the tailcone. However, this velocity deficit is greatly reduced by a single turbulence reduction screen at the inlet to the 8 - by 6 -ft test section bellmouth.

\section{$\underline{\text { Introduction }}$}

The NASA Lewis Research Center 8- by 6-Foot Supersonic/9- by 15 -Foot Low Speed Wind Tunnel is shown in Fig. 1, together with 11 measurement locations around the tunnel loop. The tunnel is a continuous flow propulsion wind tunnel. The 8 - by 6 - $\mathrm{ft}$ test section has a Mach number range of 0.36 to 2.0. The $9-$ by $15-\mathrm{ft}$ low speed test section has a Mach number range of 0 to 0.20 . Since the end result of the study is to improve the flow quality in the test sections (primarily the 8- by 6 -ft test section), the test conditions are referenced to the Mach number measured in the 8- by 6-ft test section unless otherwise noted. Measurements made in the settling chamber upstream of the 9 - by 15 -ft test section are referenced to the Mach number measured in the 9 - by 15 -ft test section.

This report describes the measurements, instrumentation, and results obtained from the experiments conducted in each area of the tunnel.

\section{Description of Facility}

The 8 - by 6 -Foot/9- by 15 -Foot Wind Tunnel ${ }^{1,2}$ is an atmospheric-pressure, continuous-flow propulsion 
wind tunnel. The 8- by 6 - $\mathrm{ft}$ test section is a porous-wall test section with a Mach number range of 0.36 to 2.0. The tunnel can be operated in either an aerodynamic (closed loop) or propulsion (open loop) cycle. For the tests described in this report, the tunnel was run in the aerodynamic cycle except where specifically noted. The test section conditions were set by controlling the following four parameters: compressor speed, flexible wall position, balance chamber pressure, and shock door (second throat) position. There are five different transonic test-section configurations in the 8 - by 6 - $\mathrm{ft}$ test section based on the test-section porosity and model position. (The test-section porosity can be varied by physically plugging the holes in the porous walls.) The test-section configuration also depends on the length of the test section to be used for a particular model. These lengths are 8 and $14 \mathrm{ft}$, where the shorter test section is simply the aft $8 \mathrm{ft}$ of the 14-ft test section (Fig. 2). The five transonic test-section configurations are as follows:

(1) $14 \mathrm{ft}, 5.8$-percent porosity

(2) $8 \mathrm{ft}, 6.2$-percent porosity

(3) $8 \mathrm{ft}, 3.1$-percent porosity

(4) $8 \mathrm{ft}, 6.2$-percent porosity modified

(5) $8 \mathrm{ft}, 3.1$-percent porosity modified

A solid wall supersonic test section lies upstream of the porous wall section. Tunnel station 0 is the beginning of this supersonic test section.

The 9- by 15 -ft test section is located in the return leg of the 8 - by $6-\mathrm{ft}$ wind tunnel loop. This test section is of slotted wall construction with an 11-percent open area and has a Mach number range of 0 to 0.2 . Conditions in the 9 - by 15 -ft test section are controlled by the large flow-control doors located upstream of the test section (Fig. 1).

The flow-conditioning devices installed in the settling chamber upstream of the 8- by 6 -ft test section include a honeycomb flow straightener (with a length-todiameter ratio (L/D) of 5) and one 12-mesh turbulence reduction screen. There are no flow conditioning devices upstream of the 9 - by 15 -ft test section.

\section{$\underline{\text { Instrumentation }}$}

\section{Flow Visualization}

Two methods of flow visualization were used in the flow quality studies. The first was the video recording of smoke and tufts. The second method used still photography to record oil flow patterns on the tunnel surfaces. The lengths and diameters of the tufts used in these studies were arrived upon as a compromise between aerodynamic considerations and the ability to view and record the tufts.
In the compressor plenum chamber, video cameras were used to record smoke traces and the motion of tufts attached to the compressor-inlet protection screen. The test setup is shown in Fig. 3. The smoke was produced in the duct between the air dryer building and the compressor plenum chamber. Small electrically ignited canisters were mounted on cables in the duct at two heights (12 and $27 \mathrm{ft}$ above the floor of the tunnel). The lower level smoke canisters were at about the same height as the center of the compressor inlet, and the upper level smoke canisters were even with the top of the compressor inlet. Each canister was capable of producing $100000 \mathrm{ft}^{3}$ of smoke over a 5 -min period. To aid in the smoke portion of the test, lights were installed in the locations shown in Fig. 3. Video cameras and recording equipment were set up in the drive motor building such that both sides of the compressor inlet could be viewed simultaneously.

Further flow visualization testing was conducted at the compressor inlet using tufts tied to the inside of the support structure of the compressor-inlet protection screen (Fig. 4). The tufts were made of 10 -in. lengths of 1/4-in. nylon rope. This setup was used in order to better visualize the flow at the compressor face. The motion of the tufts was again recorded on videotape during these tests. The size of the tufts used at the compressor inlet and on the compressor exit tailcone fairing was a compromise of aerodynamic and photographic considerations (small enough not to effect the flow patterns greatly and large enough to be seen and recorded).

To accomplish the flow visualization on the compressor exit tailcone fairing, cameras and lighting had to be installed inside the tunnel. Environmental enclosures were made to protect the cameras from both high temperatures and airstream contamination. Vortex coolers were used to cool the cameras. Each camera enclosure, together with two halogen lamps, was mounted on a tripod support which was welded to the tunnel walls downstream of the tailcone. Two such assemblies were built and mounted in the tunnel, one on either side of the tailcone (Fig. 5). The surface of the tailcone and portions of the tunnel walls were painted black to provide the contrast needed to record the motion of the tufts (Fig. 6). The tufts were made of 8 -in.-long pieces of 3/16-in.-diameter nylon rope. Tufts were mounted to the downstream $10 \mathrm{ft}$ of the tailcone surface, the upper surfaces of two of the support struts, and portions of the tunnel walls. Cables were also mounted between the end of the tailcone and the tunnel walls, with tufts attached at 6-in. intervals. Four such cables were used: two in the vertical plane and two in the horizontal plane. Monitoring and recording equipment was set up in the tunnel control room. The 
apparatus used for the flow visualization was not installed in the tunnel during the pressure surveys.

The second method of flow visualization used in the flow quality studies was still photography of oil flow patterns on the compressor exit tailcone fairing and in the contraction area upstream of the 8 - by 6 - $\mathrm{ft}$ test section. A mixture of high-viscosity oil and Zyglo dye, which fluoresces under ultraviolet light, was painted on the tunnel surfaces of interest. During tunnel operation, the streamlines on the painted surface formed patterns in the oil mixture. Since the mixture was fairly thick, the streamlines remained in place after the tunnel had been shut down. The flow patterns were then photographed in color using ultraviolet lighting and a $35-\mathrm{mm}$ camera.

Flow-Sensing Probes and Support Systems

Several different types of flow-sensing probes were used in the flow quality studies including pitot-static probes, five-hole hemispherical-head flow angularity probes, thermocouples, and hot-film probes. Each of the probe types, their associated support systems, and the locations used are described as follows.

Pitot-static probes. The pitot-static probes were used to determine pressure levels and velocities in turns 1 and 2 , at the cooler inlet, and on the honeycomb flow straighteners in the settling chamber upstream of the 8- by 6 -ft test section (Fig. 1). These probes were mounted directly to the tunnel structure.

Flow angularity probes. A typical example of a five-hole hemispherical-head probe used in this program is shown in Fig. 7. This type of probe is capable of sensing two components of flow angle as well as total and static pressure. These probes were mounted in groups of five in two rakes in order to determine the flow angles (radial and swirl) at the compressor exit and compressor tailcone fairing exit. Figure 8 shows the rake used at the compressor exit station; a similar rake was used at the tailcone exit station. These probes were also mounted to traversing plates in order to determine the flow angularity and pressure distributions at several tunnel locations. These probes were calibrated for flow angle at Mach numbers between 0.2 and 0.6 . The accuracy of the flow angle measurements with these probes based on the calibration and the measurement system is $\pm 0.25^{\circ}$.

Hot-film anemometry. Hot-film anemometry was used to measure both mean flow and turbulence intensity. The anemometer bridge circuit used was a commercial, constant-temperature, hot-film anemometer type. A commercial, personal-computer-based software package was used for bridge circuit setup and control and data acquisition and analysis.

Unsteady pressure measurements. High response dynamic pressure transducers were used in the compressor casing to detect a rotating stall cell. These transducers have an accuracy of 0.5 percent of full scale reading.

Wind anemometers. Two types of wind anemometers were used in these studies. A hand-held model was used to determine the velocity distribution at the air dryer inlet (air speed only), and a vane anemometer was used at various locations around the tunnel loop to determine air speed and flow angularity. Both types of anemometers are shown in Fig. 9. The hand-held model has an accuracy of 0.5 percent of the instrument reading. The vane anemometer accuracy is $\pm 3.28 \mathrm{ft} / \mathrm{sec}$ for airspeed, $\pm 0.35^{\circ}$ in pitch, and $\pm 0.25^{\circ}$ in yaw.

Traversing plates. In order to obtain velocity and pressure distribution data across large sections of the tunnel, a traversing plate mechanism was used. The apparatus consisted of a flat plate supported by cables at the leading and trailing edges. The cables were attached to channels that were mounted to the tunnel walls. The leading edge cable rode on a pulley that was driven by a remotely controlled electric motor so that the plate could be positioned at any point across the tunnel. This setup was used in the settling chambers of both the 8 - by 6 - $\mathrm{ft}$ and the 9 - by 15 -ft test sections, the inlet to the contraction section of the 8 - by 6 - $\mathrm{ft}$ test section, and the exit of the high-speed diffuser. Figure 10 shows this apparatus installed in the settling chamber of the 8- by 6 -ft test section. Several different types of probes were run in various combinations on these traversing plates. Instrumentation included pitotstatic probes, flow angularity probes, hot-film probes, thermocouples, and wind anemometers.

\section{$\underline{\text { Data Systems }}$}

The standard tunnel data system was used for the measurements made between the compressor exit and the 8- by 6 -ft test section. This tunnel data system consists of a VAX-based data acquisition system in conjunction with an electrically scanned pressure system (ESP). For these tests, 15-psid ESP modules were used so that the accuracy of the pressure measurements was 0.015 psia.

Since several of the test locations were large distances from the tunnel data system, a mobile data system was used. This mobile system consisted of a dual 48-channel scani-valve system and a dual 30-psia digi-quartz transducer/computer system. This system 
was used to take data at the 8- by 6-ft test section diffuser exit, in turns 1 and 2 , and in the settling chamber upstream of the 9 - by 15 -ft test section. The accuracy of the mobile system is 0.0030 psia.

\section{$\underline{\text { Results }}$}

\section{Flow Visualization}

Area 1: Compressor plenum/inlet. Area 1 (Fig. 1) is the plenum chamber which houses the seven-stage axial compressor that drives the wind tunnel. The major concern in this area was the distribution of the airflow into the compressor inlet. The airflow enters the compressor plenum room from the air dryer building via a short connecting duct (Fig. 3). Becsuse of the blockage from the drive shaft bearing housing and the large pylons which support the compressor, and the fact that the flow enters the compressor from the side, it appears that the north side of the compressor (the side away from the inlet duct) might be deprived of air. This could affect the performance of the compressor as well as the quality of the airflow downstream of the compressor.

Flow visualization techniques were used to examine the flow distribution into the compressor inlet. Smoke generators were placed at two heights in the duct in order to determine how the airflow from the air dryer enters the plenum chamber. The smoke traces were recorded with video cameras from the observation windows inside the drive motor building; there are two sets of windows, one on each side of the compressor inlet so that the inlet duct and both sides of the compressor inlet can be viewed simultaneously (Fig. 3).

The smoke produced in the inlet duct was used to answer two questions: (1) does the airflow exit the connecting duct as a jet flow or does it attempt to fill the compressor plenum and thus produce a somewhat uniform flow through the compressor, and (2) how is the flow being distributed around the compressor inlet? Figure 11 illustrates the smoke traces into the compressor inlet. The traces showed that the air was exiting the connecting duct as a jet and that there was no apparent settling of the air entering the chamber so that the effect of the plenum chamber was diminished. The smoke traces produced by the lower level smoke generators (those approximately even with the center of the compressor inlet as shown in Figs. 11(a) and (c)) showed that the flow moved straight out of the inlet duct and into the south side of the compressor inlet; none of those traces were seen moving to the far side of the compressor. The smoke from the generator nearest to the drive motor building showed that the flow impacted on the bearing housing, then entered the compressor inlet. The upper level smoke generators (those even with the top of the compressor inlet, Fig. 11(b)) produced smoke traces which entered the compressor at the top of the south side, although some traces could be seen entering on the back side of the compressor (north side). Although the smoke traces showed that the plenum chamber was not acting as a settling area, they did not confirm the actual airflow distribution into the compressor inlet.

In order to augment the smoke flow study, tufts were mounted to the compressor foreign object damage (FOD) screen in two configurations. In the first configuration, the tufts were tied directly to the inside of the screen on both sides of the inlet, thereby giving a direct comparison of the flow entering either side of the inlet. These tufts supported the concern that the airflow is not evenly distributed into the compressor inlet and that less flow may be entering the north side of the compressor. Figure 12 shows some of the general trends for the tufts in the first configuration. The tufts on the south side of the inlet indicated steady flow into the inlet (tufts pointing into the compressor with very little swirling motion). However, the tufts on the north side of the compressor indicated a very poor distribution of flow and very large swirling components. Many of the tufts indicated either no flow or very low flow velocities, especially in the lower quarter on the north side of the inlet.

In the second configuration, tufts were tied to nylon ropes which were stretched across the compressor bellmouth inlet thus showing flow paths closer to the compressor than the first configuration. From observing the motion of these tufts, it appears that the flow actually crossed the face of the inlet to enter on the north side. The tufts on the south side of the compressor inlet indicated a stronger flow into this side of the compressor than on the north side. Figure 13 shows the general tuft patterns at the compressor inlet for the second configuration.

Area 2: Compressor exit tailcone fairing. Both types of flow visualization techniques used to study the flow patterns over the compressor tailcone showed that the flow was much more stable on the south side of the tailcone than that on the north. The oil flow visualization (Fig. 14) clearly showed streamlines on the south side of the cone around the support struts, but no definite patterns on the north side. The oil pattern test was conducted in the $8-$ by 6 - $\mathrm{ft}$ test section at a Mach number of $0.8\left(\mathrm{M}_{8 \times 6}=0.8\right)$.

The tuft flow visualization was conducted over the entire operating range of the tunnel. An example of the results is shown in Fig. 15. The tufts showed that the flow was attached at the cone surface, on the support struts, and on the tunnel walls for flows corresponding to test-section Mach numbers between 0.4 and 1.6. At 
test-section Mach numbers above 1.6, the flow began to separate from the north side of the cone. The flow was fully separated on the north side of the cone at test-section Mach numbers above 1.8. This area of separation covered the downstream third of the cone (approximately $10 \mathrm{ft}$ ). There was also evidence of reversed flow and large swirl angles on the north side of the cone. The south side of the cone showed no evidence of separation. The flow appeared to be attached to the tunnel walls on both the north and south sides of the tunnel for all test conditions. At test-section Mach numbers below 1.6, the tufts on the struts near the tailcone generally followed the contour of the tailcone; however, at test-section Mach numbers above 1.6, the tufts on the north strut showed that the flow was no longer following the tailcone contours, indicating flow separation from the tailcone surface.

Area 4: Contraction. Flow visualization using oil flow was performed in the bellmouth at test-section Mach numbers of 0.8 and 1.8. The oil was applied to the south wall of the tunnel from the floor to the vertical centerline and on the floor of the tunnel from the centerline to the south wall. The oil was applied from the exit of the contraction into the flex wall section. The oil patterns showed that the flow was attached through the painted area and that there was no evidence of any large-scale flow separation in the test area. Figure 16 shows typical flow patterns on both the tunnel wall and the floor at $\mathrm{M}_{8 \times 6}=1.8$.

\section{Velocity, Flow Angle, and Pressure Surveys}

Figure 17 shows the section of the tunnel loop between the compressor discharge and the 8 - by 6 -ft test section, and presents the locations of the survey stations in this section of the tunnel.

Area 2: Compressor exit and tailcone fairing. Three different rakes were used to survey velocity, flow angularity, and boundary layer thickness along the compressor exit tailcone fairing. Each rake was run in four positions around the circumference of the tailcone as shown in Fig. 18 and, in each position, was tested over the entire test-section Mach number range. The rake positions are given in terms of clock positions referenced to a viewer standing in the settling chamber and looking upstream into the compressor discharge; 12 o'clock corresponds to the top of the tailcone, 3 o'clock is the south side of the tailcone (inside of tunnel loop), and so on. At the compressor exit station and the boundary layer rake station, the rakes were positioned at the 3, 6, 9, and 12 o'clock locations; at the tailcone exit station, the rake was positioned at the 3,6 , 7, and 9 o'clock locations. Figure 18 also defines the flow angularity orientations. It was not possible to mount a rake at the 12 o'clock position at the tailcone exit because the distance between the tailcone and the tunnel wall was physically too small to allow the rake to fit.

Compressor exit survey: Figure 19 shows the velocity distributions at the compressor exit for each rake position for selected test-section Mach numbers. The highest exit velocity occurred at a test-section Mach number of 1.0, which corresponds to the maximum mass flow condition. Also, at every test section condition except $M_{8 \times 6}=2.0$, the exit velocity was higher at the cone surface than at the tunnel wall.

The flow angularity data from the compressor exit rake are shown in Figs. 20 and 21 . The radial flow angle (Fig. 20) was generally toward the tailcone body (positive radial flow angles are toward the tailcone body) and increased as the distance from the tunnel wall increased. The radial flow angle also increased as $M_{8 \times 6}$ increased. The swirl flow angle (Fig. 21) was in the direction of the compressor rotor rotation.(Negative swirl flow angle indicates that the flow direction was in the direction of compressor rotation.) The swirl angle was between $0^{\circ}$ and $-5^{\circ}$ for each rake position and test condition.

Tailcone exit survey: The velocity distributions at the tailcone exit are given in Fig. 22. Again the maximum velocity occurred at a test-section Mach number of 1.0. The distribution in general was an annular flow. However, at test-section Mach numbers above 1.6, the distribution did not follow this type of pattern, and the velocity near the cone surface approached zero, particularly at the 7 and 9 o'clock positions. This would indicate flow separation from the cone. At the $60^{\circ}$ 'clock position, the velocity distribution was slightly skewed toward the cone, except for test conditions above $\mathrm{M}_{8 \times 6}=1.6$.

Flow angularity data are presented in Figs. 23 and 24. In the radial flow direction (Fig. 23), the flow angle was toward the cone (positive angles) except at the 9 o'clock rake position where negative radial flow angles were measured near the tunnel wall. The general trend for the radial flow direction is an increase in flow angle as distance from the tunnel wall increases. This trend is consistent with the tailcone slope of $20^{\circ}$ at this position. At all test-section Mach numbers, large radial flow angles (over $10^{\circ}$ ) measured next to the cone indicate that the flow was attempting to follow the contours of the tailcone, as it should. At the higher test-section Mach numbers, the flow angle next to the cone was over $20^{\circ}$. Although this indicates the presence of a large flow angle, the absolute magnitude is questionable because the probes were not calibrated at high angles at low air speeds. The swirl flow angles (Fig. 24) showed that the flow is in the direction of the 
compressor rotation (negative angles). The swirl flow angles were between $0^{\circ}$ and $-5^{\circ}$, except for the $6 o^{\prime}$ clock rake position, where the flow angles range from $-5^{\circ}$ to $-10^{\circ}$. The magnitude of the flow angle was fairly constant at each survey plane for all $\mathrm{M}_{\mathbf{8 \times 6}}$ conditions, with slightly smaller flow angles recorded at the cone.

Tailcone boundary layer rake: The total pressure surveys made using the boundary layer rake are given in Fig. 25. The data presented were normalized using the total pressure measured by the probe located 8 in. from the cone surface. The pressure profiles had the largest slope at a test-section Mach number of 1.0. The pressure gradient decreased as $\mathrm{M}_{\mathbf{8 \times 6} 6}$ moved away from 1.0.

Area 3: Settling chamber (8- by 6-ft test section). To determine the flow characteristics in the settling chamber, both moving and fixed probes were used. Traversing plates with pitot-static probes, hot films, and thermocouples attached to them were used to make both horizontal and vertical surveys. Also, 16 pitot-static probes were mounted to the honeycomb flow straightener to survey the flow at the honeycomb face.

Traversing survey data: The velocity distributions in the settling chamber obtained with pitot-static probes along both horizontal and vertical centerlines are given in Fig. 26. The surveys along the horizontal centerline showed a velocity deficit at the center of the tunnel, with the highest velocities occurring on the south side of the tunnel centerline. The vertical surveys also showed a velocity deficit at the center of the tunnel, but the vertical surveys are symmetrical with respect to the tunnel centerline. Note that along both survey planes, the deficit area is larger at the higher test-section Mach numbers. This is due to the separated flow off the north side of the compressor tailcone. Also note that the horizontal and vertical survey planes are not in the same axial plane in the settling chamber; the horizontal test plane is about 3 - $\mathrm{ft}$ upstream of the vertical test plane (a necessity to conduct surveys along both survey paths simultaneously). This offset could explain the offset between the points measured at the centerline of the tunnel along the horizontal and vertical survey planes.

Velocity and axial turbulence distributions compiled using hot-film anemometry equipment are given in Figs. 27 and 28, respectively. The velocity distributions from the hot films showed the same trends as measured with the pitot-static probe velocities, although the magnitude of the measured velocities from the two sources did not agree. The distributions measured with the hot film did not indicate as high a peak or as low a trough as those measured with the pressure probes. This difference in magnitude is mainly due to losses in the cables used between the hot-film probe and the bridge circuitry. (The required cable lengths were longer than recommended for this system because of measurement location constraints.) Turbulence intensity data (Fig. 28) showed that for test-section Mach numbers below 1.6, the turbulence intensity in the settling chamber was between 10 and 20 percent, with the higher values near the tunnel walls. At conditions above $M_{8 \times 6}=1.6$, the turbulence intensity was higher, generally between 20 and 40 percent, with the highest values recorded at the centerline of the settling chamber. This is most likely due to flow separation from the tailcone.

Temperature distributions are presented in Fig. 29. These surveys show that, over most test conditions $\left(\mathrm{M}_{8 \times 6}\right.$ below 1.8$)$, there were only small temperature variations along both the vertical and horizontal survey planes in the settling chamber. At these conditions, the total temperature at the center of the tunnel was 3 to $5{ }^{\circ} \mathrm{R}$ higher than at the tunnel walls, the temperature at the tunnel walls being equal. At the $\mathrm{M}_{8 \times 6}=2.0$ condition, however, there was a noticeable temperature gradient along both survey planes. The variation in total temperature is particularly evident along the horizontal survey plane, where the temperature at the south tunnel wall was $35^{\circ} \mathrm{R}$ higher than at the north tunnel wall. The cause of this temperature gradient at $M_{8 \times 6}=2.0$ is not apfarent.

Honeycomb-mounted probes: Sixteen pitot-static probes were mounted to the honeycomb flow straightener in the settling chamber as shown in Fig. 30. Each of the radial legs consisted of five probes, with the remaining probe at the center of the honeycomb. Figure 31 shows the velocity distributions along each of the three legs at each test condition. Note the deficit in the center of the tunnel at all operating conditions. At the higher test-section Mach numbers, the velocity in the settling chamber was greater at the tunnel walls than in the center of the tunnel. Also note that the highest velocities were generally recorded near the middle of each arm. This is due to the presence of the tailcone fairing upstream of the settling chamber. The results from the honeycomb-mounted probes are consistent with those from the settling chamber traverses.

Area 4: 8- by 6-ft test section bellmouth. Two tests were conducted in the bellmouth area: a horizontal survey at the bellmouth inlet using the traversing probes, and boundary layer profiles at the bellmouth exit (beginning of the flexible wall section).

Bellmouth inlet survey data: The same measurements that were made in the settling chamber were made at the bellmouth inlet. These measurements were used to determine the effect that the present honeycomb and screen have on the flow and to determine what additional flow manipulators may be needed to improve 
the quality of the flow entering the test section. The bellmouth itself begins directly downstream of the turbulence reduction screen; the survey plane in the bellmouth inlet was about 12 in. downstream of this screen.

Figure 32 shows the velocity distributions measured with the pitot-static probes. In general, for test conditions corresponding to $\mathbf{M}_{8 \times 6} \leq 1.6$, the velocity distribution profiles at the bellmouth inlet matched those for the settling chamber, although the magnitudes were smaller in the bellmouth and the velocity peaks were smoothed somewhat because of the presence of the turbulence reduction screen. At test section conditions above $M_{8 \times 6}=1.6$, the effect of the screen was more significant. The screen redistributed the flow such that the nonuniformity in the velocity distribution is greatly reduced at the bellmouth inlet.

Hot-film anemometers were also used in the bellmouth inlet survey. The velocity results (Fig. 33) showed trends similar to the velocity measurements made with the pressure probes, but, as in the settling chamber, the magnitudes were not the same. Turbulence intensity results (Fig. 34) showed that, for all test conditions, the turbulence intensity was between 4 and 10 percent. This reduction in turbulence intensity is due to the honeycomb flow straightener and screen. The honeycomb and screen reduced the turbulence levels from about 20 percent in the settling chamber to 5 percent at the bellmouth inlet.

Total temperature data is presented in Fig. 35. The trends here are the same as those found in the settling chamber, including the large temperature gradient at the $\mathrm{M}_{8 \times 6}=2.0$ condition.

Boundary layer rakes: Two boundary layer rakes (total pressure rakes) were mounted at the exit of the bellmouth as shown in Fig. 36, one mounted near the centerline of the tunnel floor and the second in the corner along the south tunnel wall. Over the entire test range, both rakes showed that the boundary layer at the bellmouth exit was less than 2 in.: centerline rake, 1.22 in.; corner rake, less than 1.75 in. (Fig. 37). Also, no indication of flow separation was observed at the rake stations. This is consistent with the flow visualization results from this location.

Areas 5 and 6: Test section and high-speed diffuser. Static pressure distributions through the test section and diffuser are given in Fig. 38. These data are for empty test section conditions (no model installed). The porous section of the test section begins at around tunnel station 109 and extends to tunnel station 282 (14 ft, 5 in. total length). The 8-ft-long test section begins at tunnel station 186 . At this point a discontinuity in static pressure was recorded. Static pressure de- creased at supersonic test conditions, but increased at subsonic conditions. This is due to the change in local test section porosity between the two test section lengths and the distribution of the porosity holes. The test section configuration for these tests was $14 \mathrm{ft}$, 5.8-percent porosity (full open test section).

Traversing probes were used to determine the velocity distribution of the flow exiting the high-speed diffuser. The results of these surveys are given in Fig. 39. For the conditions studied, the profiles across the exit of the diffuser were very flat except for the $\mathrm{M}_{\mathbf{8 \times 6}}=\mathbf{1 . 8}$ condition, which showed a velocity gradient near the south tunnel wall.

Areas 7, 8, and 9: Turn 1, turn 2, and the cooler inlet. Pitot-static probes were mounted in these areas in order to determine velocities and pressure levels. However, because of the low airspeeds in these areas, the measurements from most of these probes were determined to be unreliable and were not used in the flow quality analysis.

One set of probes was used to determine the velocity at the exit of the acoustic muffler section between turns 1 and 2 . There are six passages through the muffler section, two each at three levels. Each passage is 10 by $10 \mathrm{ft}$. These probes were used to determine if the airflow was being evenly distributed through each of the six ducts. Figure 40 shows that most of the airflow was moving through the inside of the tunnel loop and that the highest recorded velocity was in the lower inside duct.

Area 10: Settling chamber (9- by 15 -ft test section). The measurements made in this area of the tunnel were to help determine the quality of the flow entering the 9 - by 15 -ft test section. Currently there are no flow conditioning devices upstream of the 9 - by $15-\mathrm{ft}$ test section, although the cooler produces a pressure drop that tends to smooth the flow. The measurements were made using the traversing plates and probes. The first configuration had two traverses oriented horizontally, one at $13 \mathrm{ft}$ above the floor and the other at $26 \mathrm{ft}$. Each of the plates carried two flow angularity probes and a thermocouple; the lower traverse also had a hotfilm anemometry probe. The second configuration retained the horizontal traverse at $26 \mathrm{ft}$ above the floor, but the second traverse was oriented vertically just north of the tunnel centerline. The intrumentation carried by these traverses was the same as in the first configuration, except that both traverses carried hot-film probes and the vertical traverse carried a vane anemometer. These tests were conducted over the operating range of the 9 - by 15 -ft test section $\left(M_{9 \times 15}=\right.$ 0 to 0.2 ). 
Because of the low velocity in the settling chamber, the flow angularity probe data were not deemed accurate enough to warrant being reduced. Also, because of the long distance that the hot-film signals had to travel before reaching the bridge circuitry, the magnitude of the velocity data from these probes was also questionable, although the trends in the data are considered correct. For these reasons, most of the data from the first configuration has not been reduced and only part of the second configuration data has been reduced. The hot-film data is presented in Fig. 41 (vertical and horizontal survey planes); wind anemometer data from the vertical traverse are shown in Fig. 42. Although the magnitudes measured by these instruments did not match, the trends were the same across the cross sections. There was no velocity gradient along the horizontal survey plane. The vertical surveys showed a low-velocity region near the floor just upstream of the bellmouth inlet. This low-velocity region, sensed by both the hot-film and the vane anemometers, is due to a 3-ft-high step from the tunnel floor to the inlet of the bellmouth. The fact that the flow is not skewed to either side of the tunnel in the settling chamber is probably due to the effect of the cooler on the flow as it exits turn 2. The temperature surveys along the vertical survey showed the opposite trend in that the highest temperatures were recorded at the tunnel floor (Fig. 43).

Area 11: Air dryer inlet. The air flow distribution into the dryer beds was studied in order to determine the percentage of flow entering each bed and to determine if each bed was being used effectively. A two-man team made a velocity survey in front of the dryer beds and in turn 3 using a hand-held anemometer. The surveys at the dryer bed entrance were made with the dryer configured for both wet and dry air cycles (testsection Mach numbers of 0.45 and 1.2 , respectively). The surveys in turn 3 were made during the dry air cycle only $\left(\mathrm{M}_{8 \times 6}=1.2\right)$. Figure 44 shows the locations of the surveys made at the dryer bed entrance and in turn 3. Survey plane 5 is at the entrance to the dryer beds; velocity measurements were made at each of the 20 inlets ( 4 bed inlets each on 5 levels). Measurements in the other four planes (survey locations 1 to 4 ) were made at ground level (anemometer positioned $8 \mathrm{ft}$ above tunnel floor).

Figure 45 shows the velocity distributions measured in turn 3. At the inlet to turn 3, however (survey plane 1), the flow was skewed toward the inside of the tunnel (Fig. 45(a)). The survey midway through the turn (survey plane 2) also showed that the flow was skewed toward the north end of the survey at this point (inside of the tunnel loop). These surveys showed that the flow did not appear to fully turn after entering the corner but rather acted as a jet and impinged on the east wall of the corner. The flow then stayed along the east wall (outside of tunnel loop) up to the dryer inlet (survey planes 3 and 4). The survey made upstream of the FOD screen (survey plane 3, Fig. 45(b)) showed that the flow was skewed to the outside of the tunnel and that the velocity near the outside wall was twice the velocity at the inside wall. A similar distribution was present at the survey plane downstream of the FOD screen (survey plane 4, Fig. 45(c)). Figure 46 shows the results of the velocity survey at the dryer inlets (survey plane 5) for both wet and dry operation. In the wet air mode, air could pass through only levels 2 and 4 . In the drying mode, air could pass through all five levels, but it appears that most of the flow was routed through the center three levels $(2,3$, and 4$)$ and that the flow was skewed toward the outside of the tunnel loop.

\section{Dynamic Pressure Measurements}

Another area of concern was the possibility of rotating stall in the compressor. Pressure transducers were mounted in the compressor casing in existing static pressure taps. The transducers were mounted in two configurations: (1) sixth and seventh stages only and (2) first four stages of the seven-stage compressor. Theory shows that stall cells rotate at approximately one-third to one-half of the rotor speed. A very low frequency analysis was done to look for rotating stall. Figure 47 shows the 0 - to $20-\mathrm{Hz}$ spectra for the first two stages of the compressor at $\mathrm{M}_{8 \times 6}=2.0$. No significant peaks in the range of one-third to one-half of the shaft rotation speed were found during this analysis. From this it is concluded that no rotating stall was present in the compressor.

\section{Summary of Results and Recommendations}

The purpose of these studies was to collect information about the flow characteristics in the NASA Lewis 8- by 6- Foot/9- by 15-Foot Wind Tunnel in order to determine what type of improvements could be made to the facility to increase the flow quality throughout the tunnel loop.

The initial flow visualization studies conducted in the compressor plenum/inlet area indicated the possibility for a redesign of the compressor inlet in order to better distribute the flow into the compressor. However, further flow visualization studies revealed that the airflow distribution at the inlet is not as bad as originally thought. The velocity surveys at the compressor exit also indicated that the flow is evenly distributed exiting the compressor so that the nonsymmetric inlet distribution is not feeding through the compressor. Another indication that the inlet flow is not causing problems in the compressor is the lack of evidence of a rotating stall cell in the aft stages of the compressor. 
Therefore, it was recommended that no redesign of the compressor inlet be undertaken.

Because of the large flow separation found on the north side of the compressor exit tailcone, the tailcone contour should be redesigned, and vortex generators should be added to the tailcone. These additions should improve the flow distributions in the settling chamber upstream of the 8 - by 6 - $\mathrm{ft}$ test section.

Turbulence-reduction screens and honeycomb flow straighteners should be installed upstream of both the 8 - by 6 -ft and 9 - by 15 -ft test sections. The pressure and velocity surveys completed in the settling chambers upstream of each test section were used in making this recommendation. The high turbulence levels and skewed velocity profiles in the settling chamber upstream of the 8- by 6-ft test section show that flow conditioning is needed.
Turning vanes should not be installed in any of the turn, since the air velocity is too low in these areas to warrant the need for turning vanes. It was also discovered during the studies that the cooler upstream of the 9 - by 15 -ft test section does a good job of redistributing the flow as it exits turn 2.

\section{References}

1. Swallow, R.J., and Aiello, R.A.: NASA Lewis 8- By 6-Foot Supersonic Wind Tunnel-Facility Description With Performance Data. NASA TM X-71542, 1974.

2. Yuska, J.A., Diedrich, J.H.; and Clough, N.: Lewis 9- By 15-Foot V/STOL Wind Tunnel. NASA TM $\mathrm{X}-2305,1971$. 


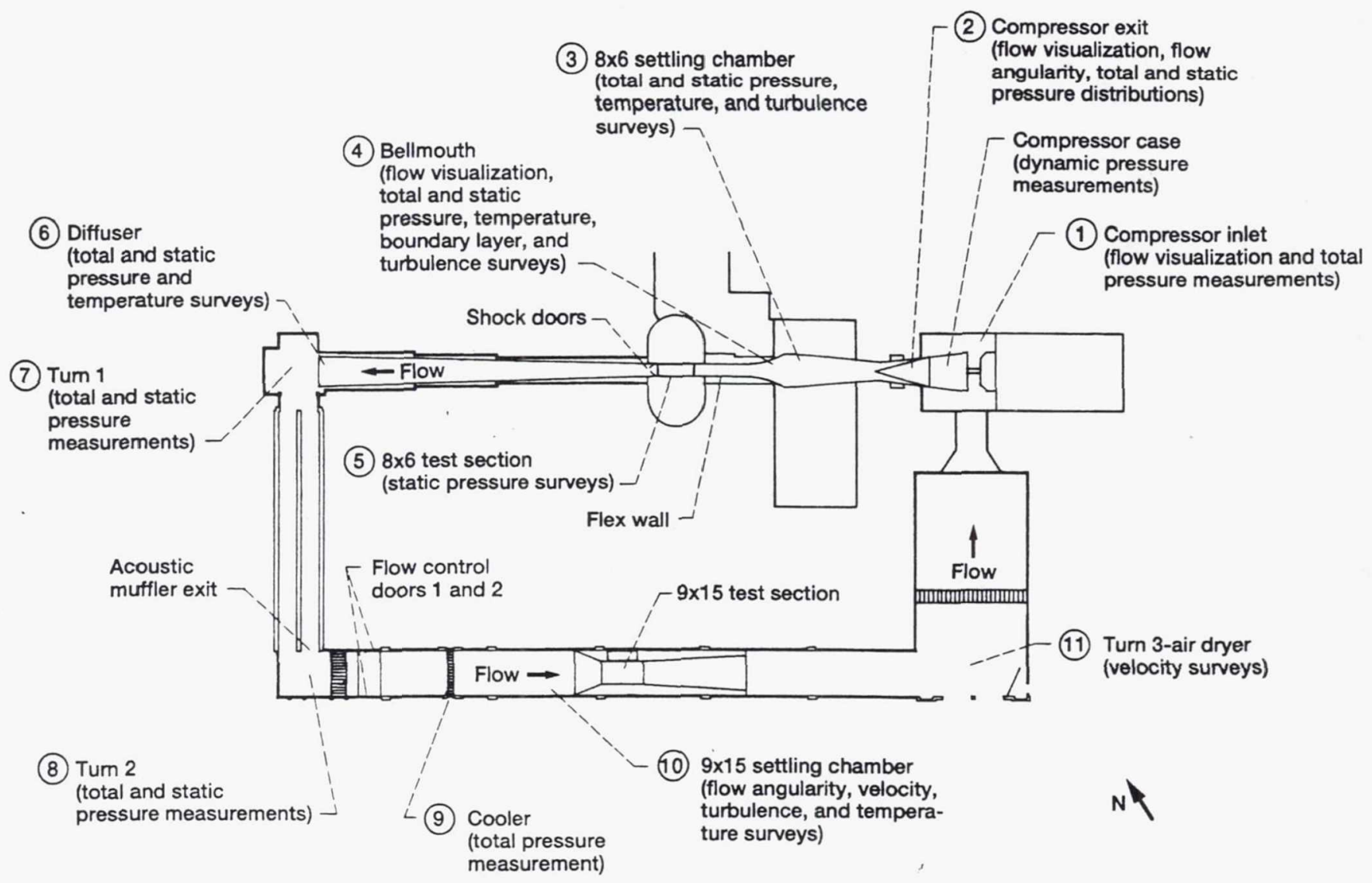

Figure 1.-Diagram of 8- by 6-Foot Supersonic/9- by 15-Foot Low Speed Wind Tunnel facility showing areas studied and measurements taken in flow quality studies (study areas designated by circled numbers).

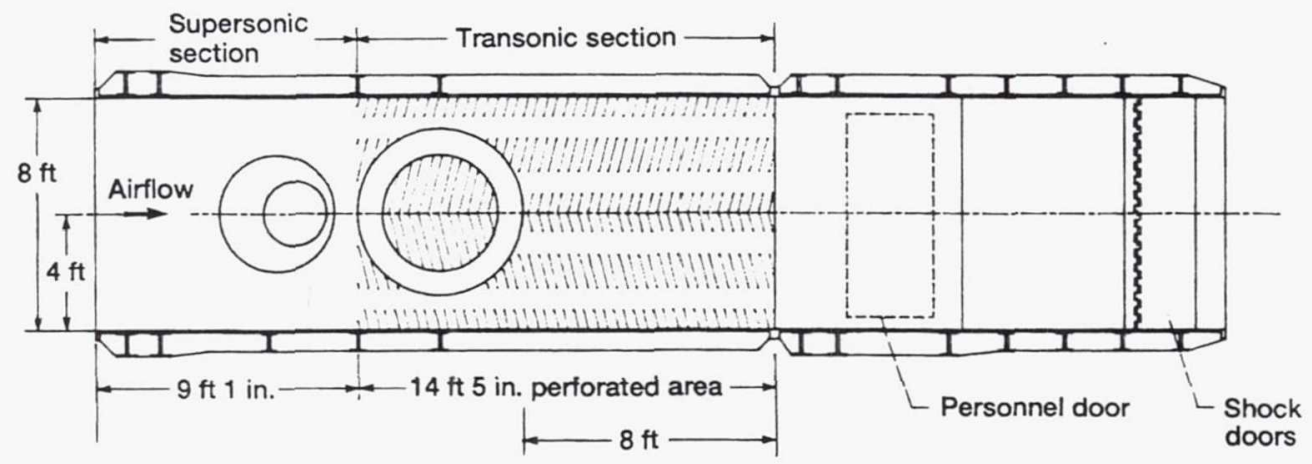

Figure 2.-Elevation view of 8 - by 6 -ft test section. 


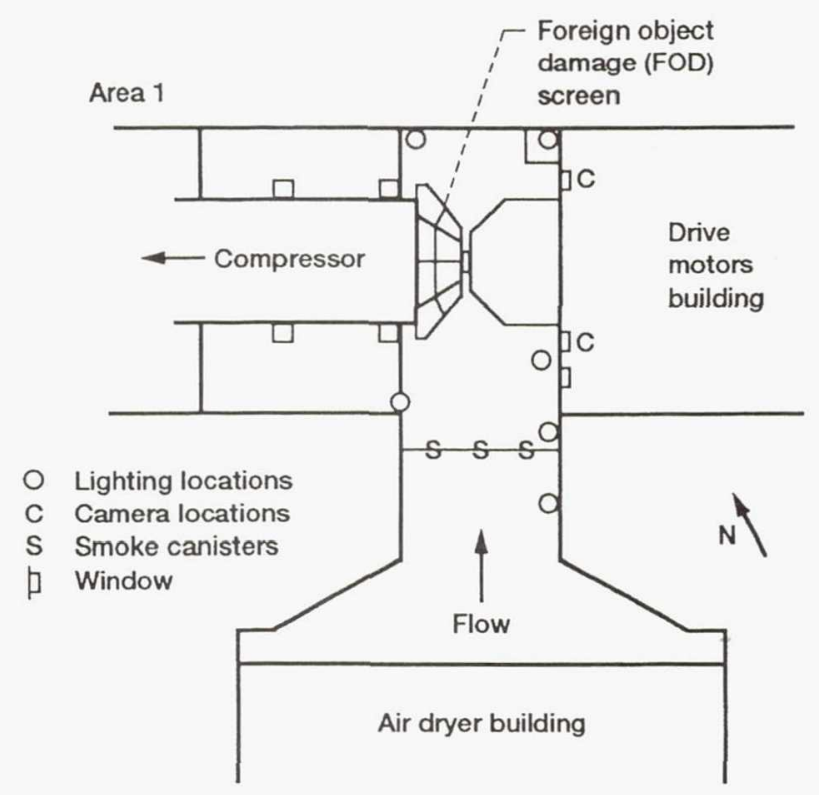

Figure 3.-Detail of compressor plenum showing flow visualization equipment locations.

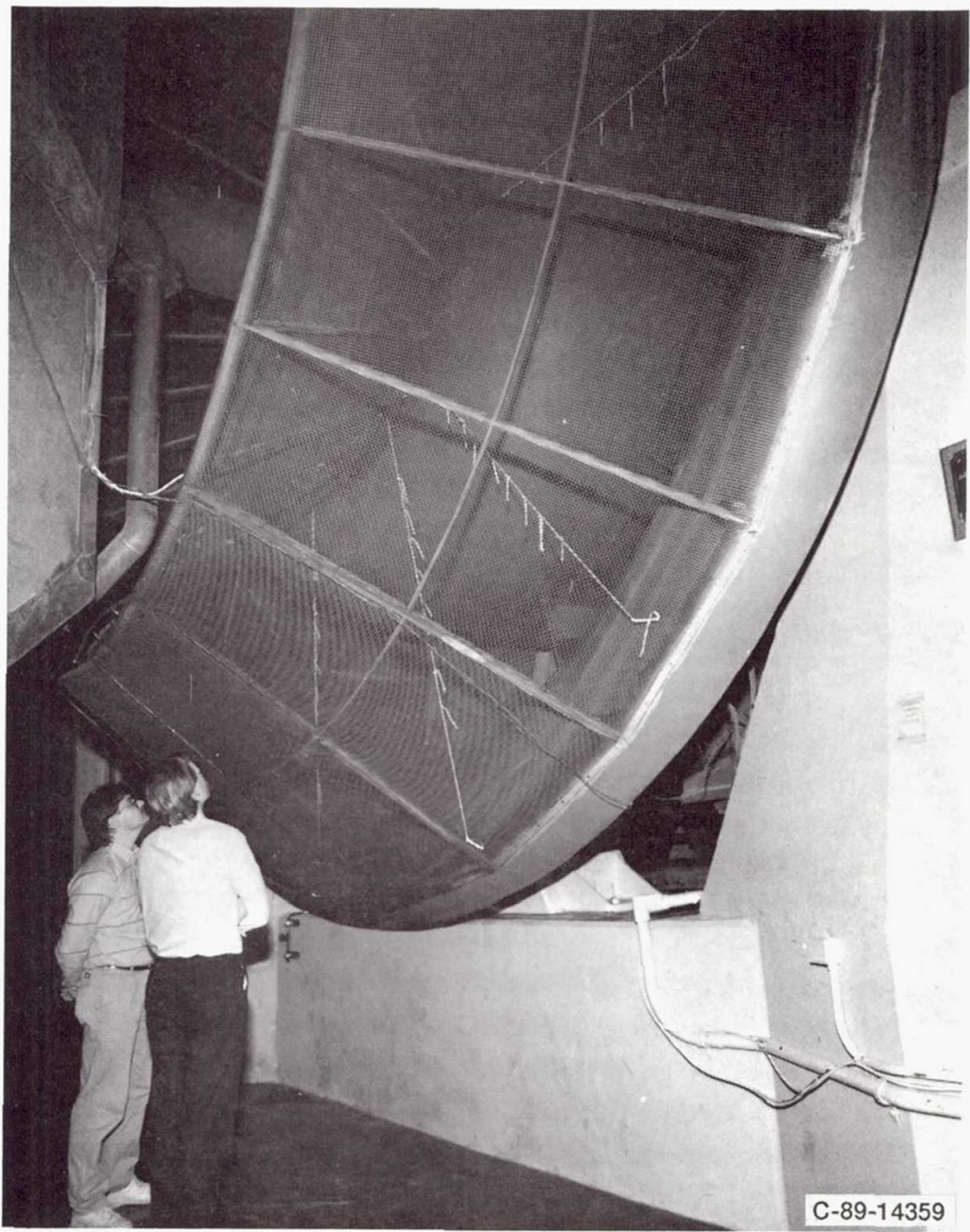

Figure 4.-Inlet to seven-stage axial flow compressor showing flow visualization tufts (view is north side of inlet). 


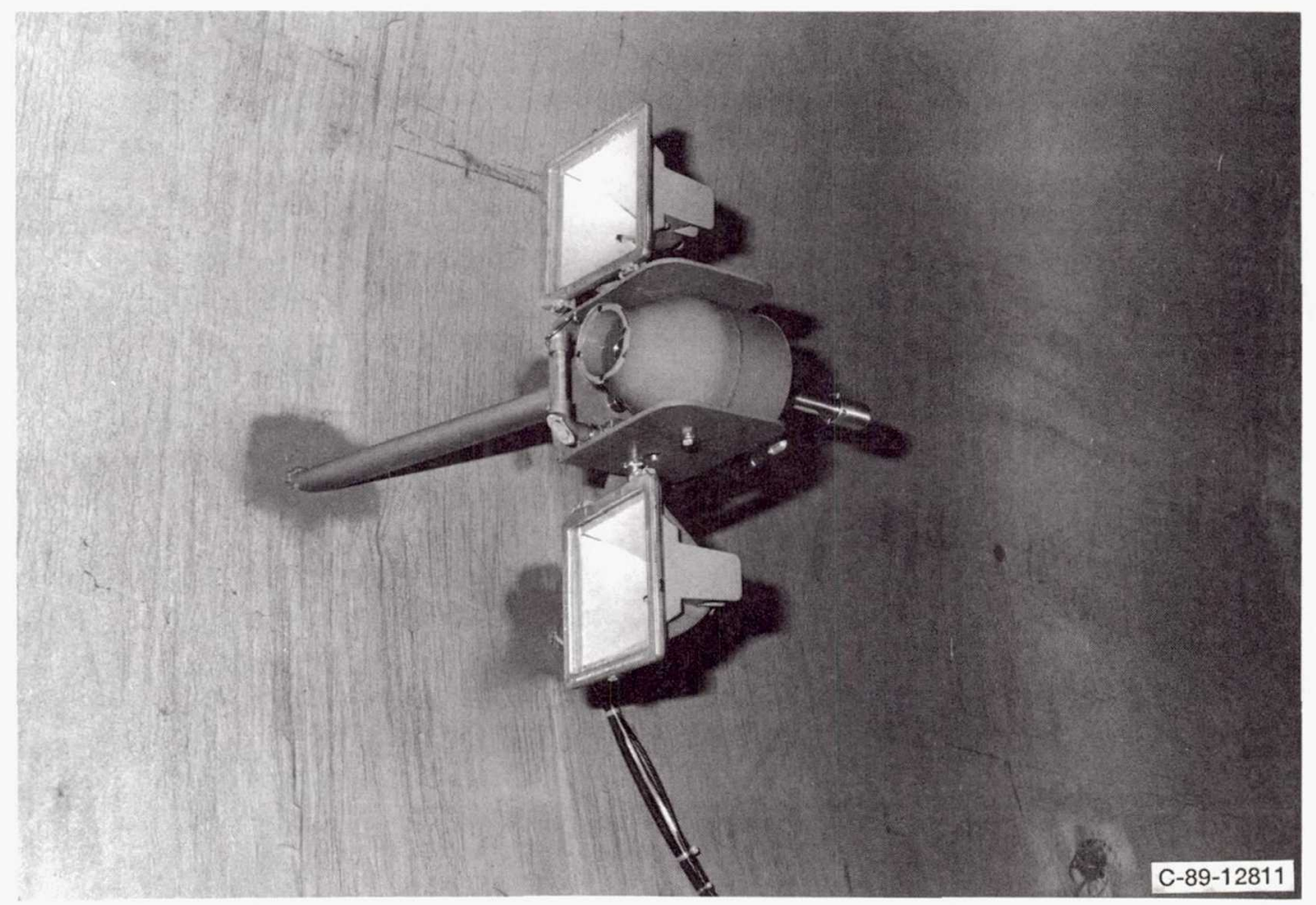

Figure 5.-Camera/lighting assembly mounted to south tunnel wall downstream of compressor exit tailcone fairing as used in tailcone flow visualization.

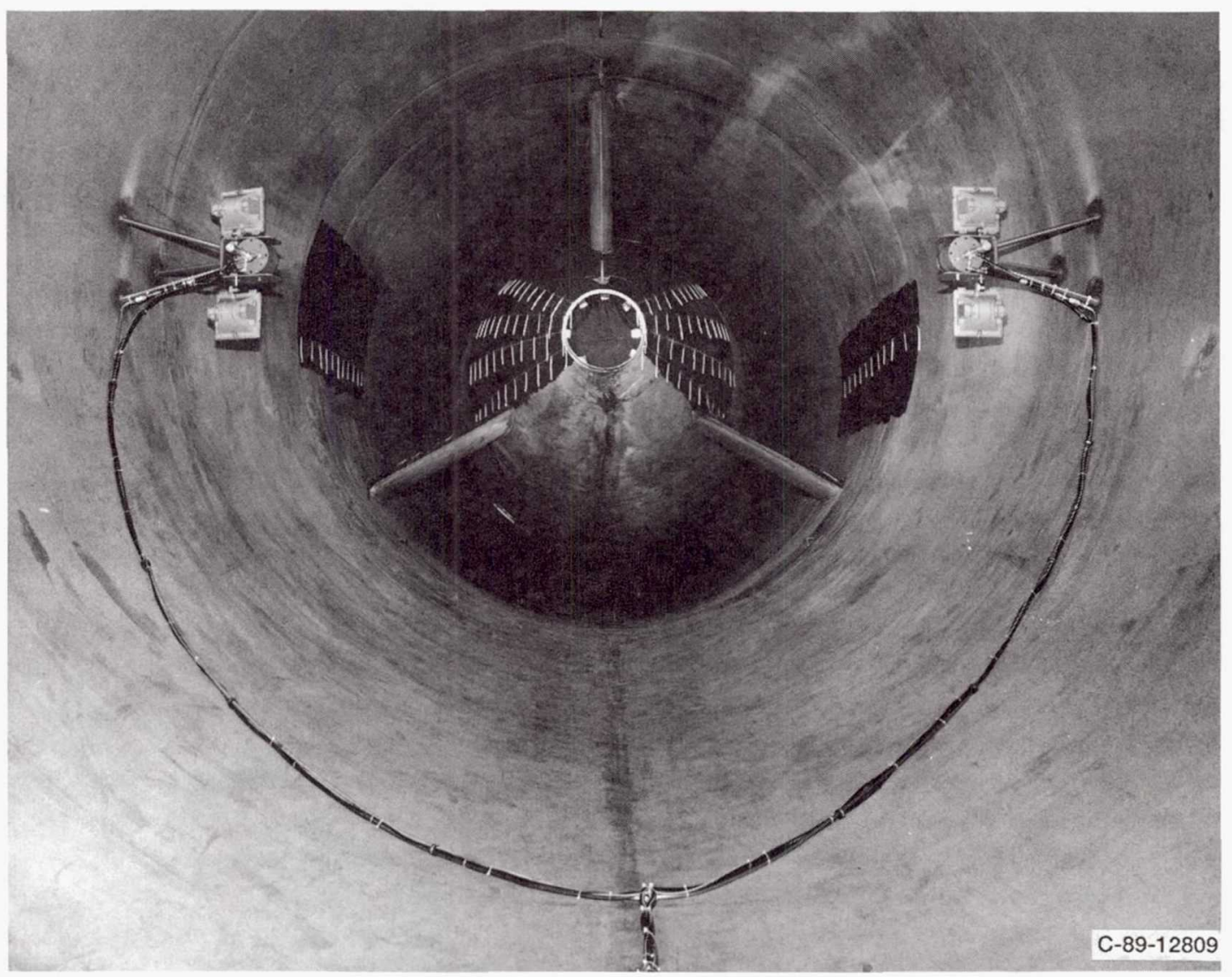

Figure 6.-Compressor exit tailcone flow visualization setup (view looking upstream). 


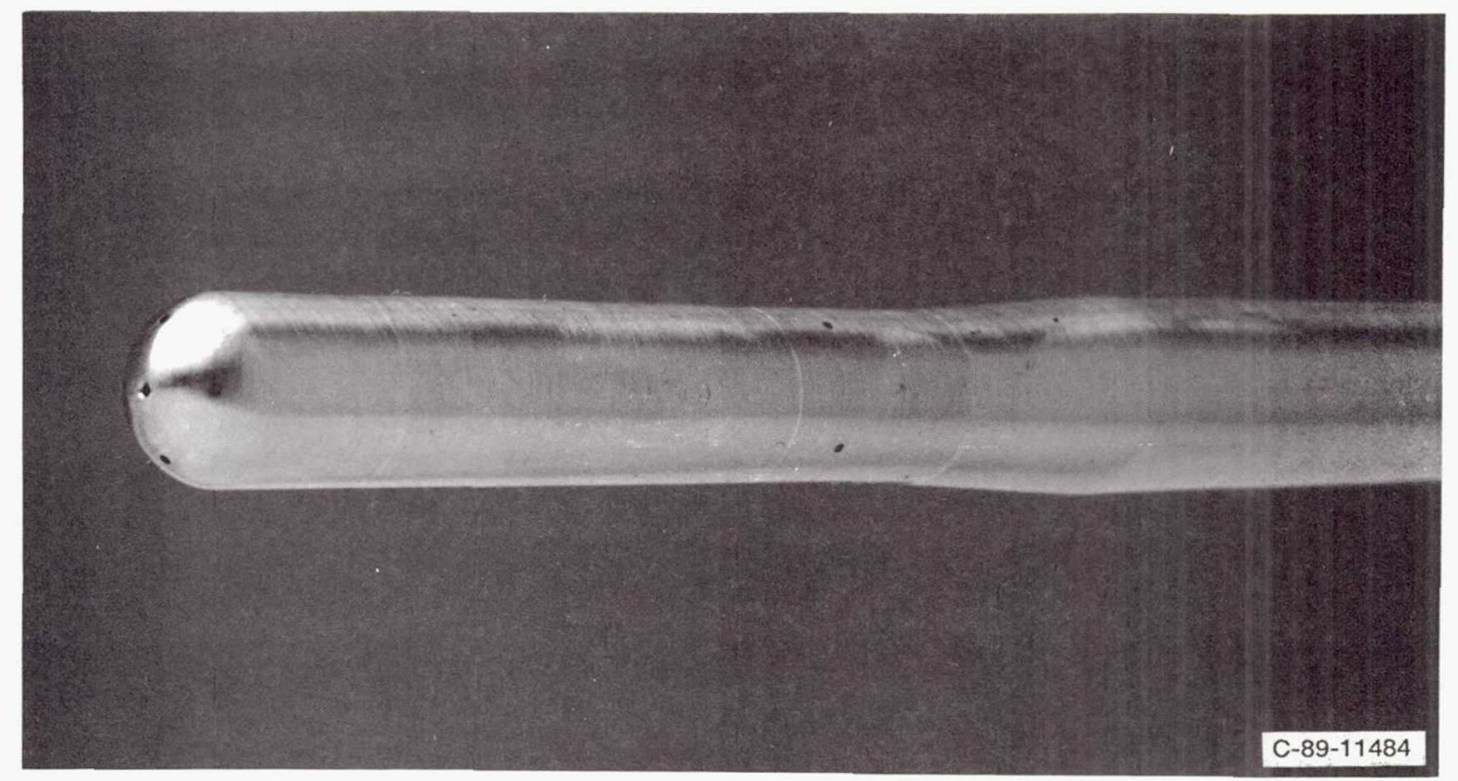

Figure 7.-Five-hole hemispherical-head flow angularity probe (probe diameter, $3 / 8 \mathrm{in.}$ ).

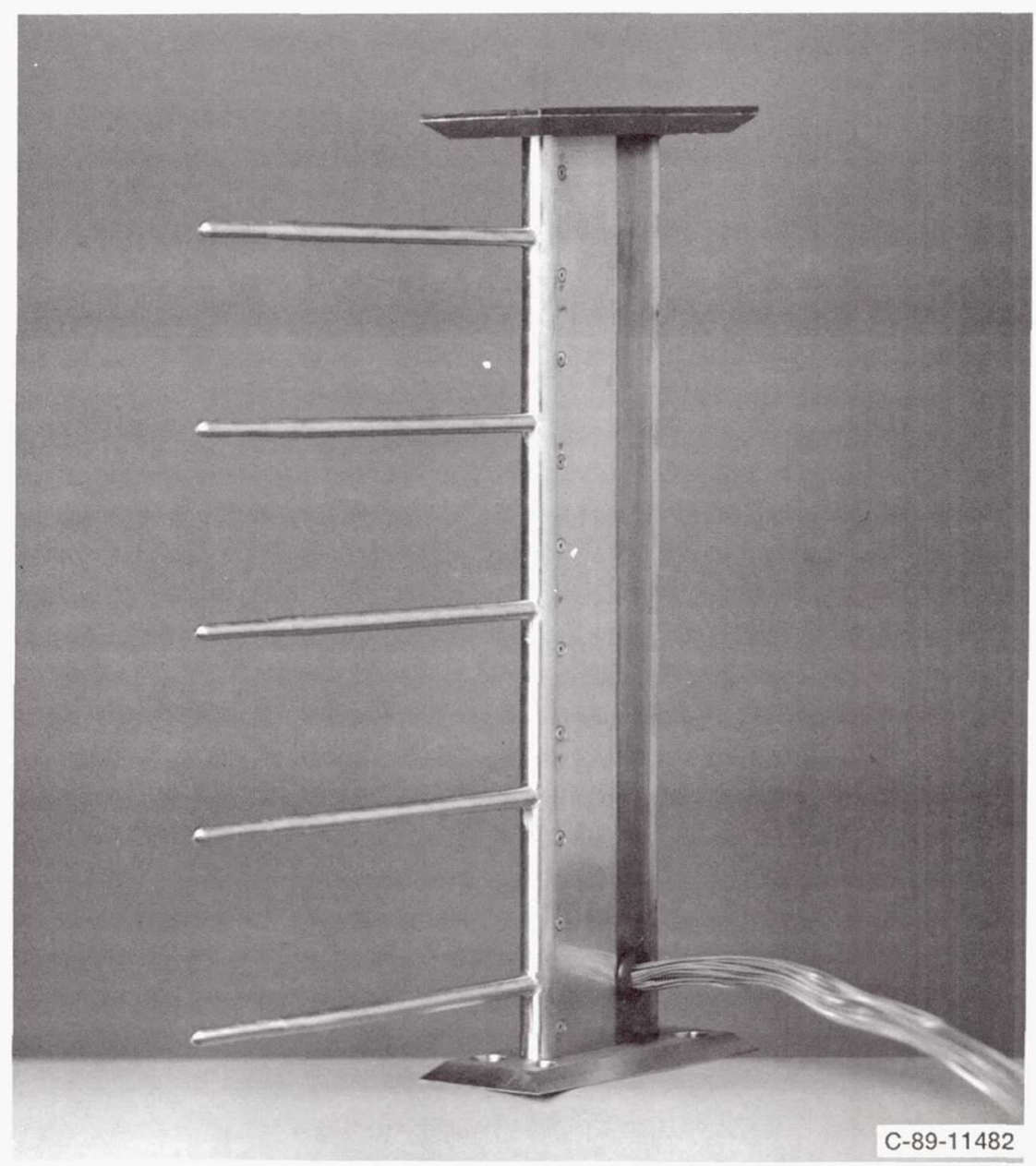

Figure 8.- Rake used to collect flow angularity data at compressor exit (rake height, 18 in.). 


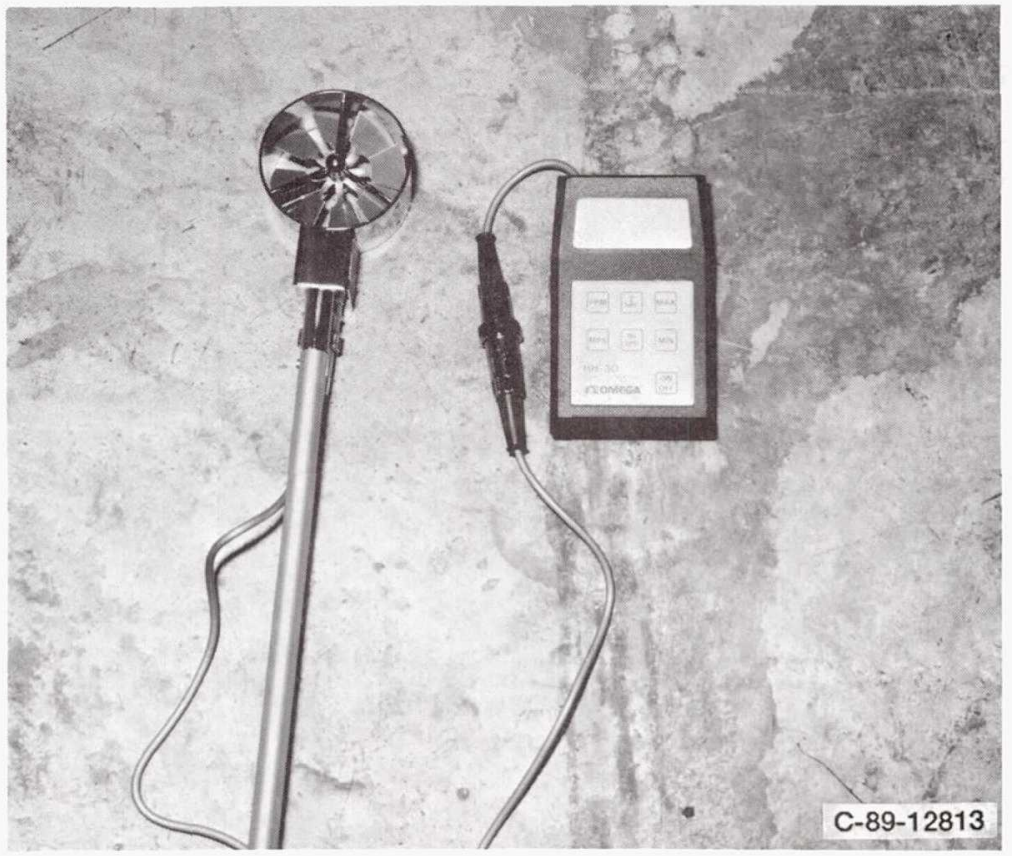

(a) Hand-held anemometer.

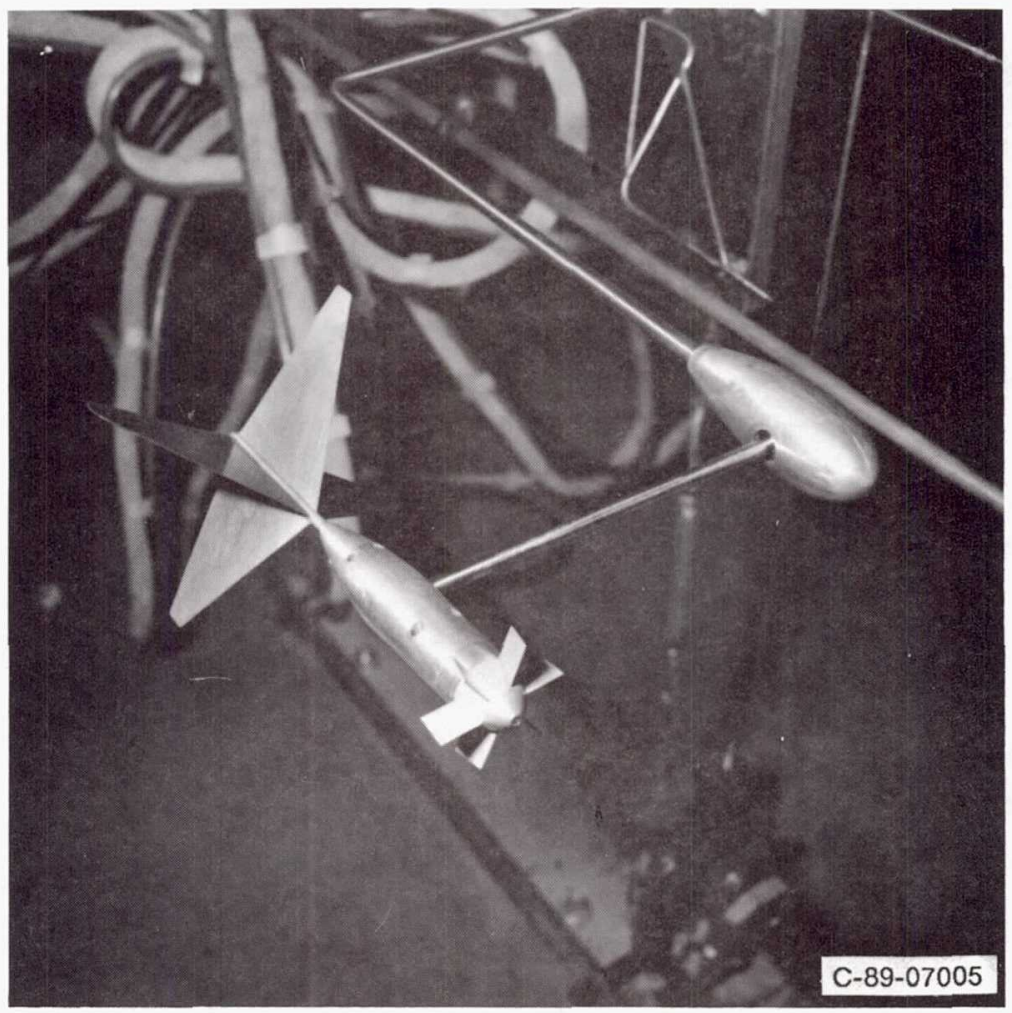

(b) Vane anemometer

Figure 9.-Wind anemometers used in flow quality studies. 


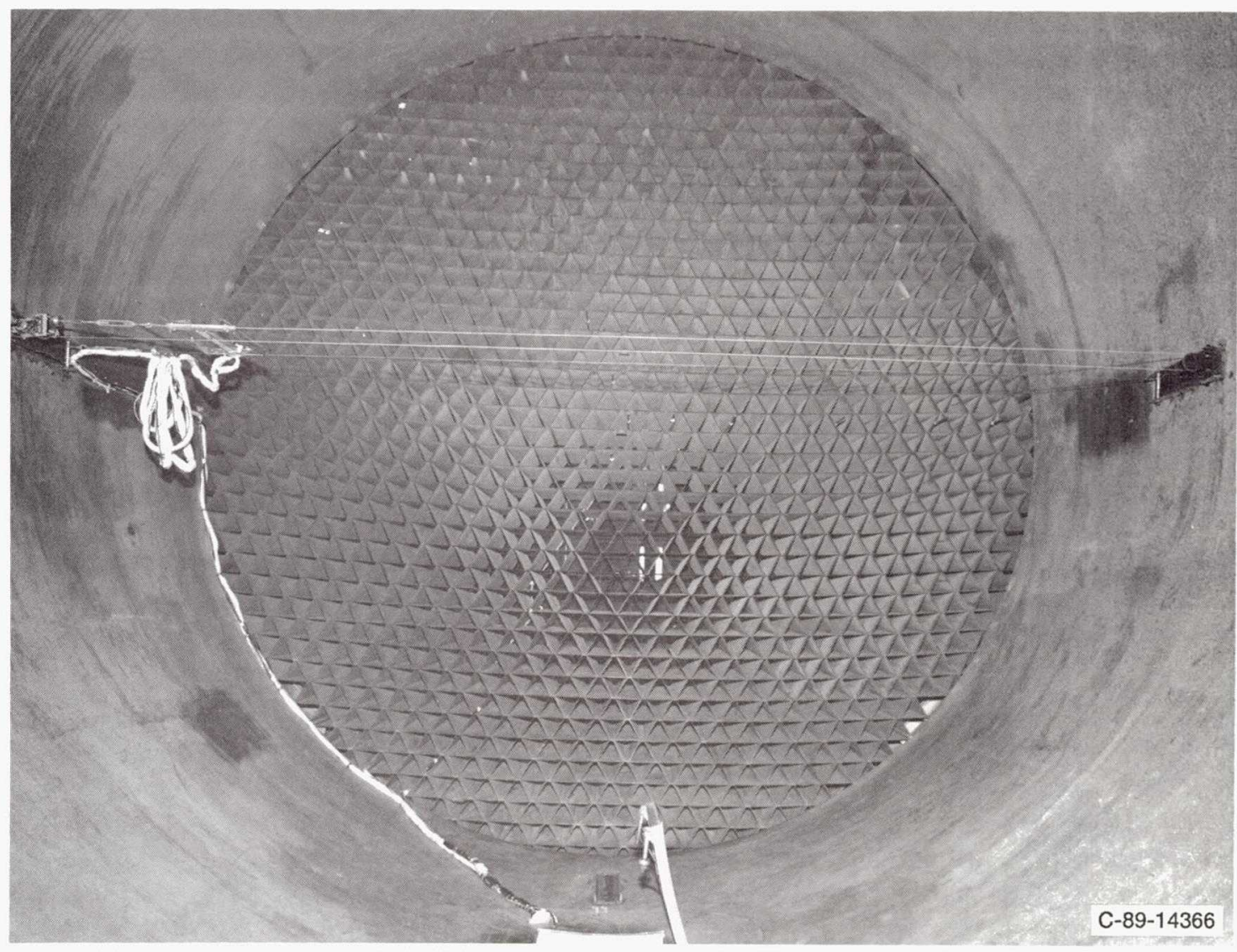

Figure 10.-Traversing plate mechanism setup in settling chamber upstream of 8 - by 6 - $\mathrm{ft}$ test section.

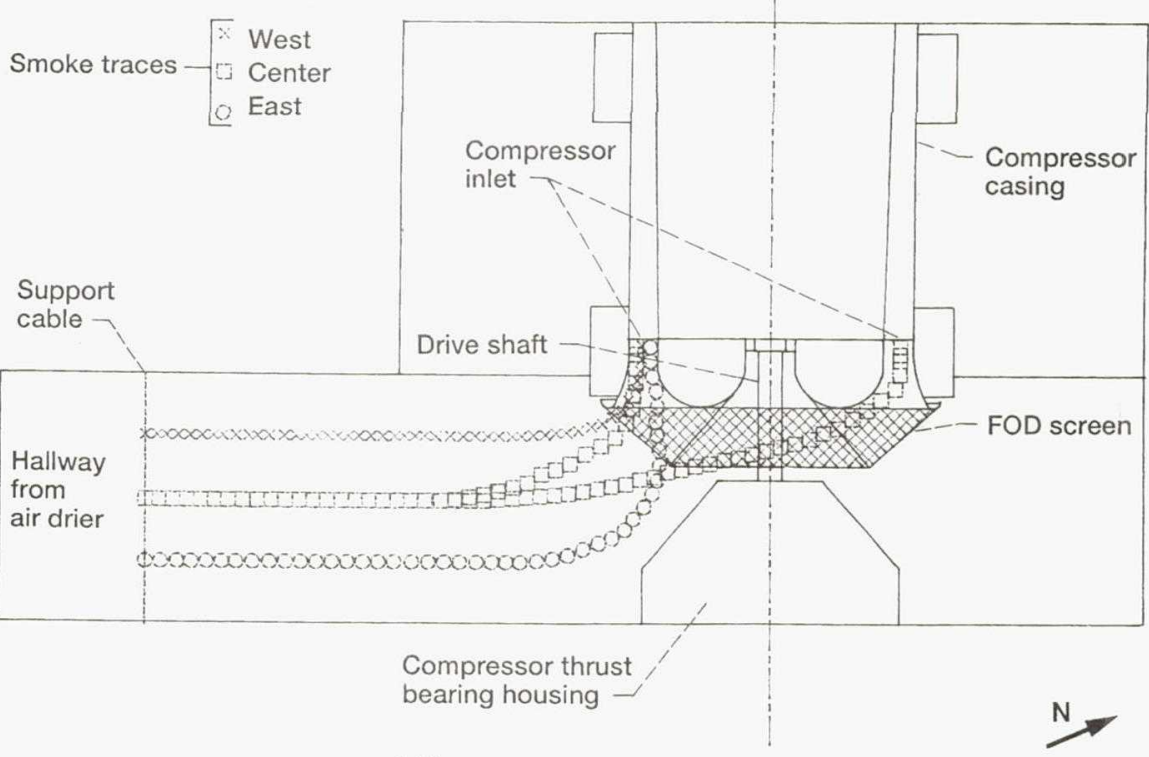

(a) Lower level - plan view.

Figure 11.-Compressor smoke flow visualization traces. 


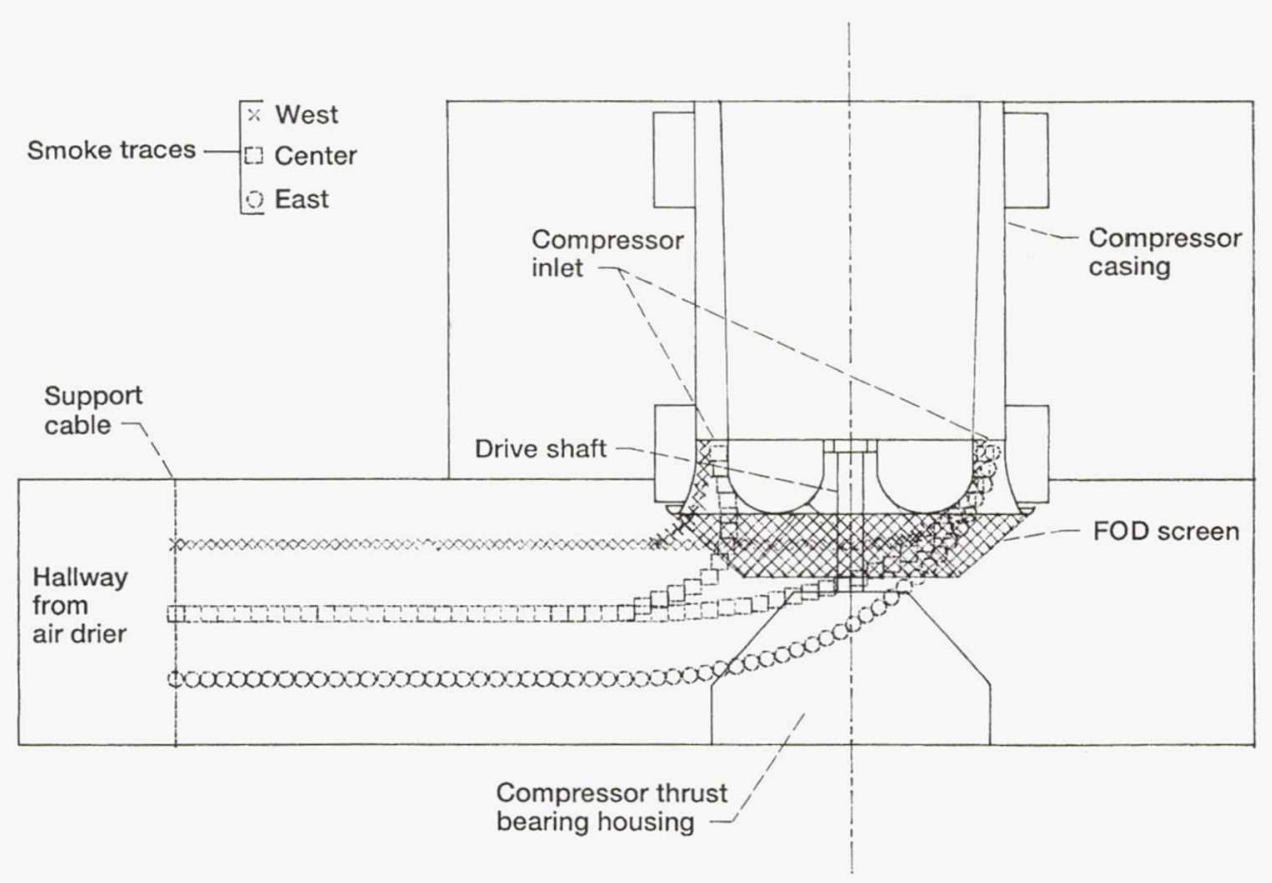

(b) Upper level - plan view.

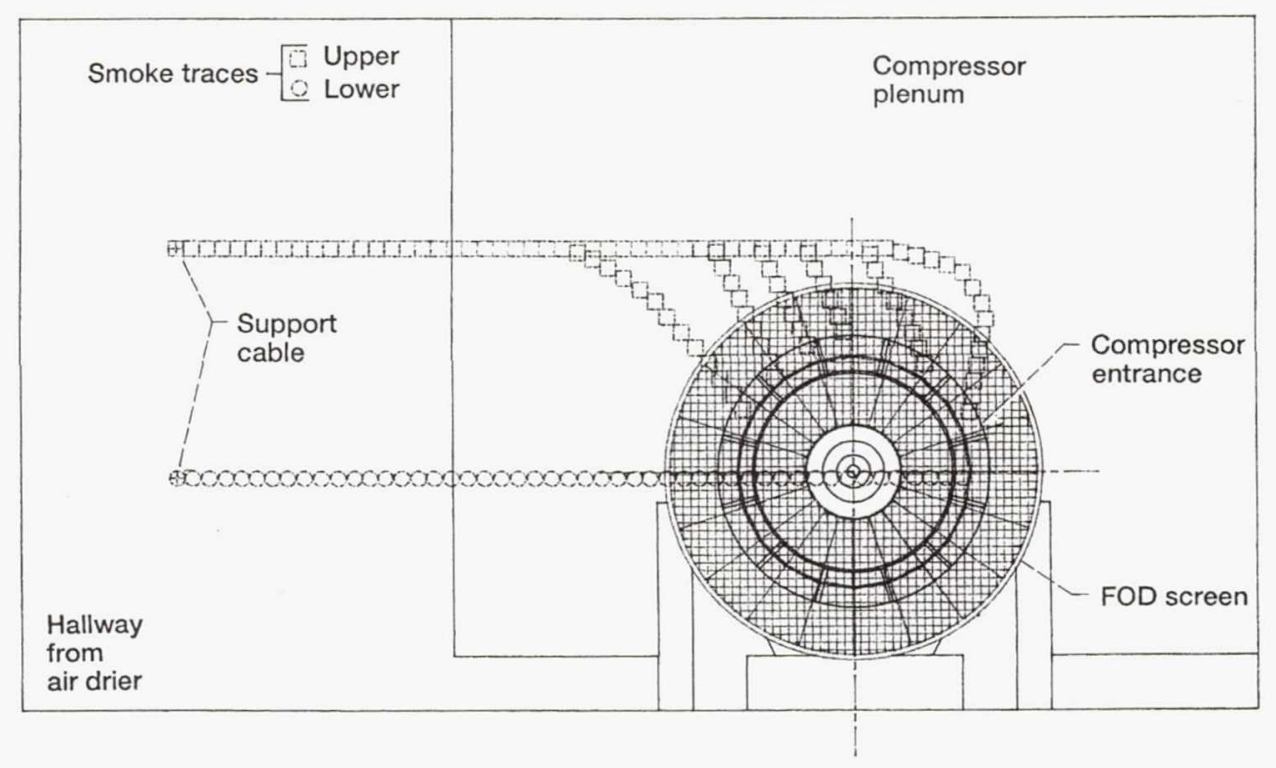

(c) Compressor entrance - elevation view.

Figure 11.-Concluded. 


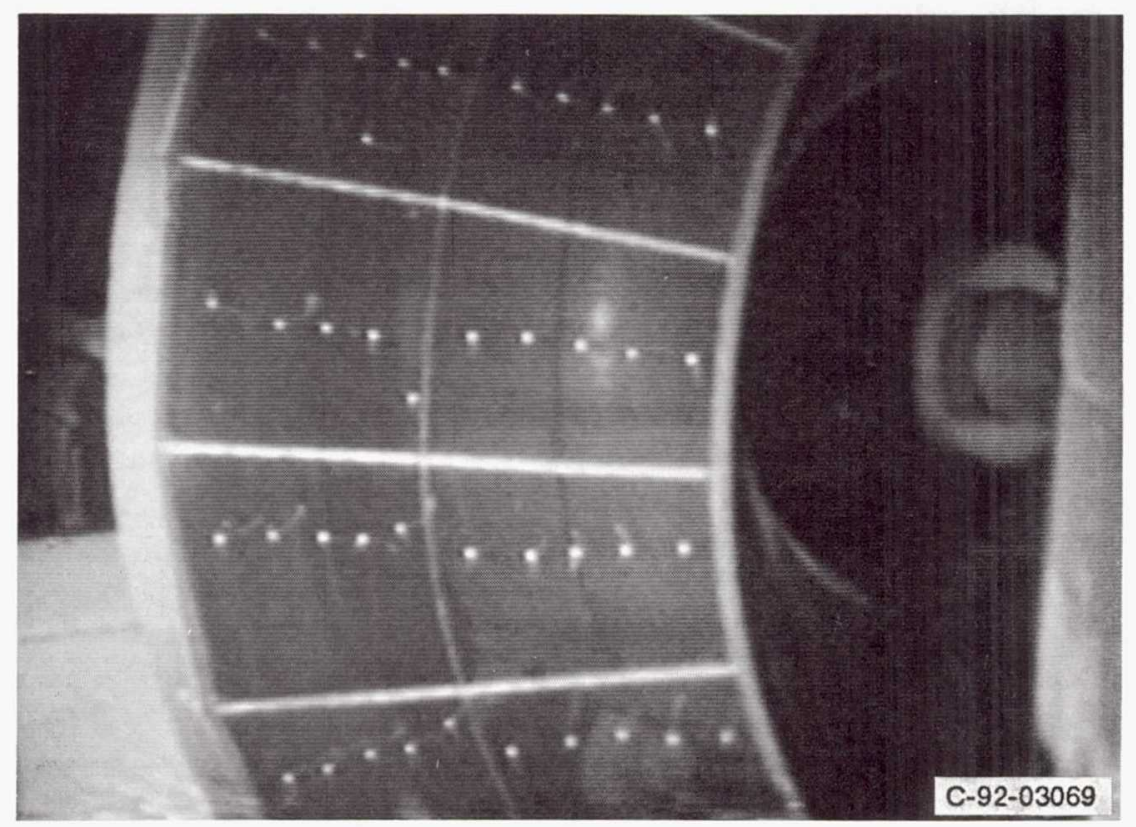

(a) South side of inlet.

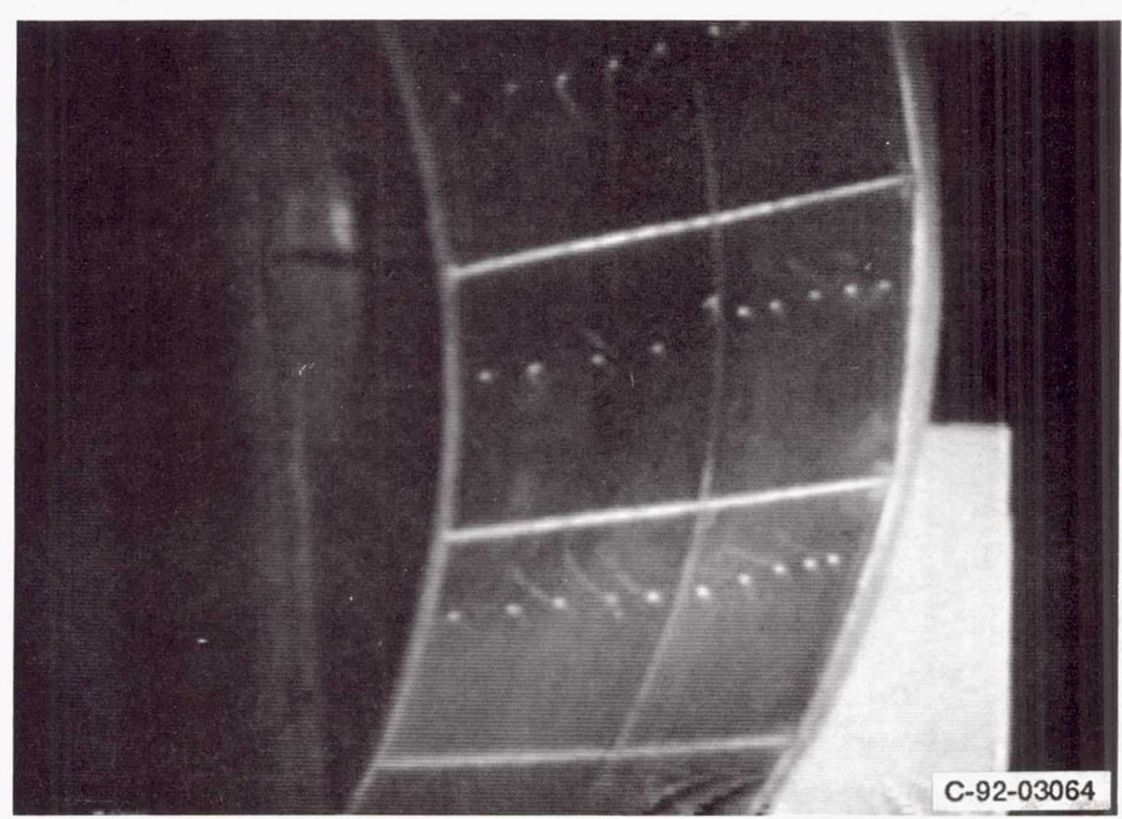

(b) North side of inlet.

Figure 12.-Compressor inlet flow visualization using tufts mounted directly to FOD screen (first configuration) at $M_{8 \times 6}=1.0$. 


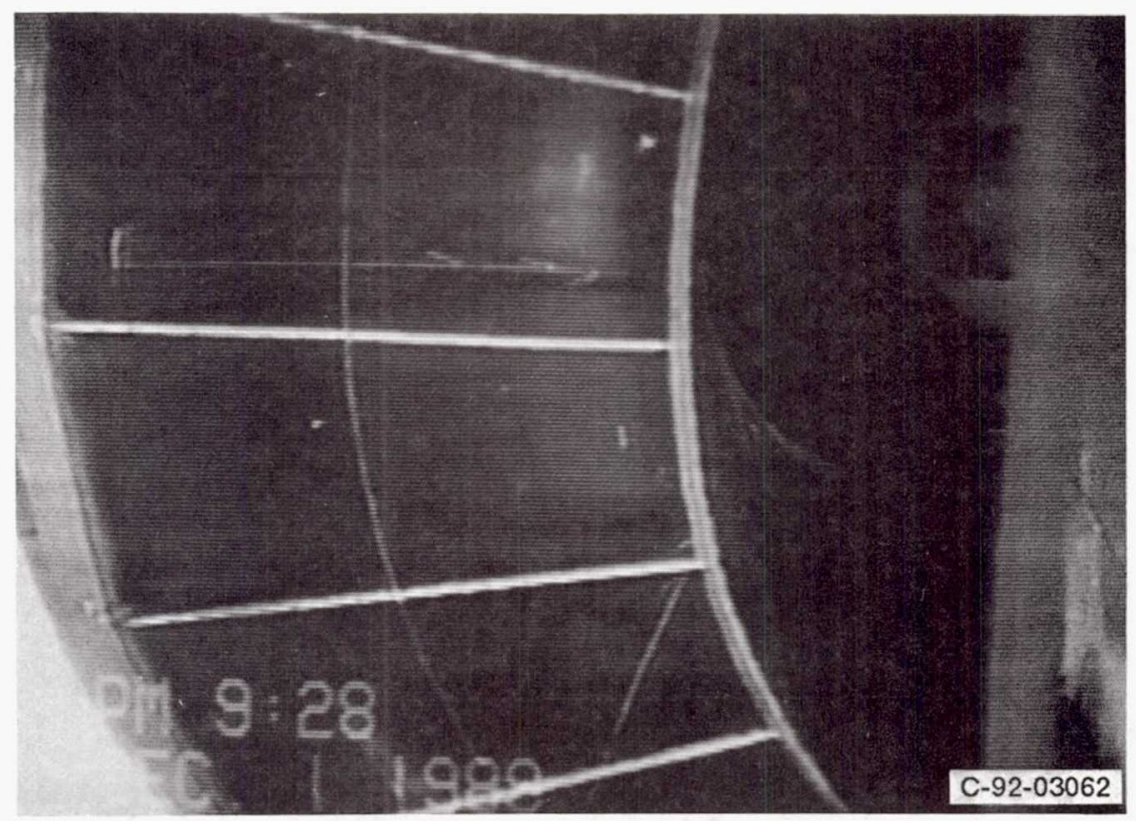

(a) South side of inlet.

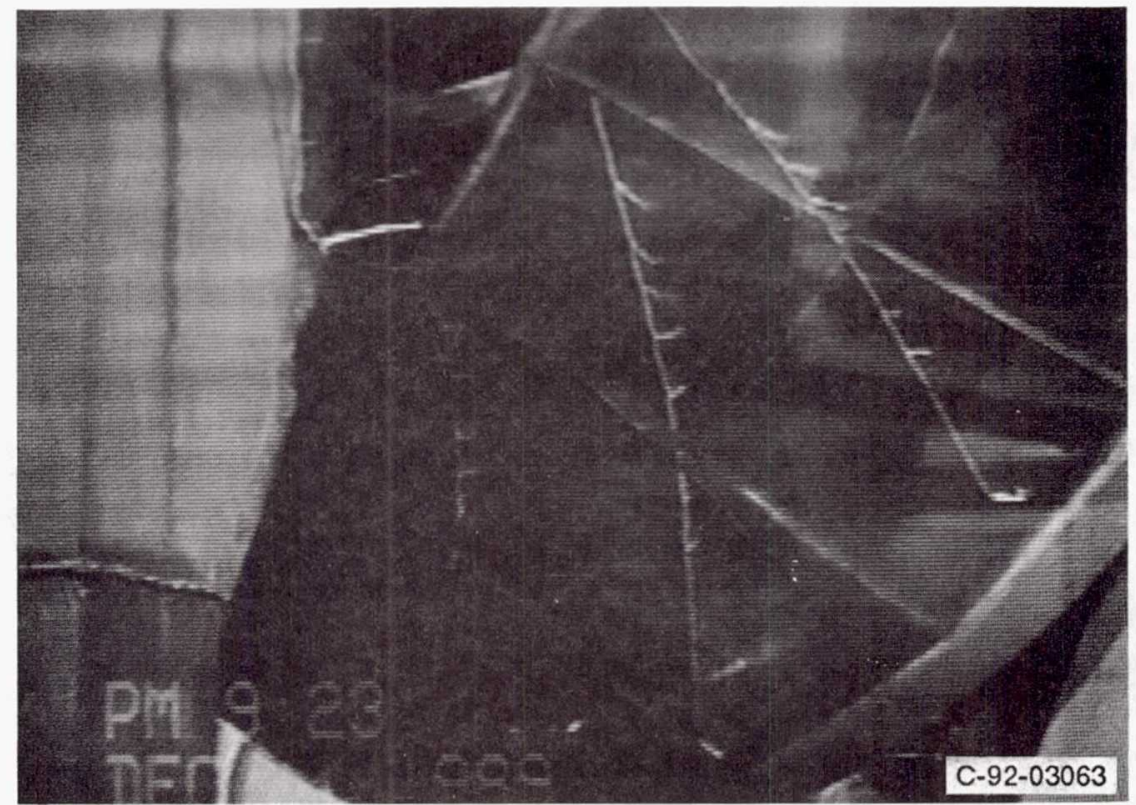

(b) North side of inlet.

Figure 13.-Compressor inlet flow visualization using tufts mounted inside FOD screen (second configuration) at $\mathrm{M}_{8 \times 6}=1.0$. 


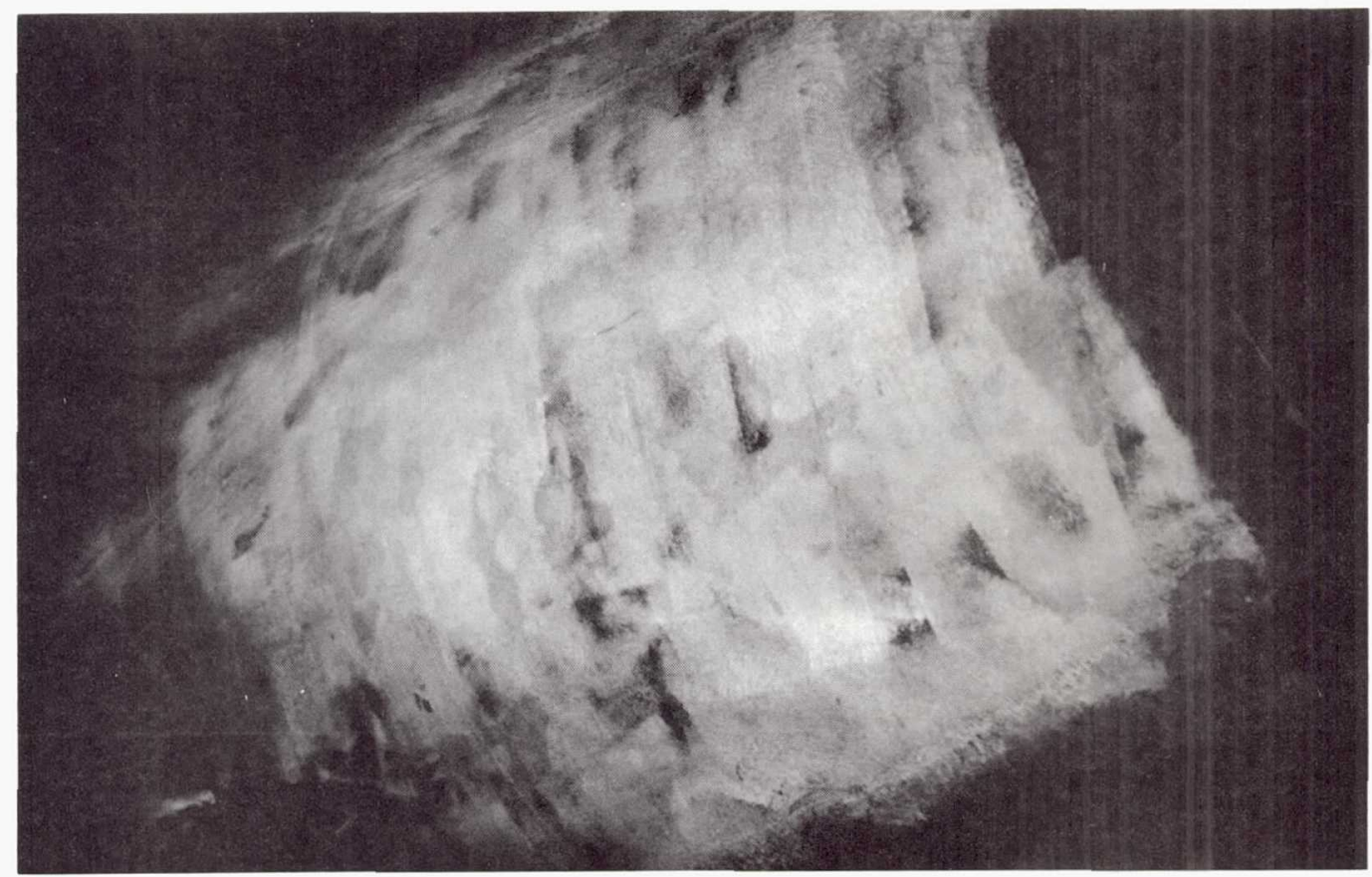

(a) North side of tailcone (flow from left to right).

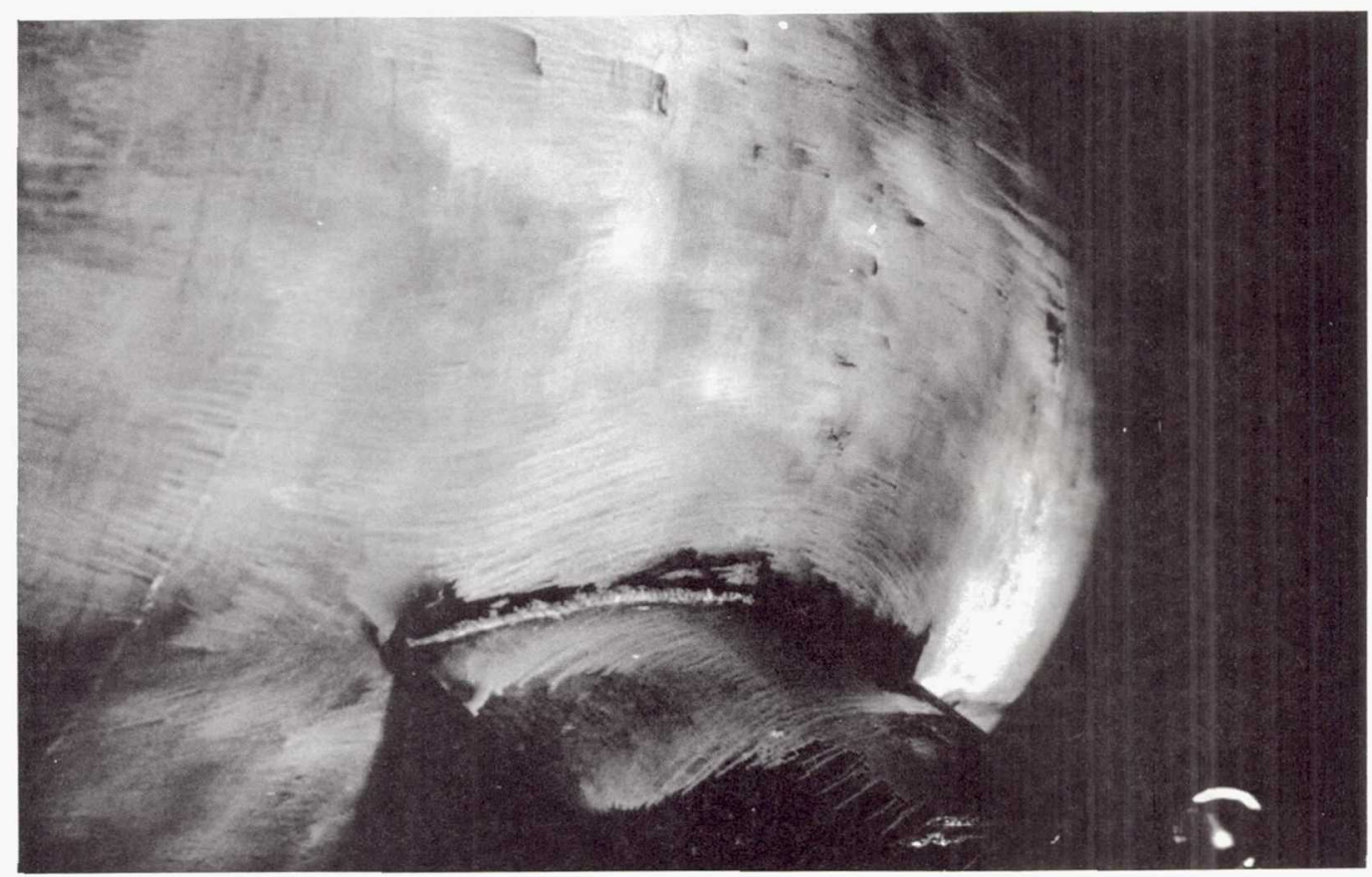

(b) South side of tailcone (flow from right to left).

Figure 14.-Tailcone oil flow visualization at $M_{8 \times 6}=0.8$. 
North side

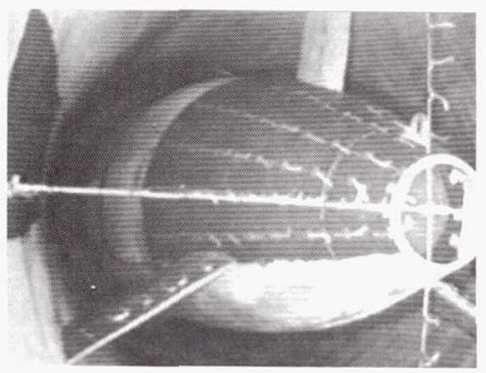

South side

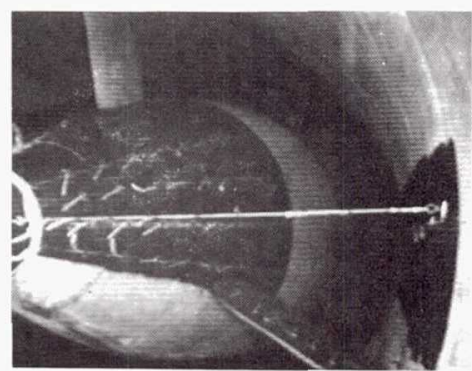

(a) $M_{8 \times 6}=0.8$.
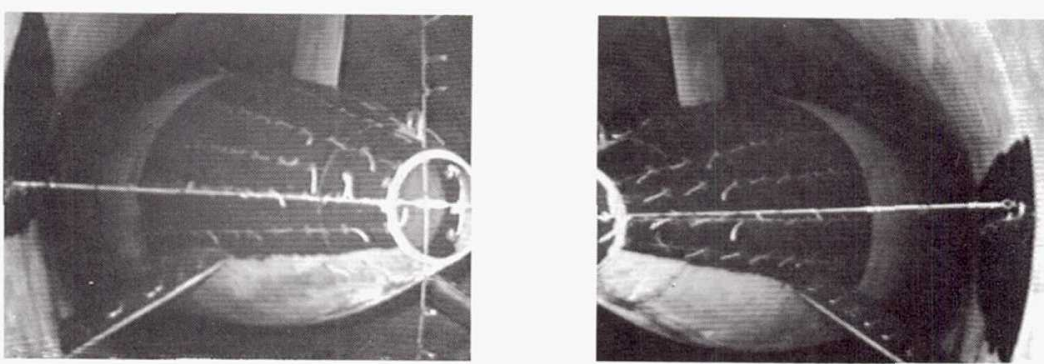

(b) $M_{8 \times 6}=1.2$.
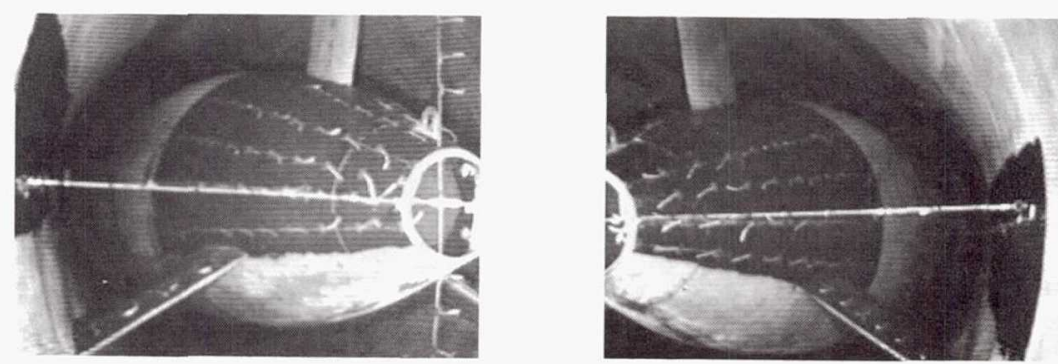

(c) $M_{8 \times 6}=1.6$.
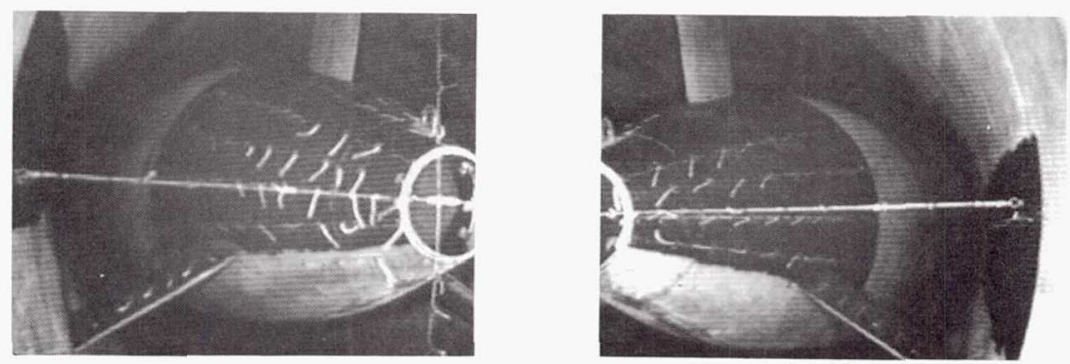

(d) $M_{8 \times 6}=2.0$.

Figure 15.-Tailcone flow visualization showing tuft patterns at various test-section Mach number conditions. 
South elevation view - area 4

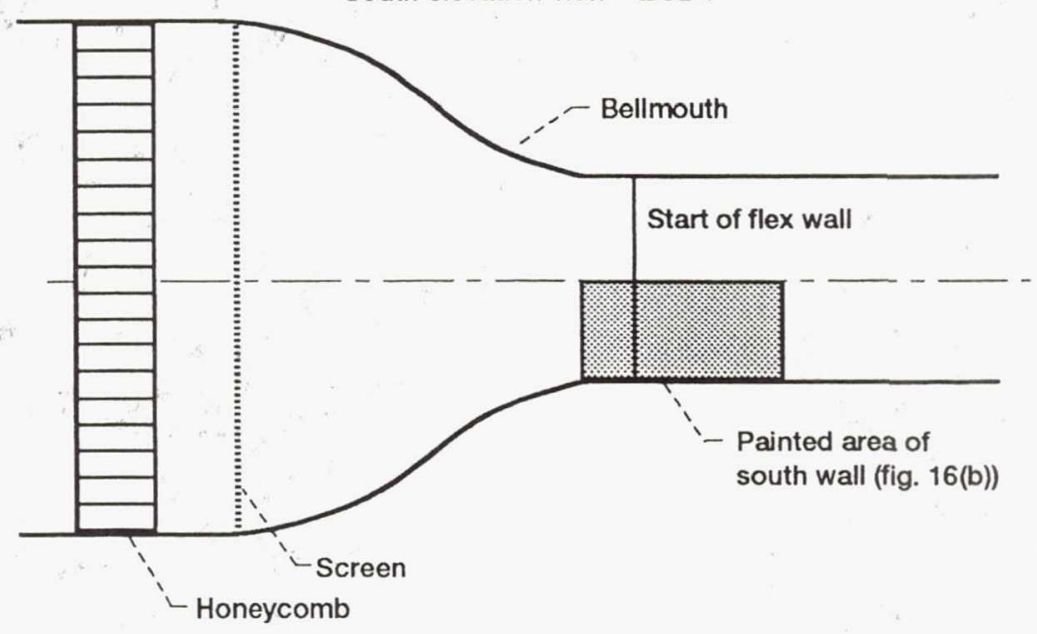

Plan view - area 4

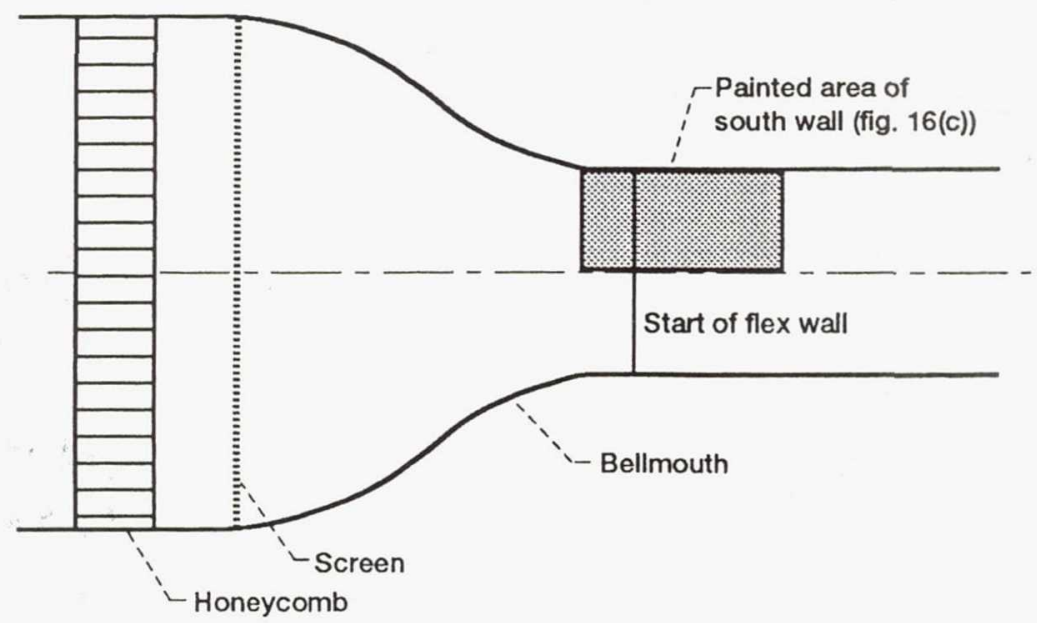

(a) Sections of bellmouth area studied using oil flow visualization techniques.

Figure 16.-Oil flow patterns in bellmouth exit upstream of 8 - by 6 -ft test section. 


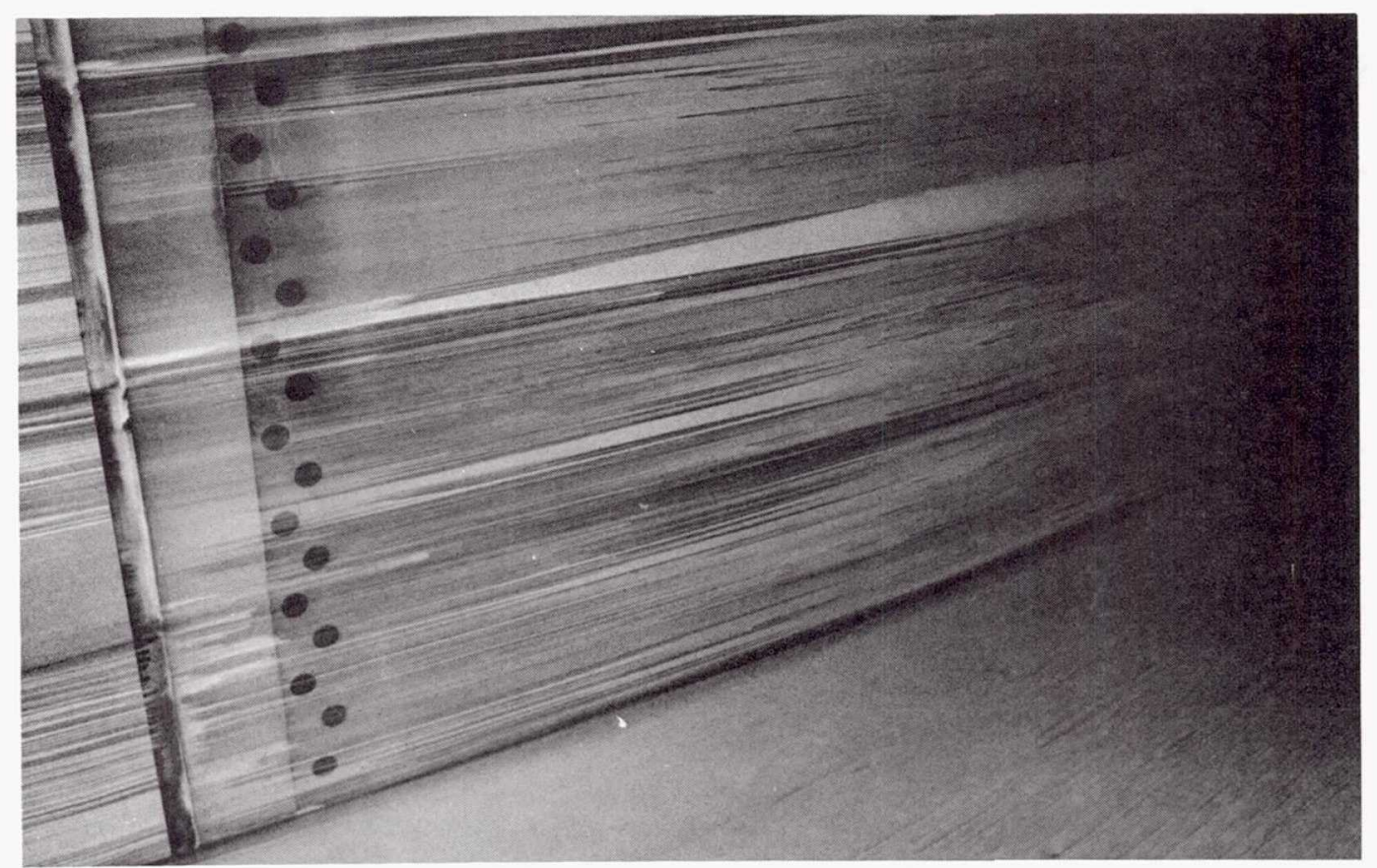

(b) South wall (flow from left to right).

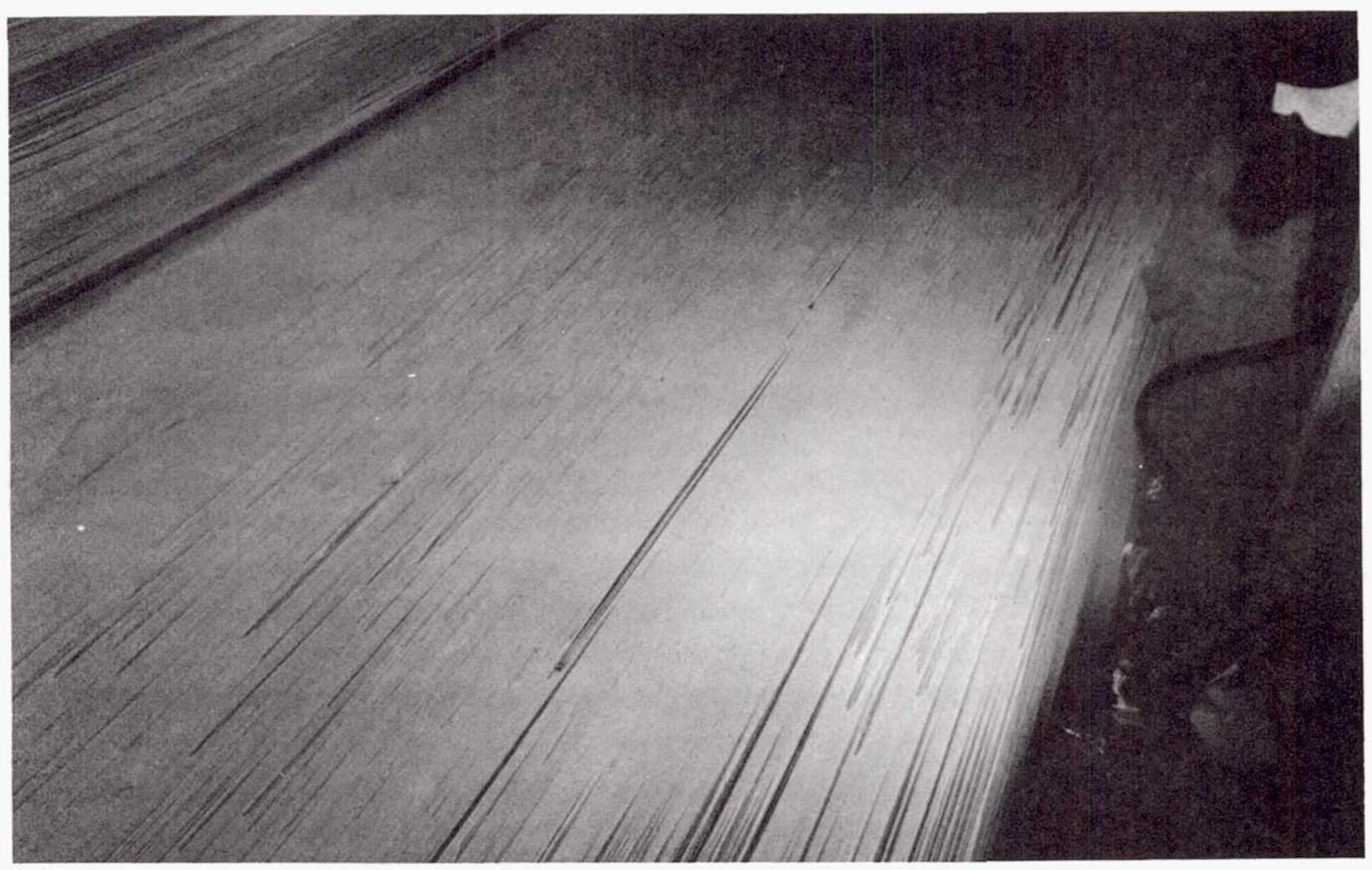

(c) Tunnel floor (flow from lower left to upper right).

Figure 16.-Concluded. 


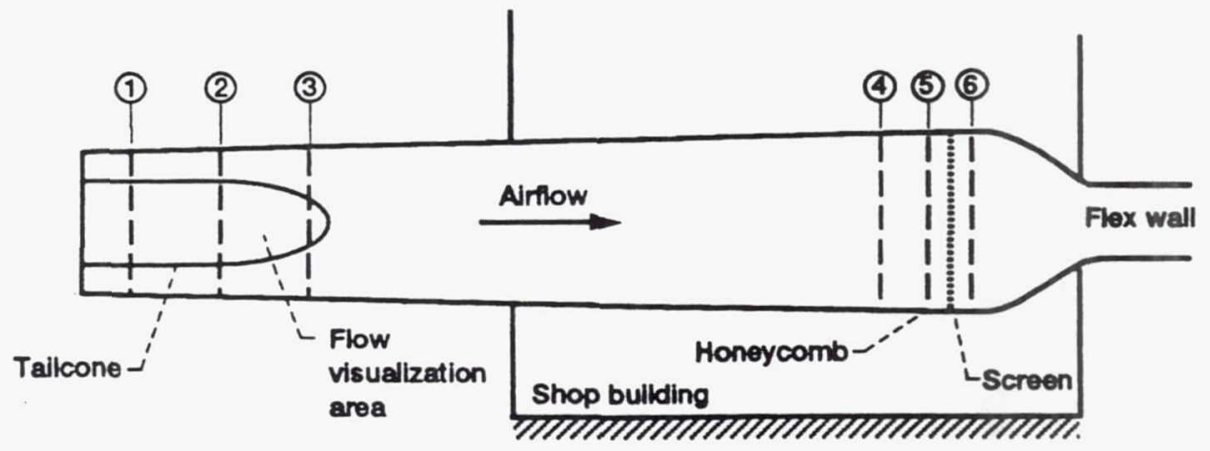

Instrumentation stations

(1) Compressor exit rake (short rake) station

(2) Tailcone boundary layer rake station

(3) Tailcone extt rake (kong rake) station

(4) Settling chamber traverse station

(5) Honeycomb-mounted pitot-static probes (16)

(6) Bellmouth traverse station

Figure 17.-Survey planes at compressor extt, 8- by 6-ft test section settling chamber, and bellmouth inlet (test areas 2, 3, and 4).

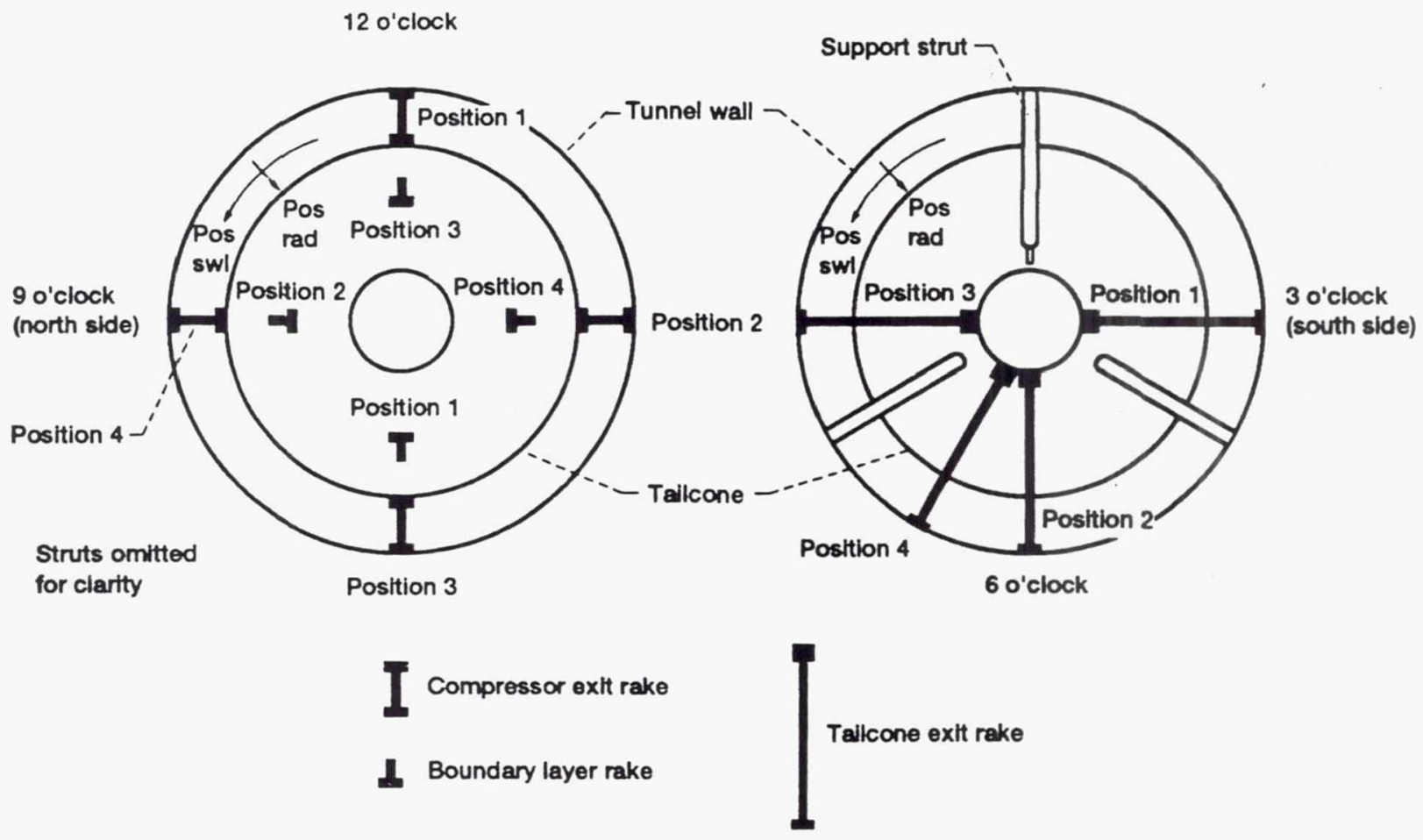

Figure 18.-Compressor exit, boundary layer, and tailcone exit rake positions (view looking upstream; Pos swl indicates posithe swirl flow angularity, Pos rad indicates positive radial fiow angularity). 


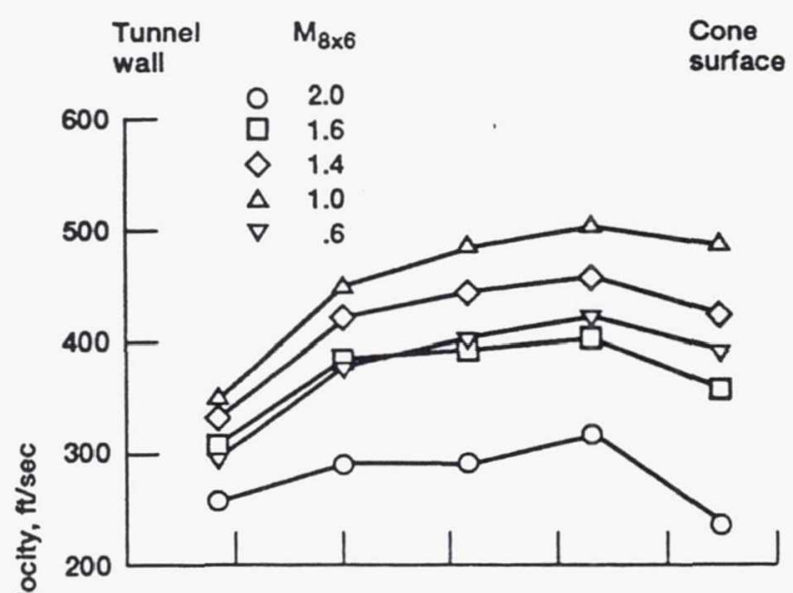

(a) 3 o'clock position.

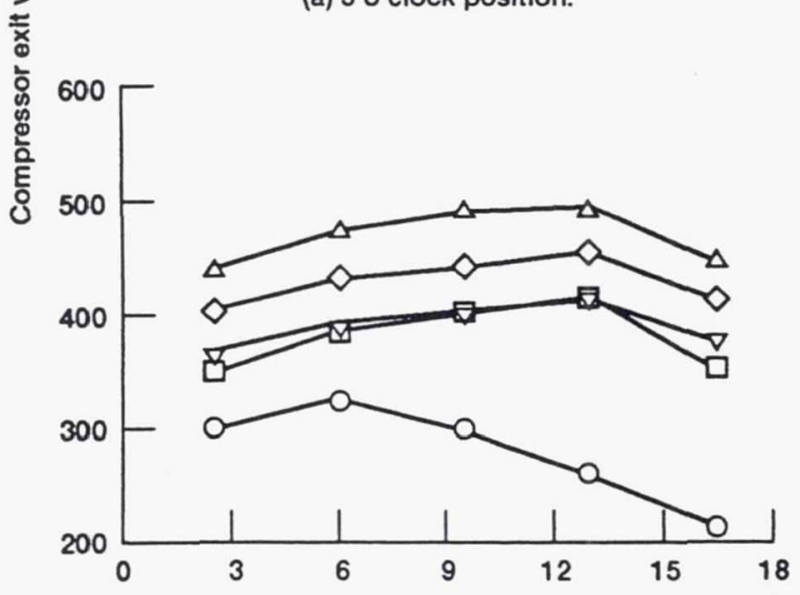

(c) 9 o'clock position.

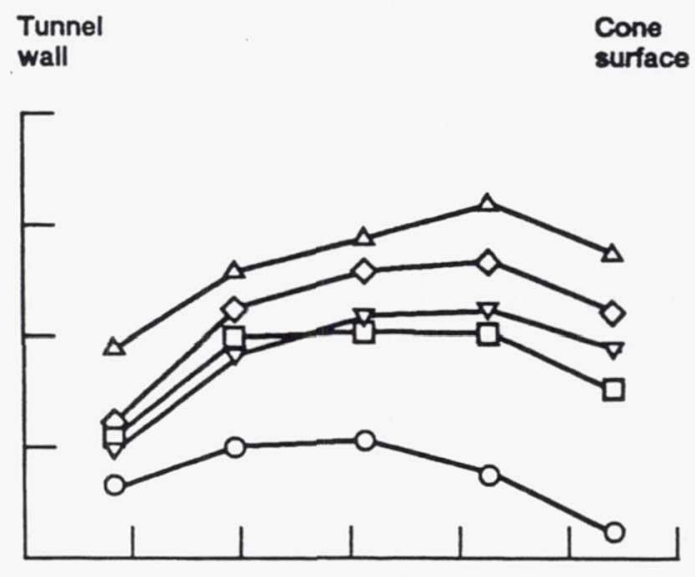

(b) 6 o'clock position.

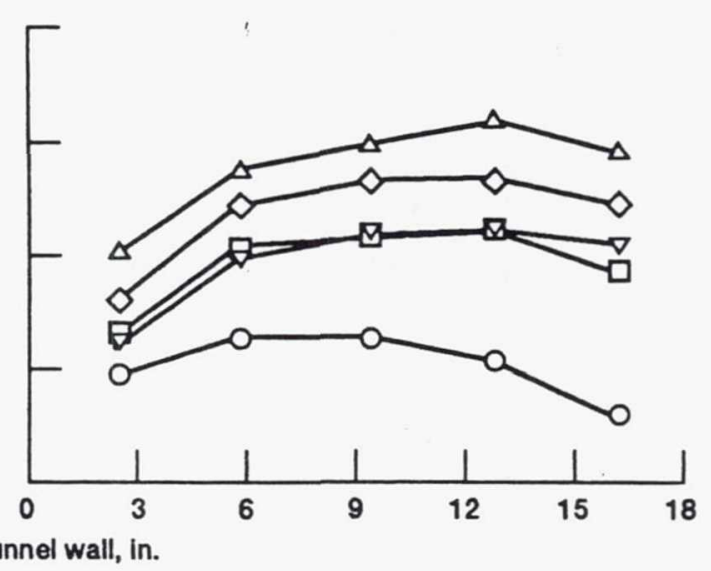

(d) 12 o'clock position.

Figure 19.-Velocity distributions at compressor exit as measured by flow angle probes. 


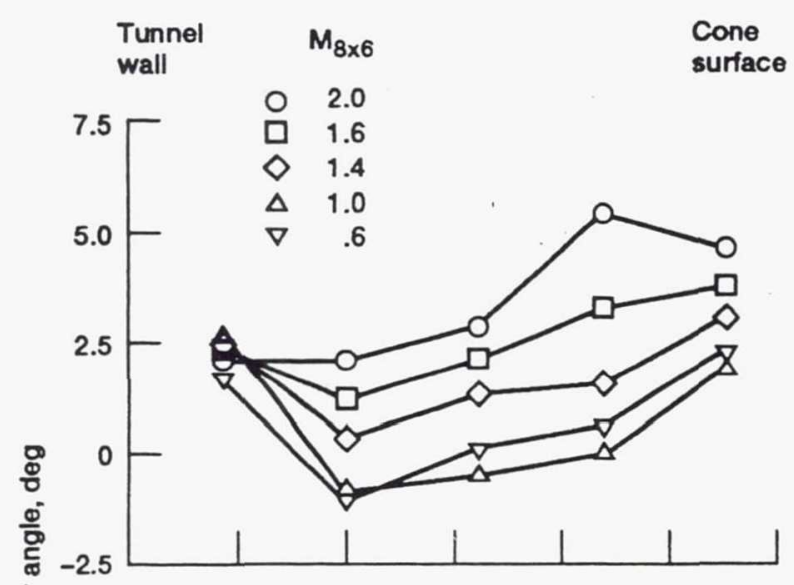

(a) 3 o'clock position.

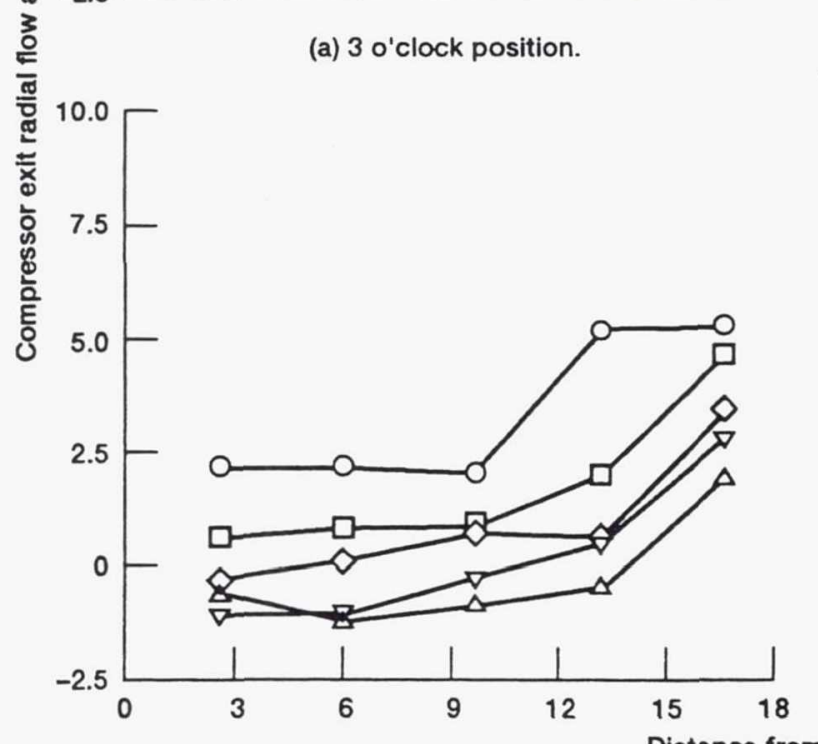

Distance from tunnel wall, in.

(c) 9 o'clock position.

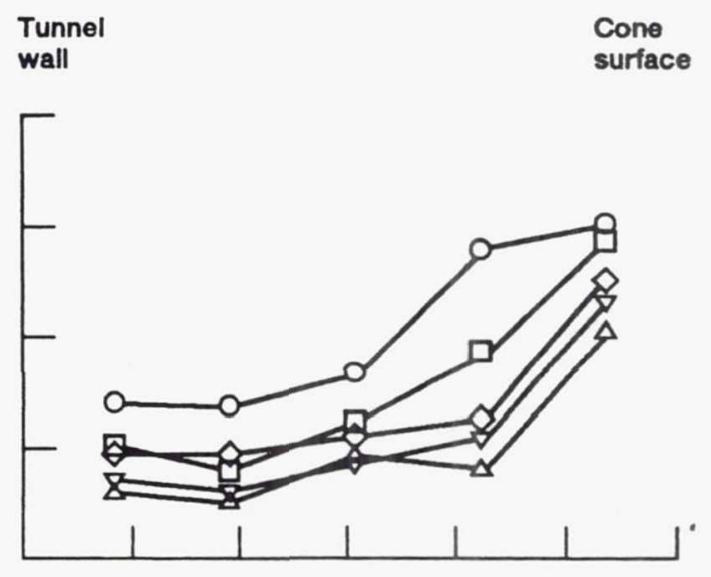

(b) 6 o'clock position.

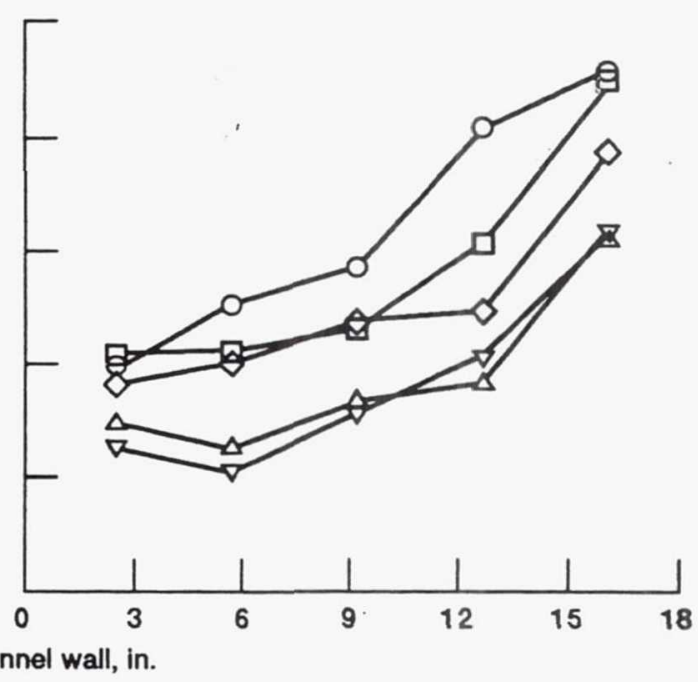

(d) 12 o'clock position.

Figure 20.-Radial flow angularity data at compressor exit (positive toward tailcone). 


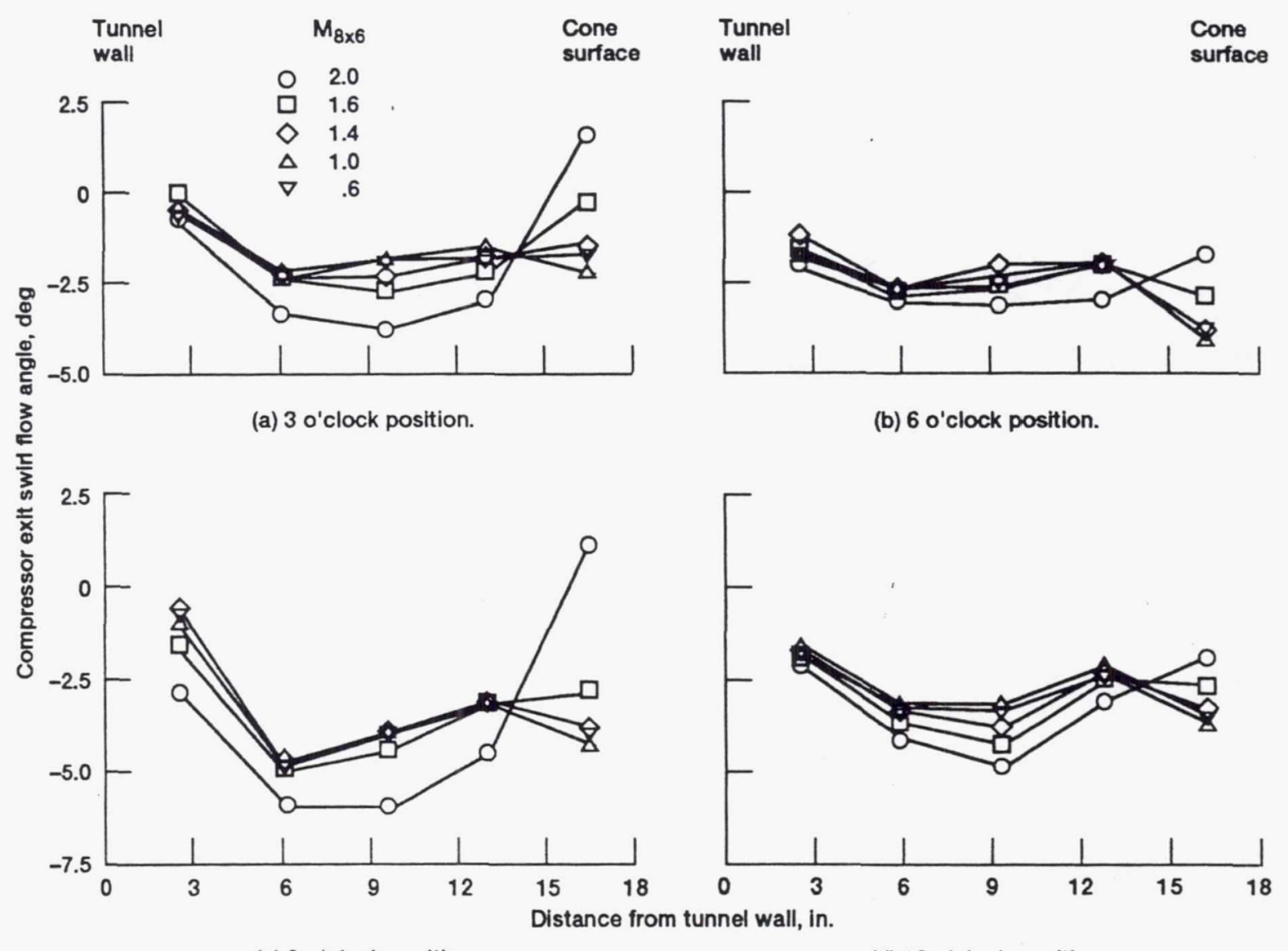

(c) 9 o'clock position.

(d) 12 o'clock position.

Figure 21. Swirl flow angularity data at compressor exit (negative in direction of compressor rotation). 


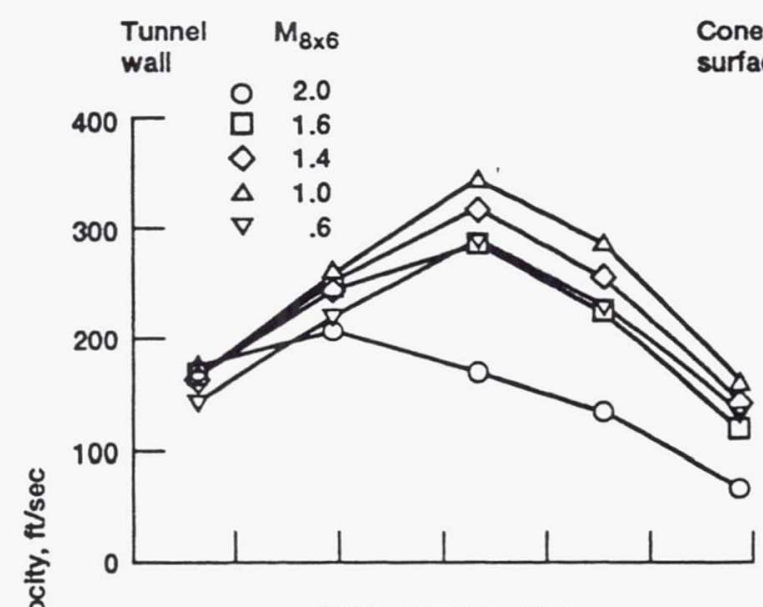

(a) 3 o'clock position.
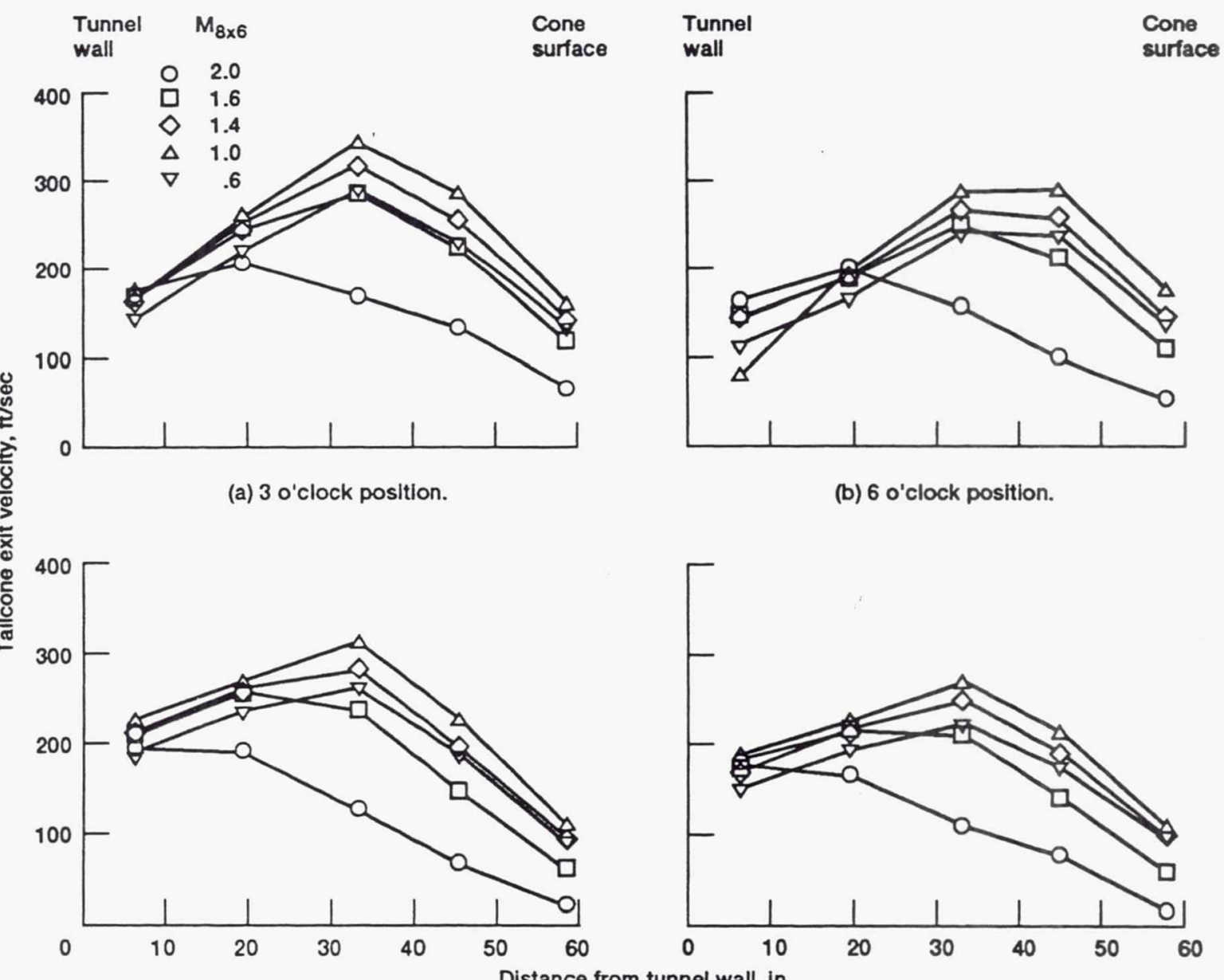
(c) 9 o'clock position.
(d) 7 o'clock position.

Figure 22.-Velocity distributions at tailcone exit as measured by flow angle probes. 


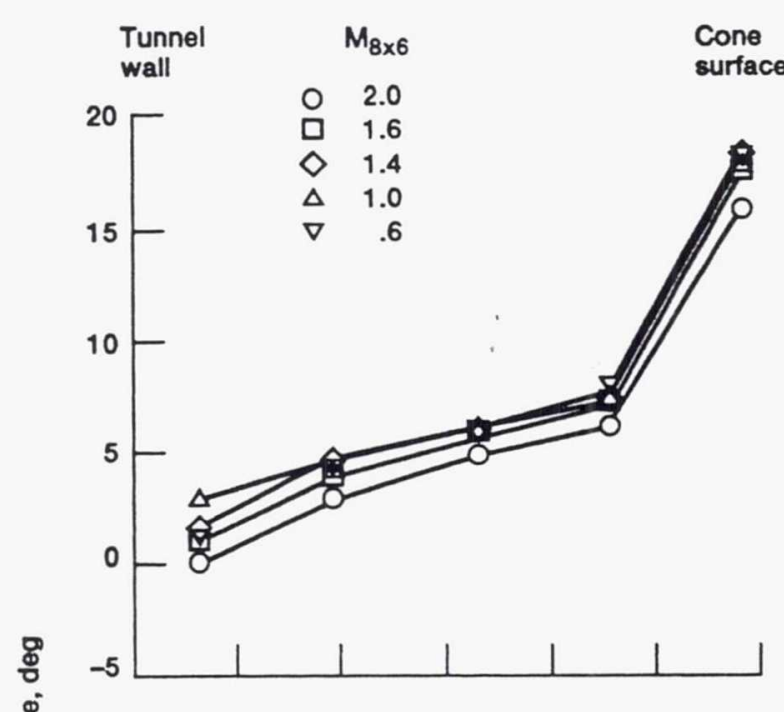

(a) 3 o'clock position.

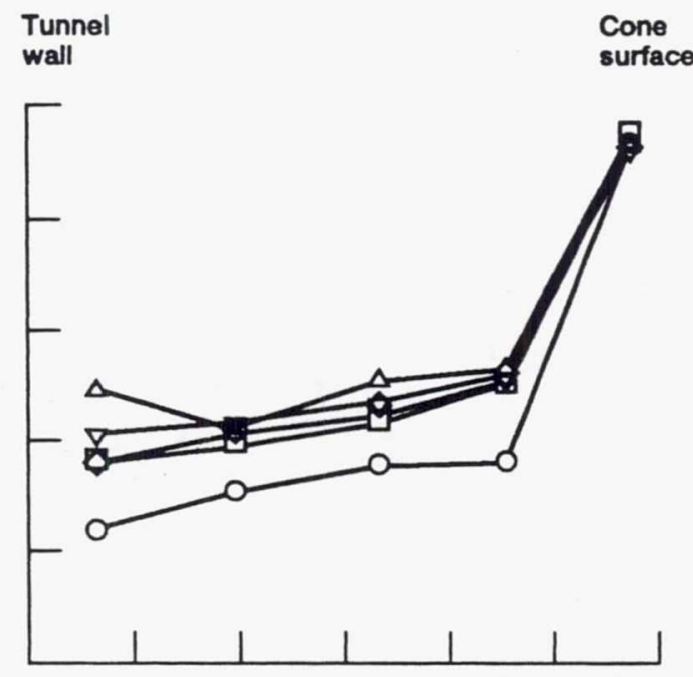

(b) 6 o'clock position.

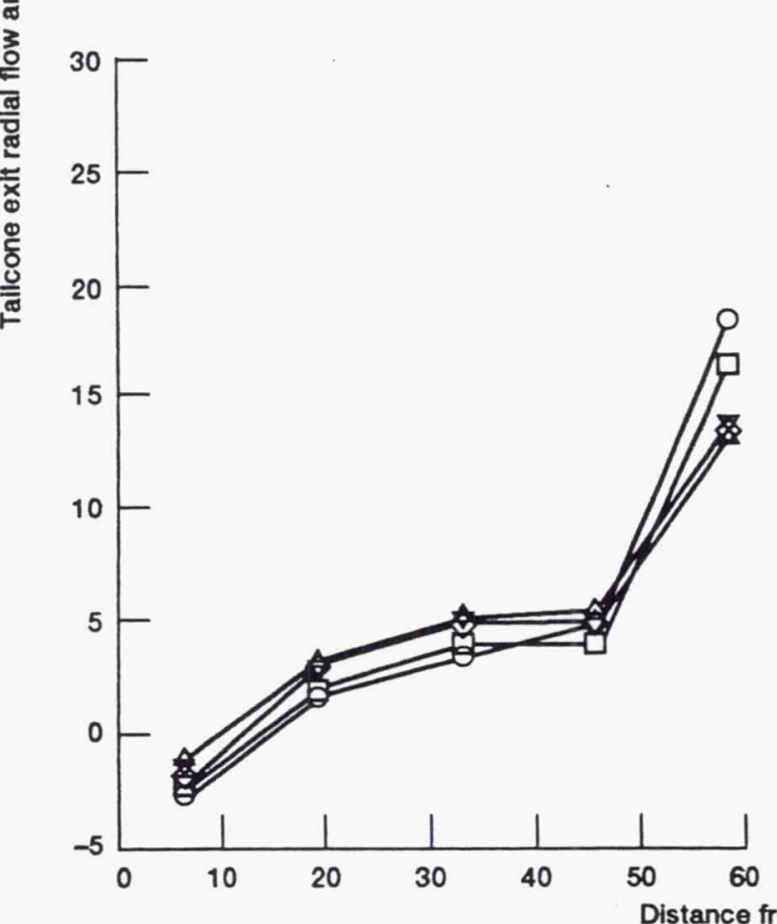

(c) 9 o'clock position.

(d) 7 o'clock position.

Figure 23.-Radial flow angularity data at tailcone exit (positive toward tailcone). 


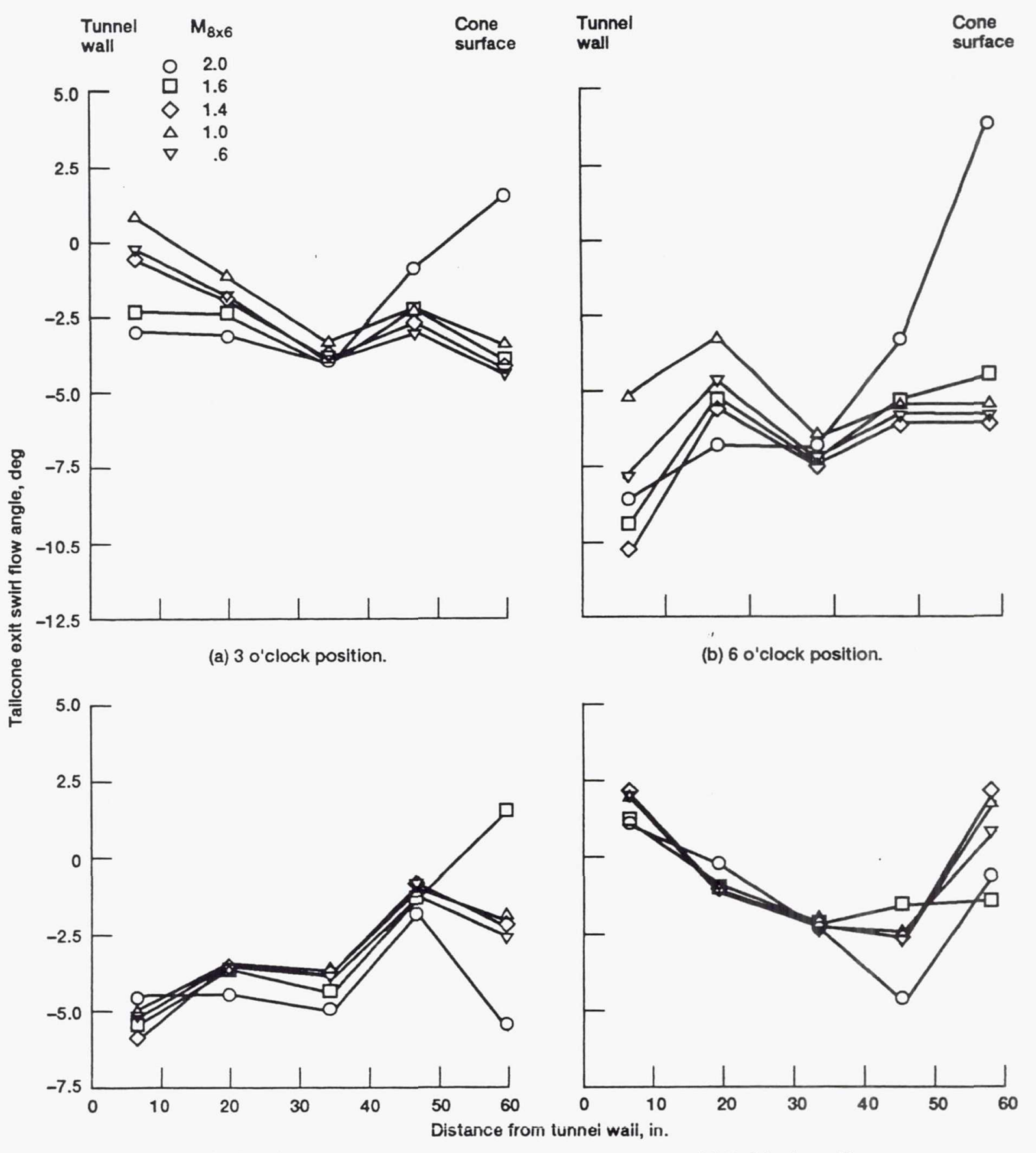

(c) 9 o'clock position.

(d) 7 o'clock position.

Figure 24. Swirl flow angularity data at tailcone exit (negative is in direction of compressor rotation). 


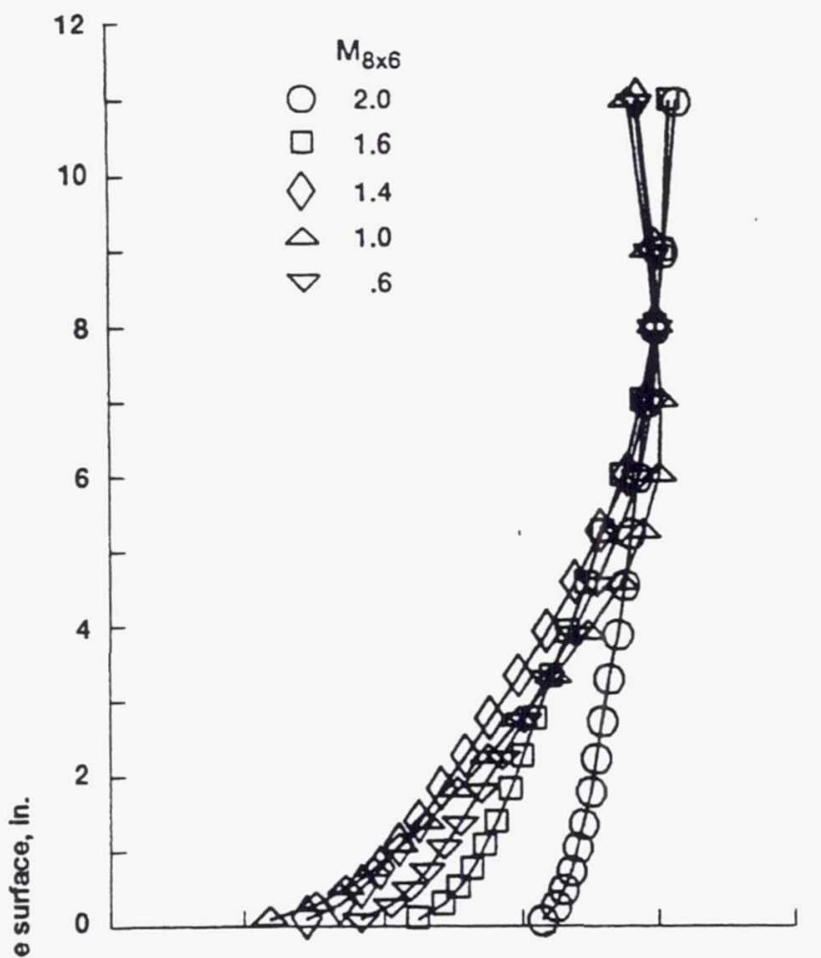

(a) 3 o'clock position.

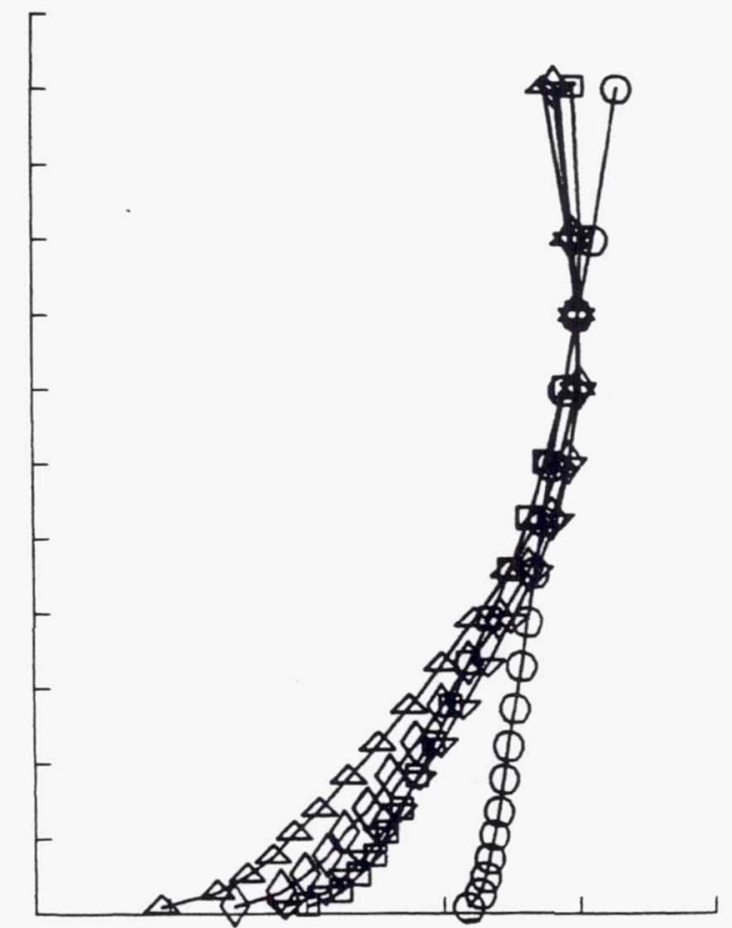

(b) 6 o'clock position.

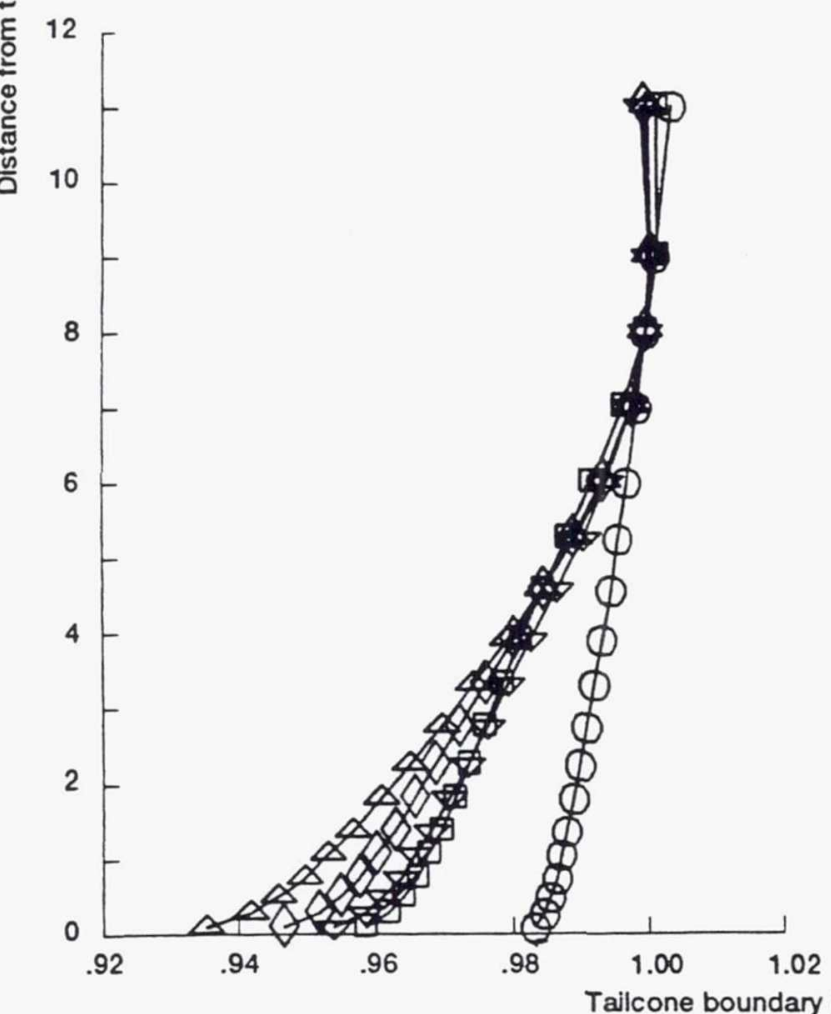

(c) 9 o'clock position.

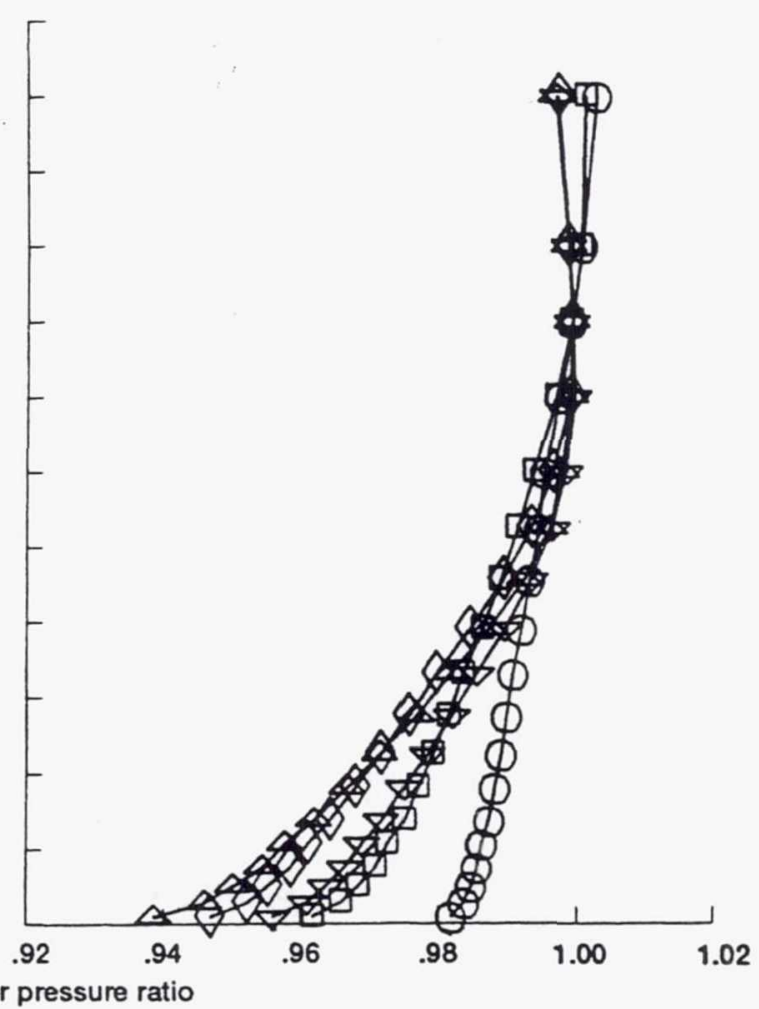

(d) 12 o'clock position.

Figure 25.-Boundary layer rake total pressure surveys at tailcone surface. 


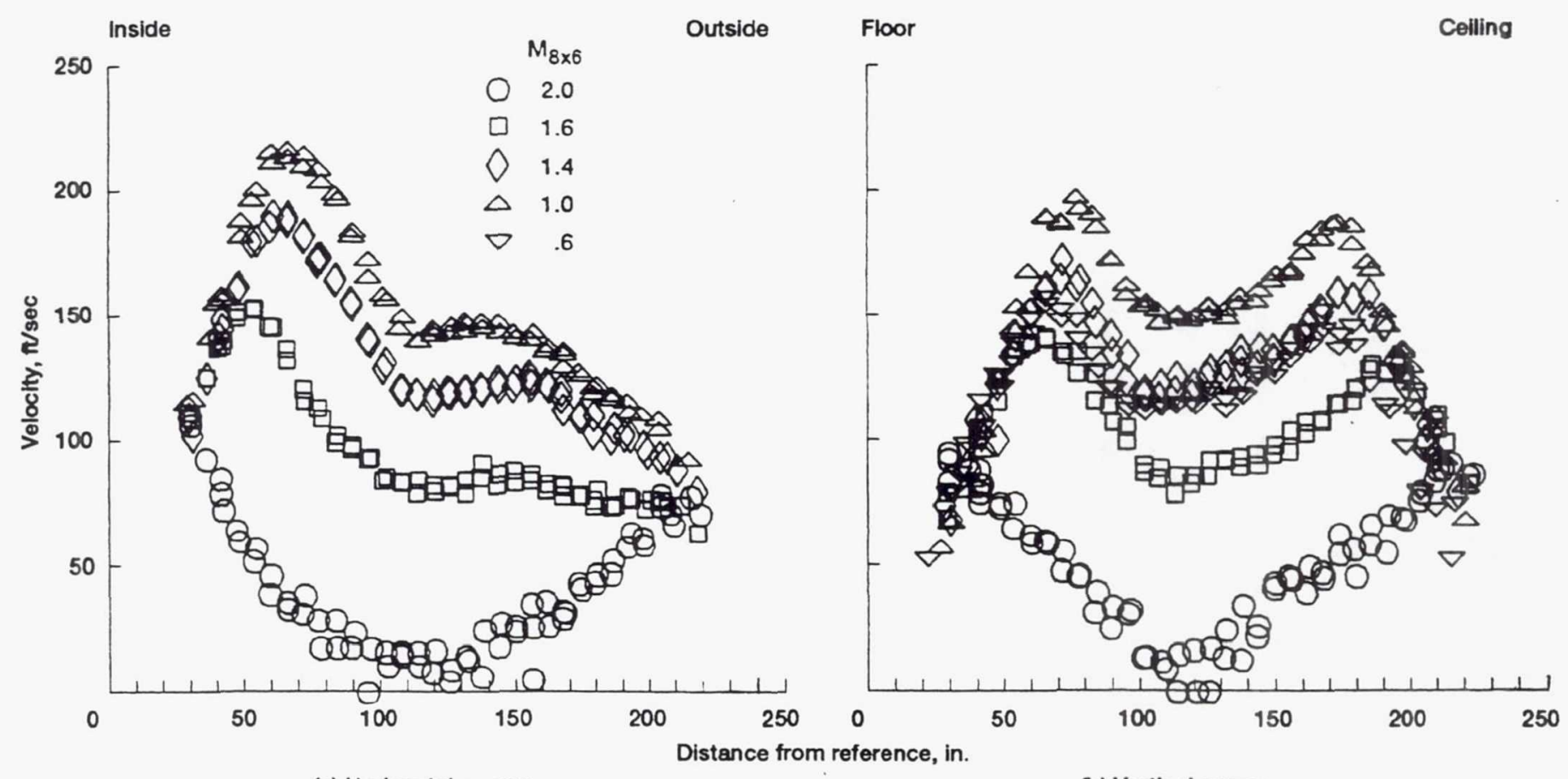

(a) Horizontal survey.

(b) Vertical survey.

Figure 26.-Velocity distributions in settling chamber upstream of 8- by 6-ft test section from pitot-static probe data.

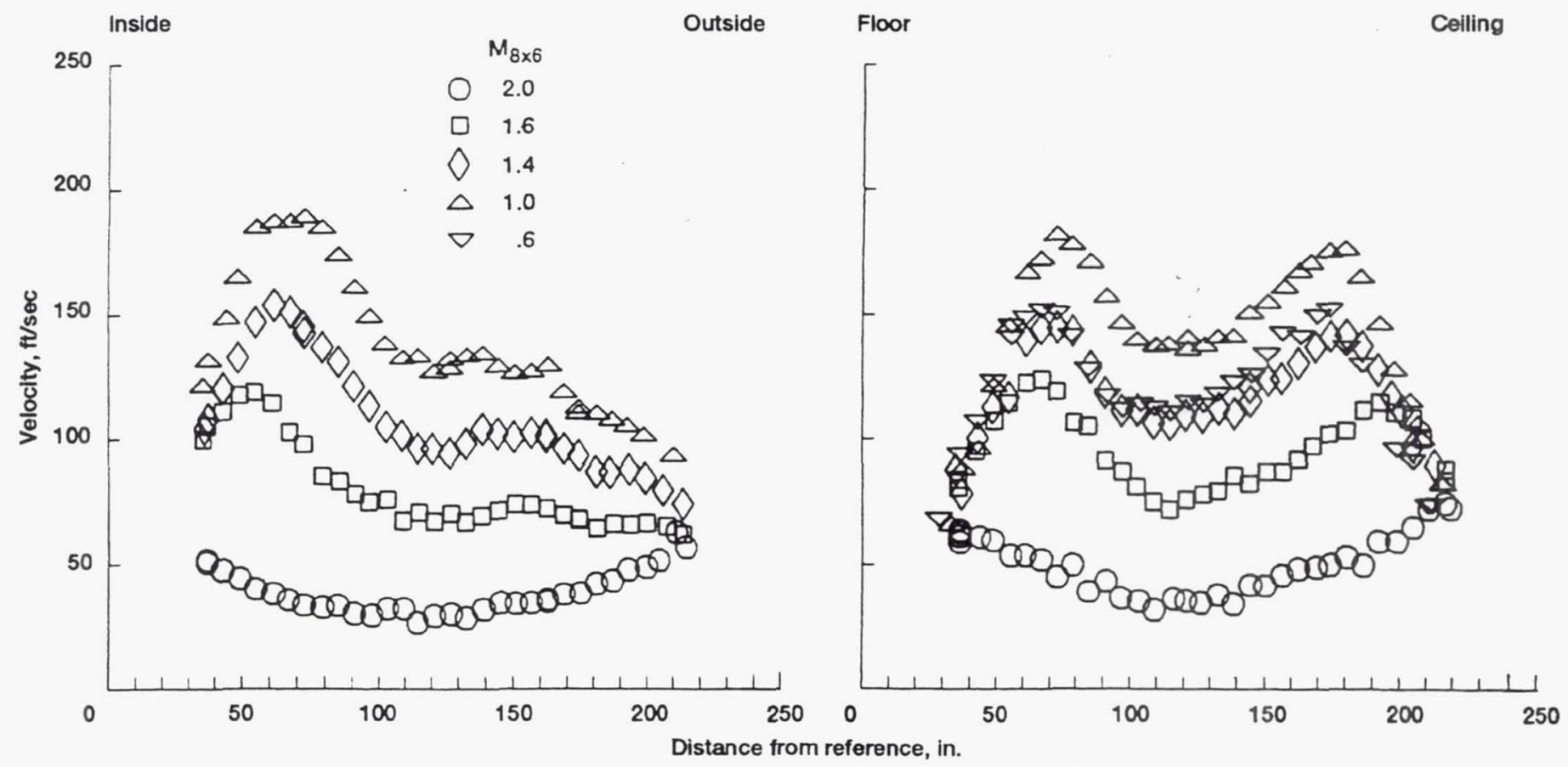

(a) Horizontal survey.

(b) Vertical survey.

Figure 27.-Velocity distributions in settling chamber upstream of \&- by 6-ft test section from hot-film anemometry data. 


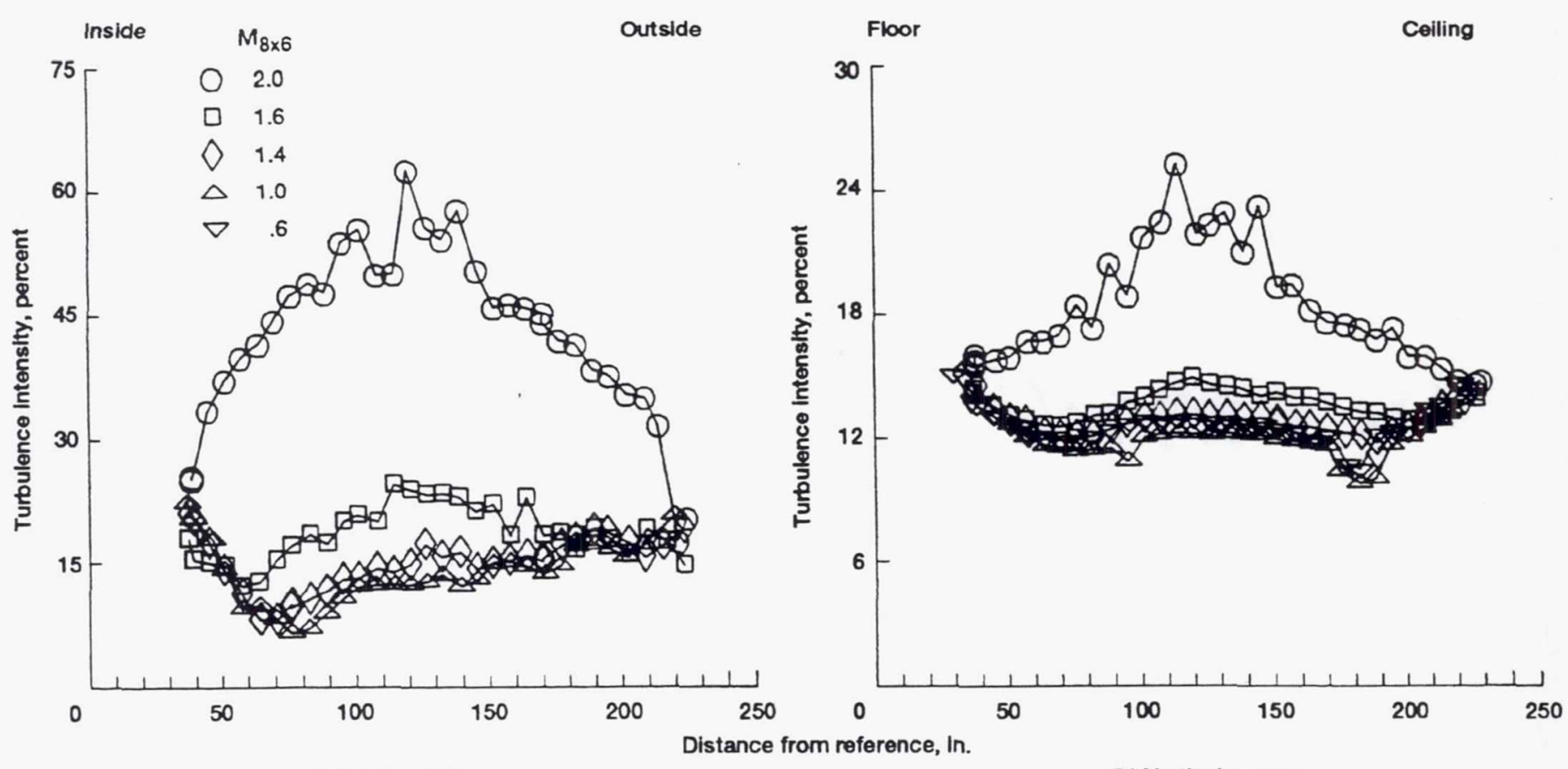

(a) Horizontal survey.

(b) Vertical survey.

Figure 28.-Turbulence intensity data in settling chamber upstream of 8 - by 6-ft test section.

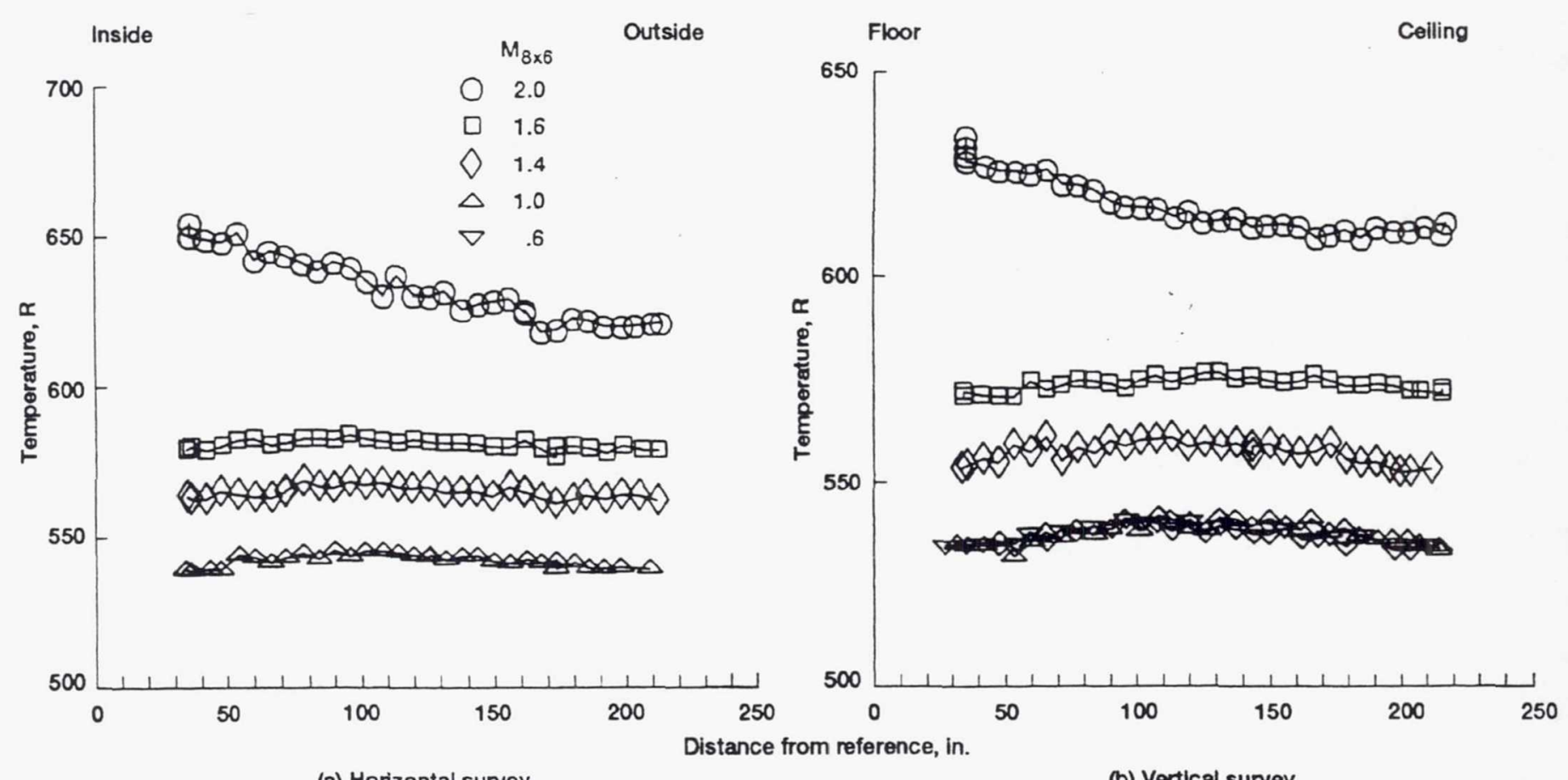

(a) Horizontal survey.

(b) Vertical survey.

Figure 29.-Total temperature survey data in settling chamber of 8- by 6-ft test section. 


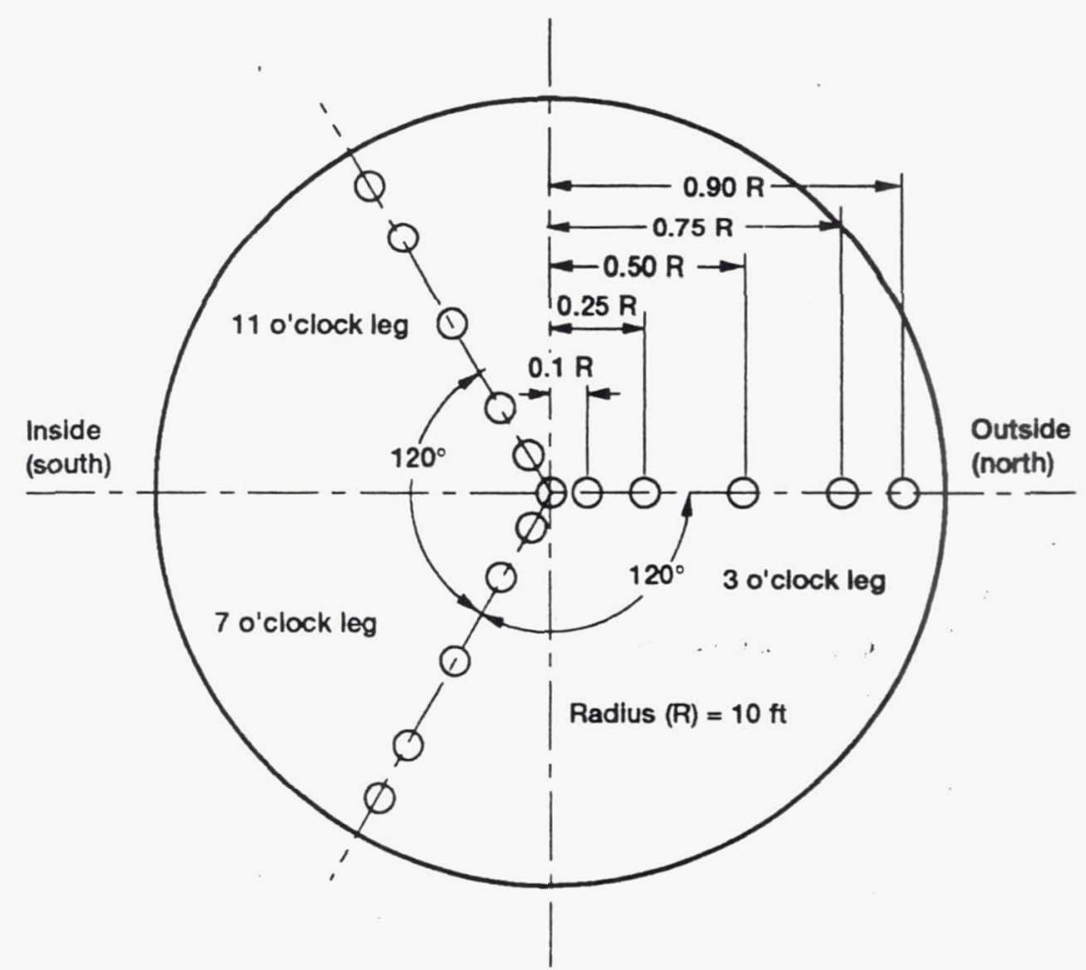

Figure 30.-Honeycomb-mounted pitot-static probe locations (view looking downstream).

33 


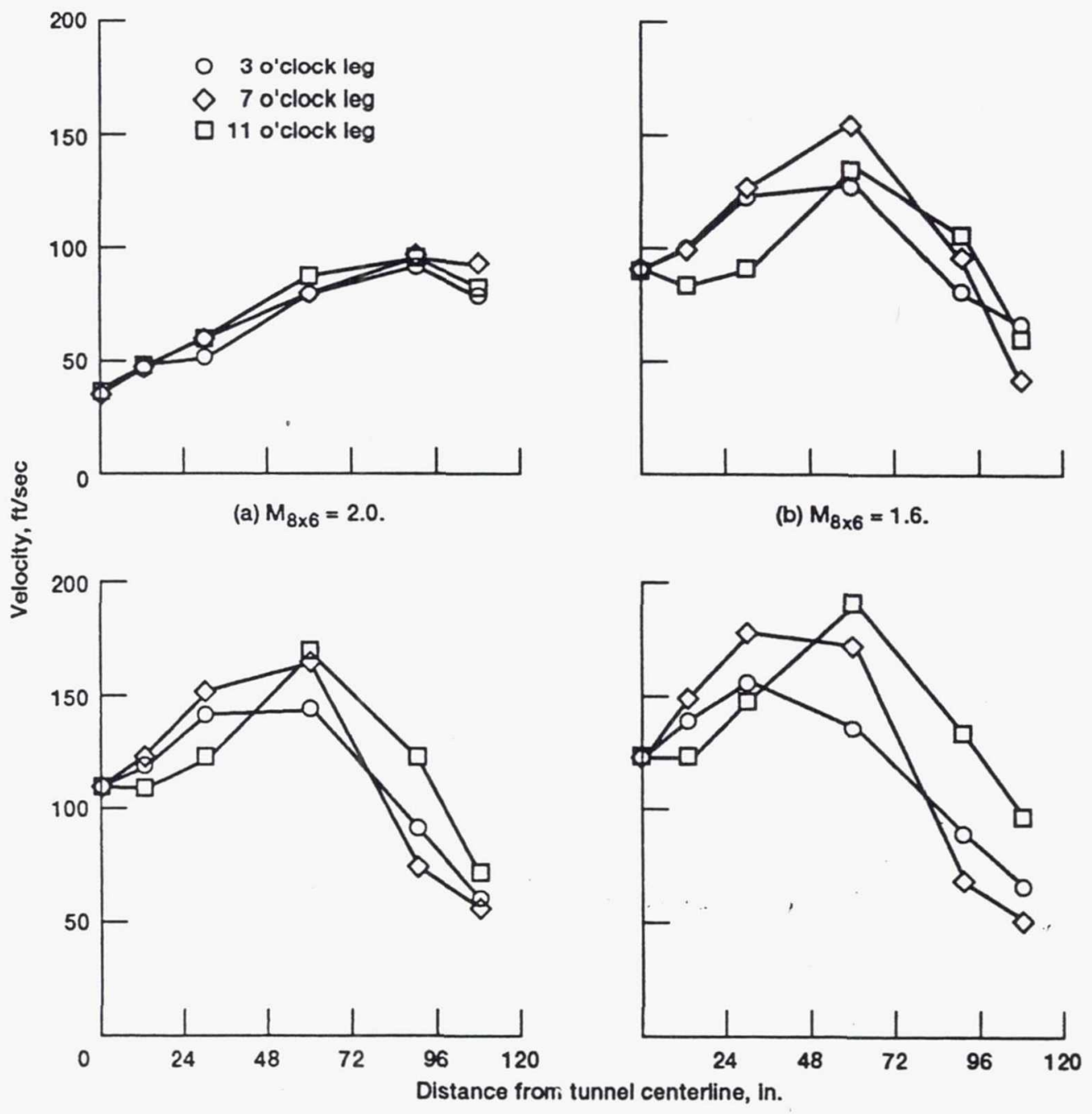

$\begin{array}{ll}\text { (c) } M_{8 \times 6}=1.4 . & \text { (d) } M_{8 \times 6}=1.0 .\end{array}$

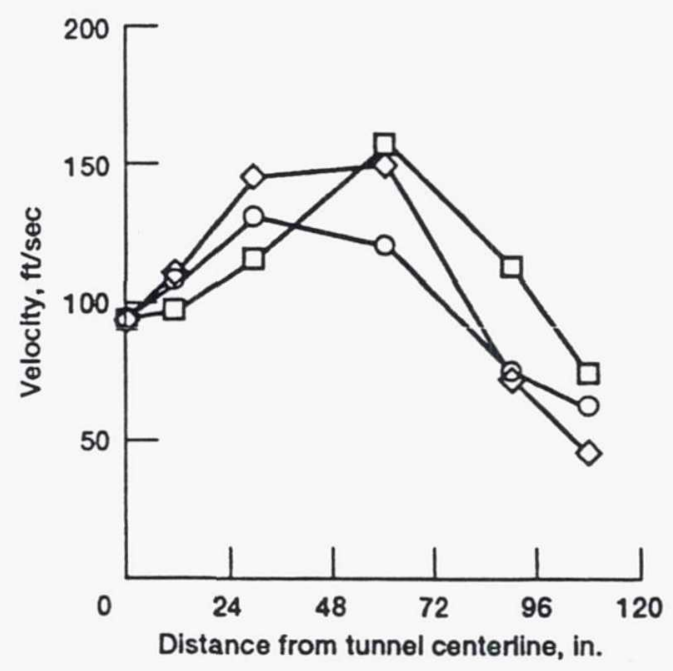

(e) $M_{8 \times 6}=0.6$.

Figure 31.-Velocity distributions along each of three radial legs of honeycomb-mounted pressure probes at various $M_{8 \times 6}$ conditions. 


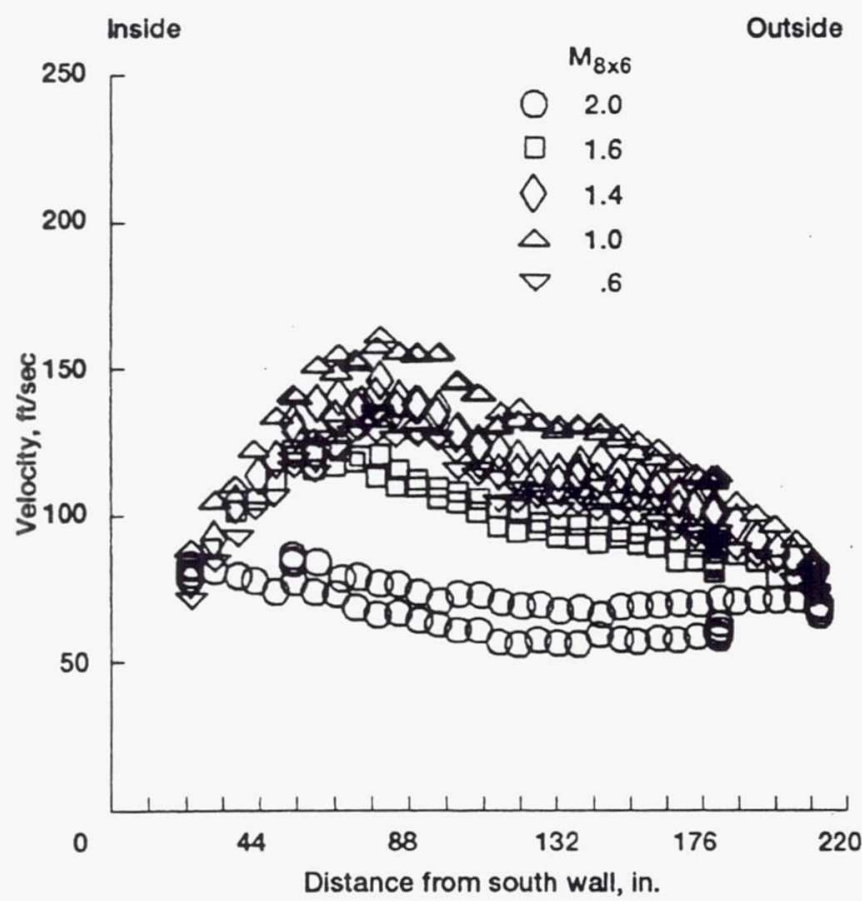

Figure 32.-Velocity distribution from pressure data along horizontal survey plane at inlet of bellmouth upstream of 8- by 6-ft test section (survey plane downstream of flow conditioning screen).

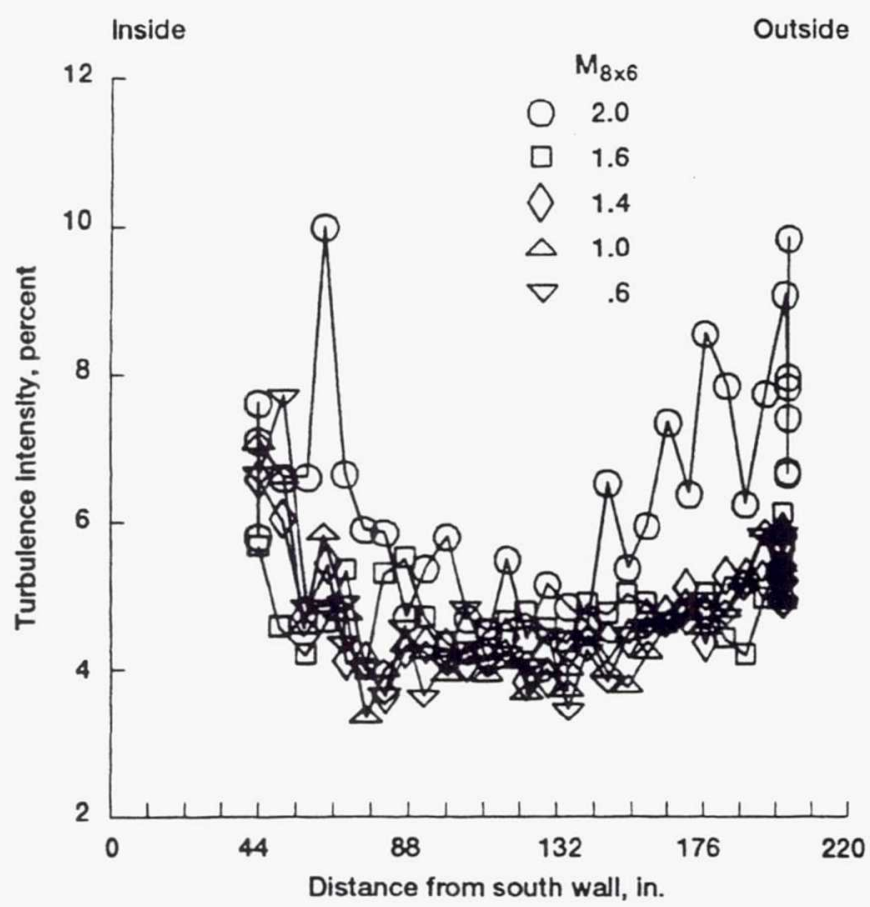

Figure 34.-Turbulence intensity data results along horizontal survey plane at inlet of belimouth upstream of 8- by 6-ft test section (survey plane downstream of flow conditioning screen).

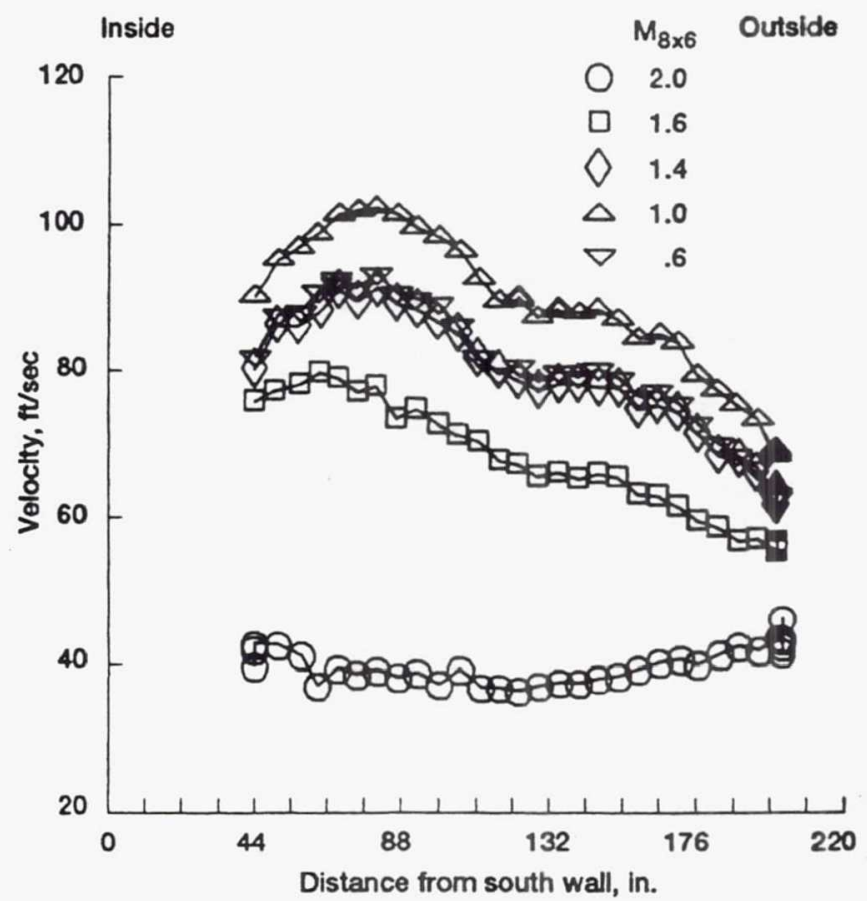

Figure 33.-Velocity distribution from hot-film anemometry along horizontal survey plane at inlet of bellmouth upstream of 8- by 6-ft test section (survey plane downstream of flow conditioning screen).

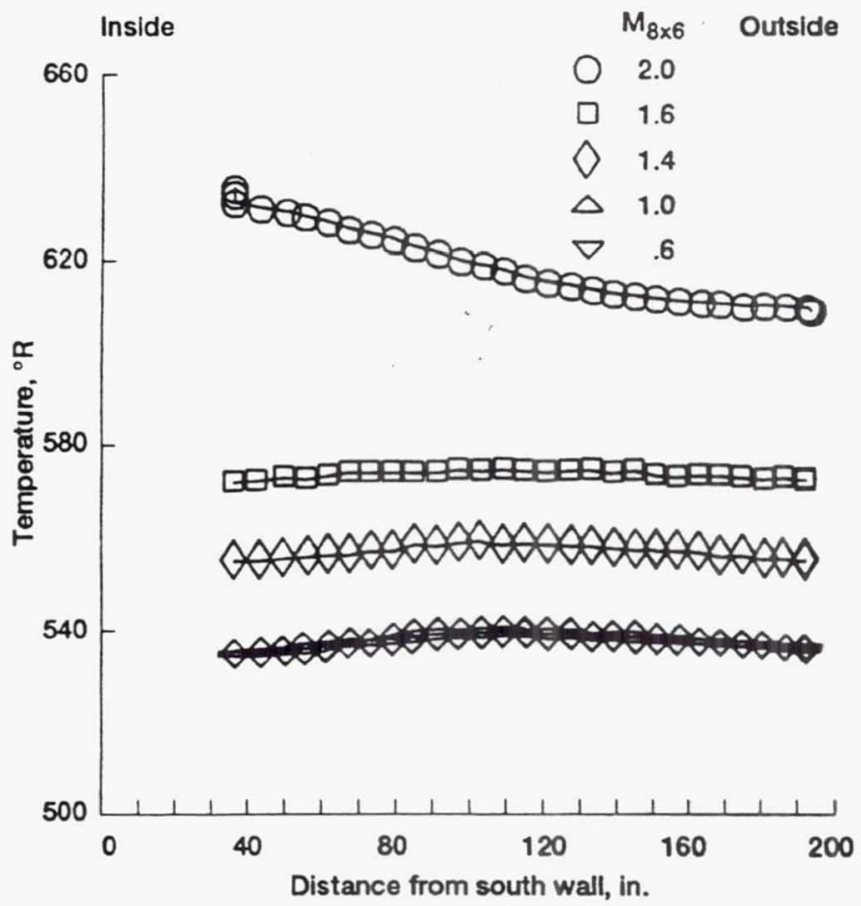

Figure 35.-Total temperature data along horizontal survey plane at inlet of bellmouth upstream of 8 - by 6 -ft test section (survey plane downstream of flow conditioning screen). 


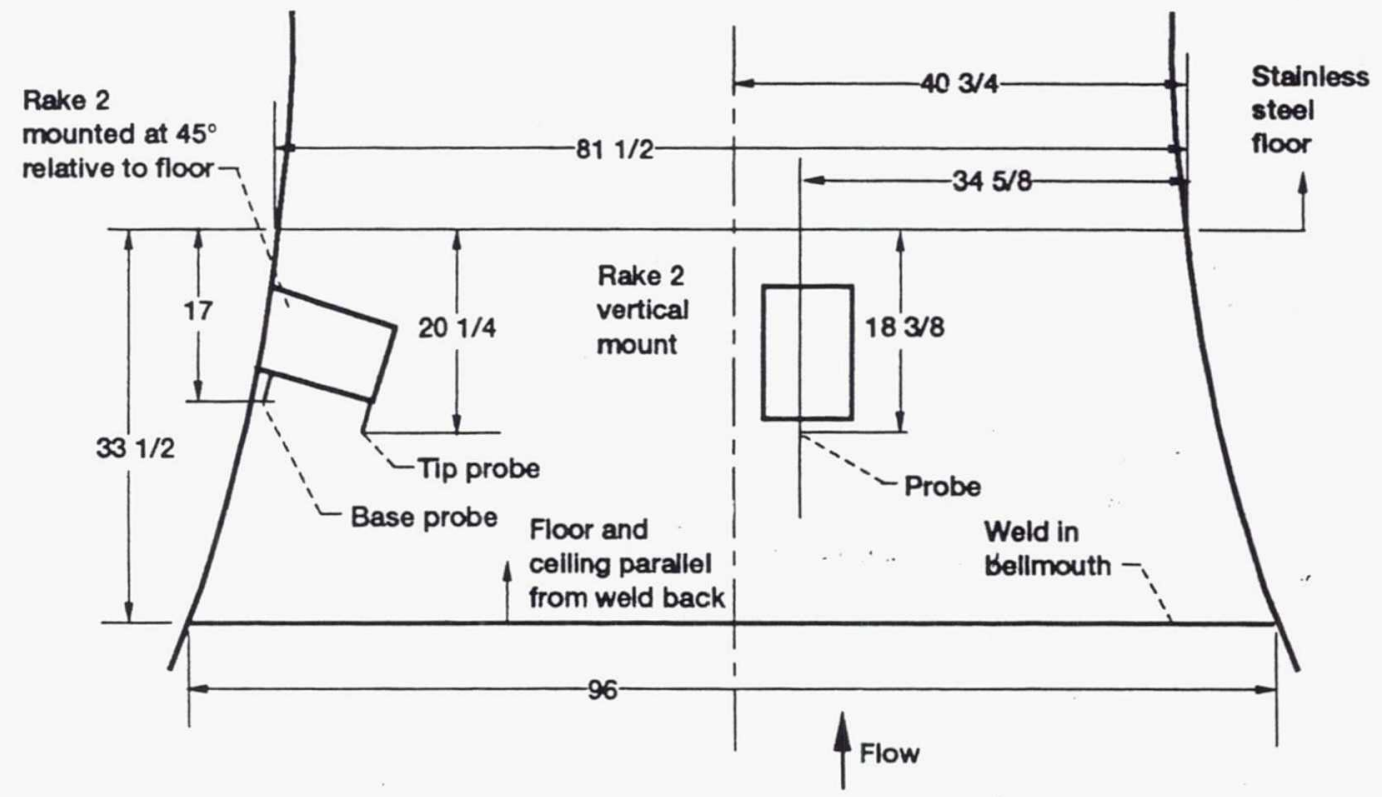

Figure 36.-Bellmouth boundary layer rake locations (dimensions in inches). 


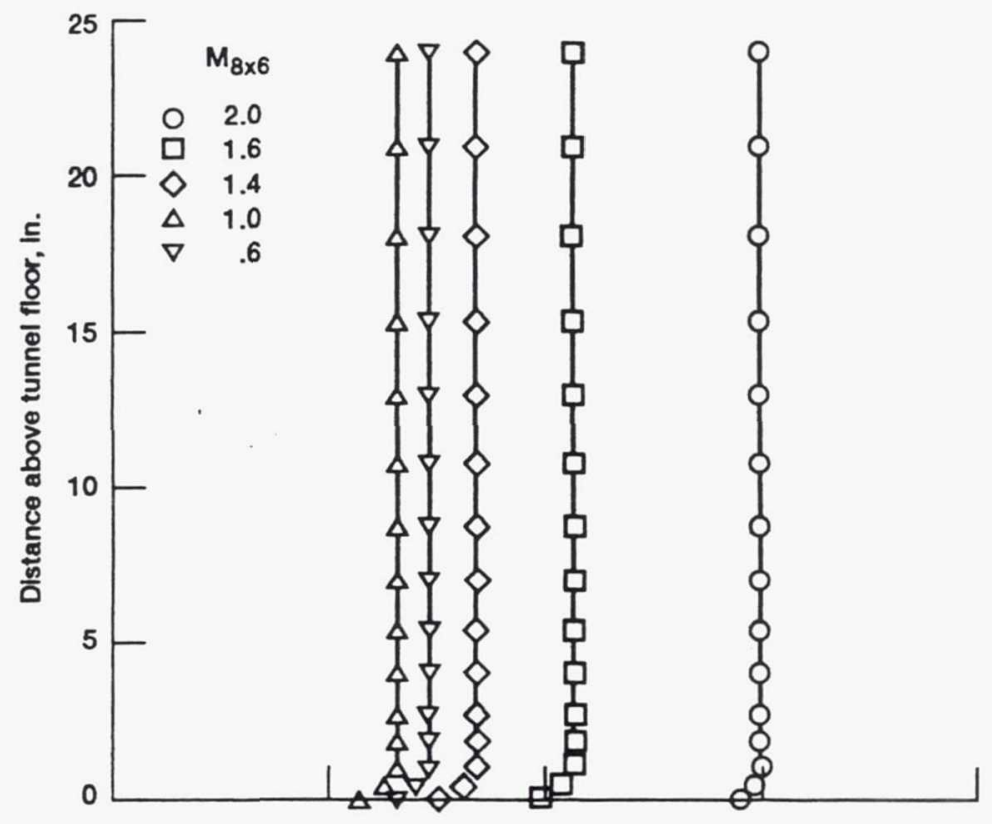

(a) Centerline rake.

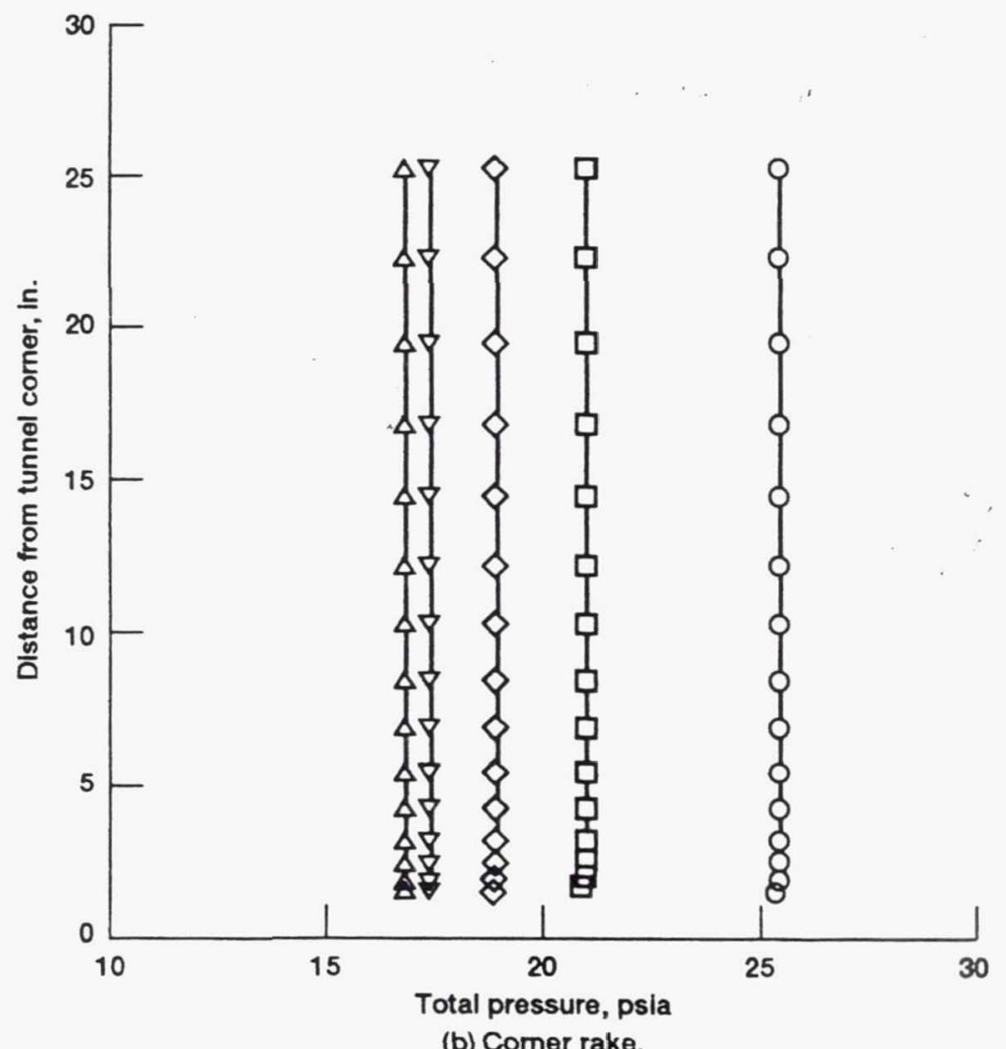

Figure 37.-Boundary layer rake total pressure distributions at bellmouth exit. 


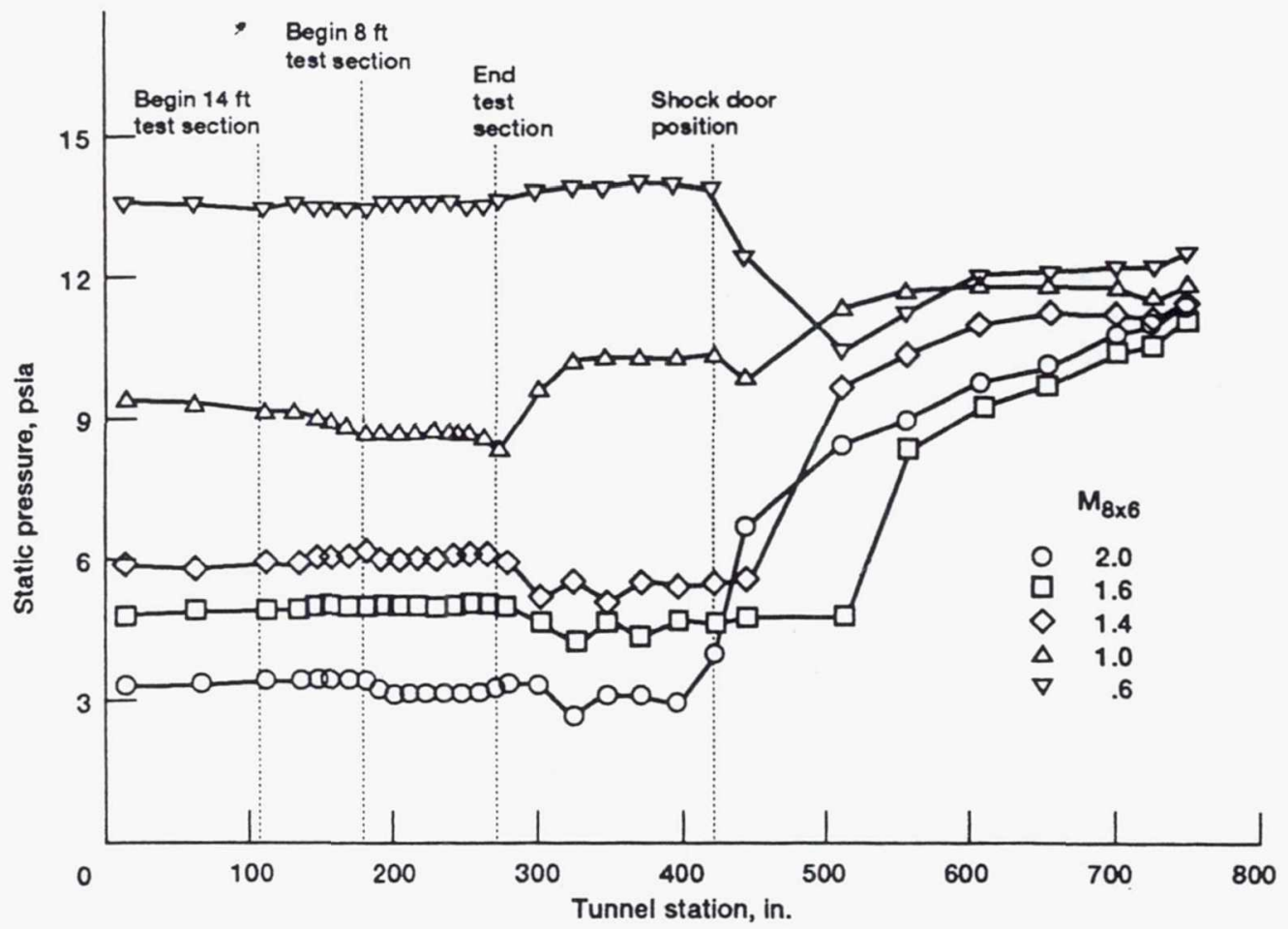

Figure 38.-Ceiling static pressure distribution through 8 - by 6 -ft test section and forward diffuser section.

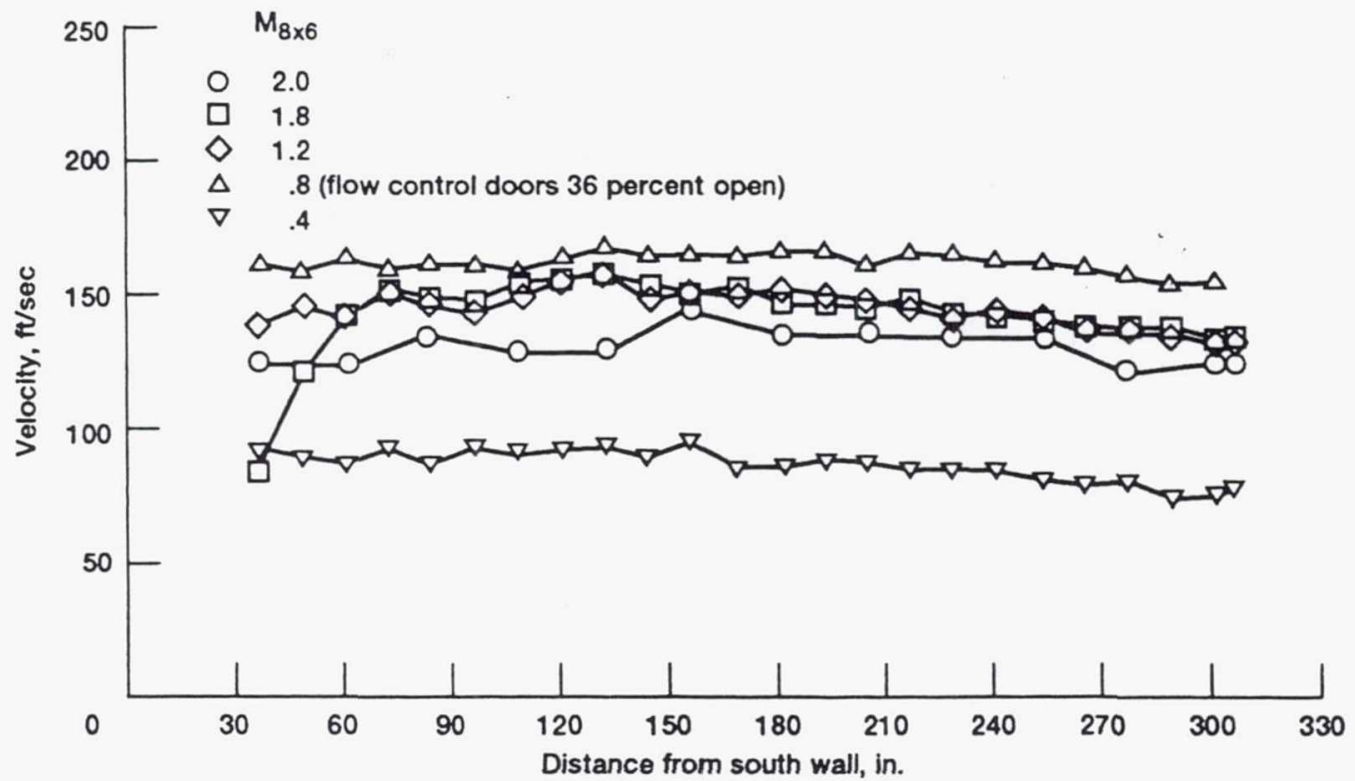

Figure 39.-Velocity distributions at discharge of high-speed diffuser section. 


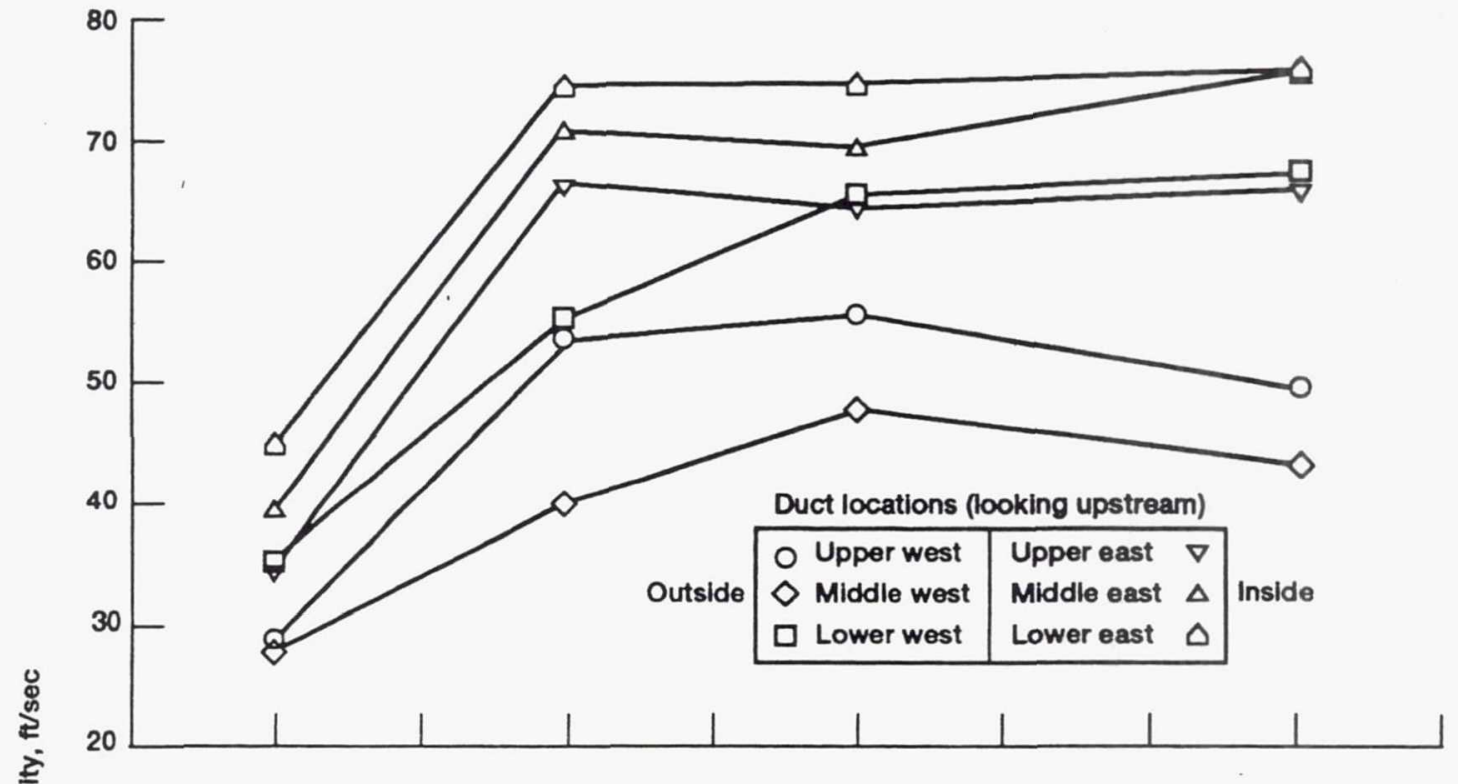

(a) Propulsion cycle.

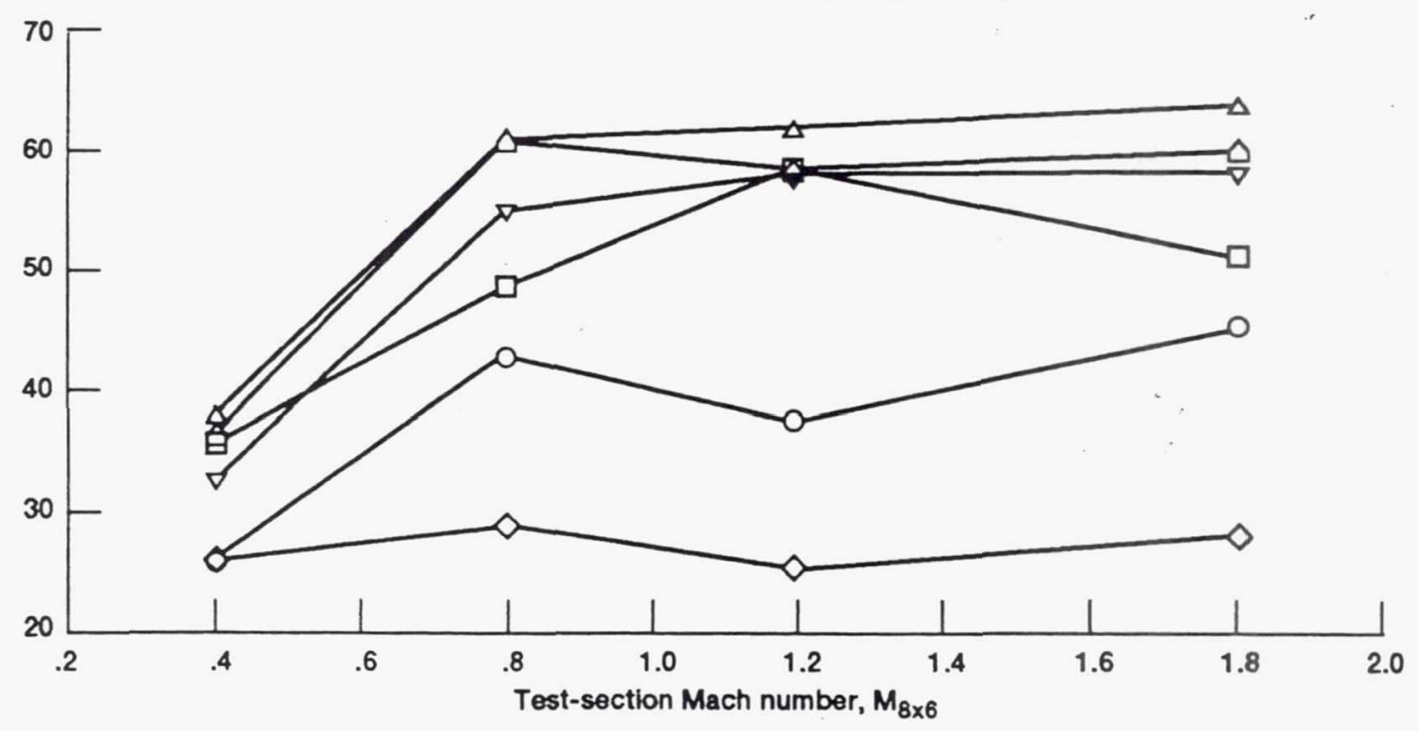

(b) Aerodynamic cycle.

Figure 40.-Velocity distributions at exit of each of six acoustic muffler ducts. 


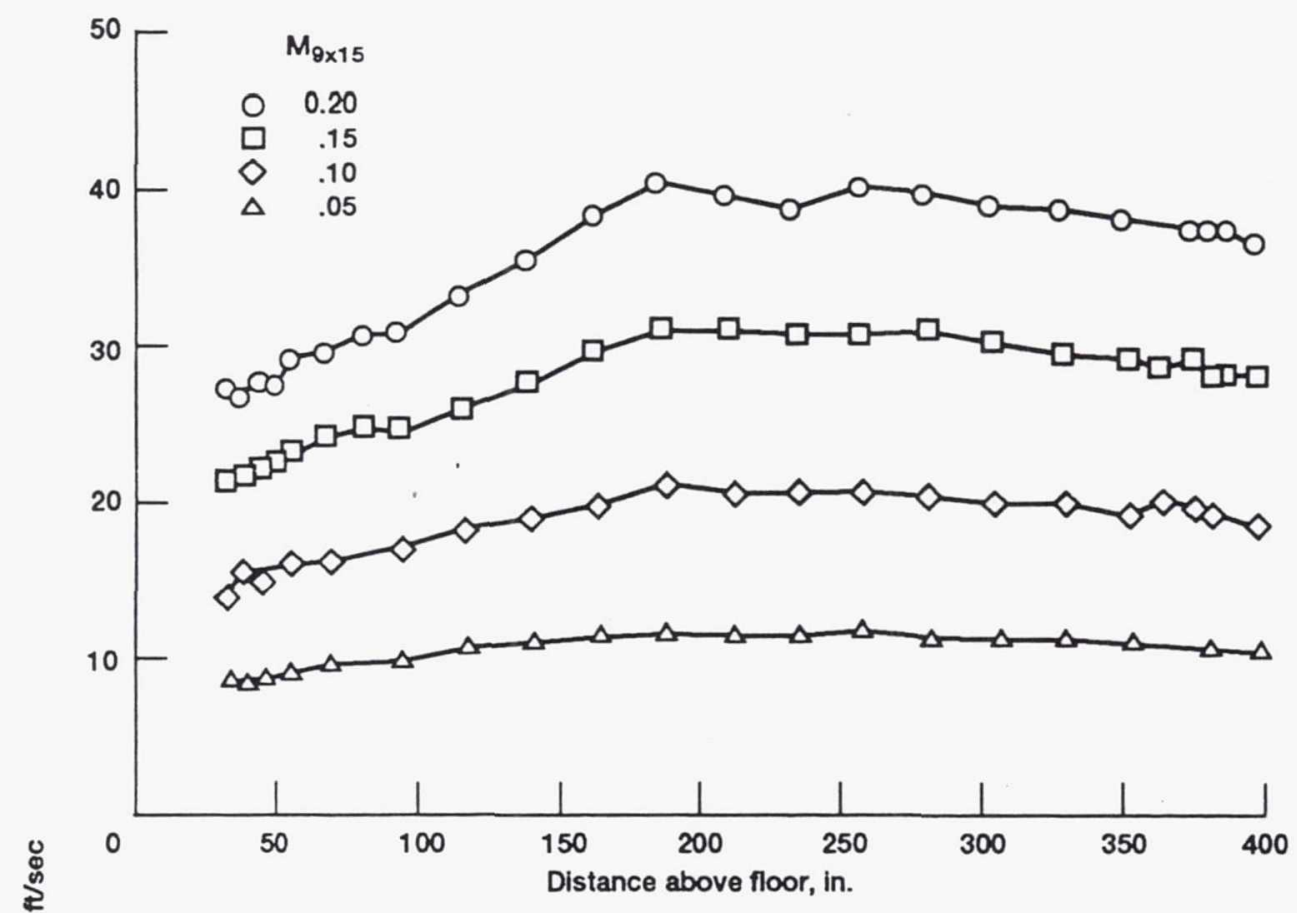

(a) Vertical traverse.

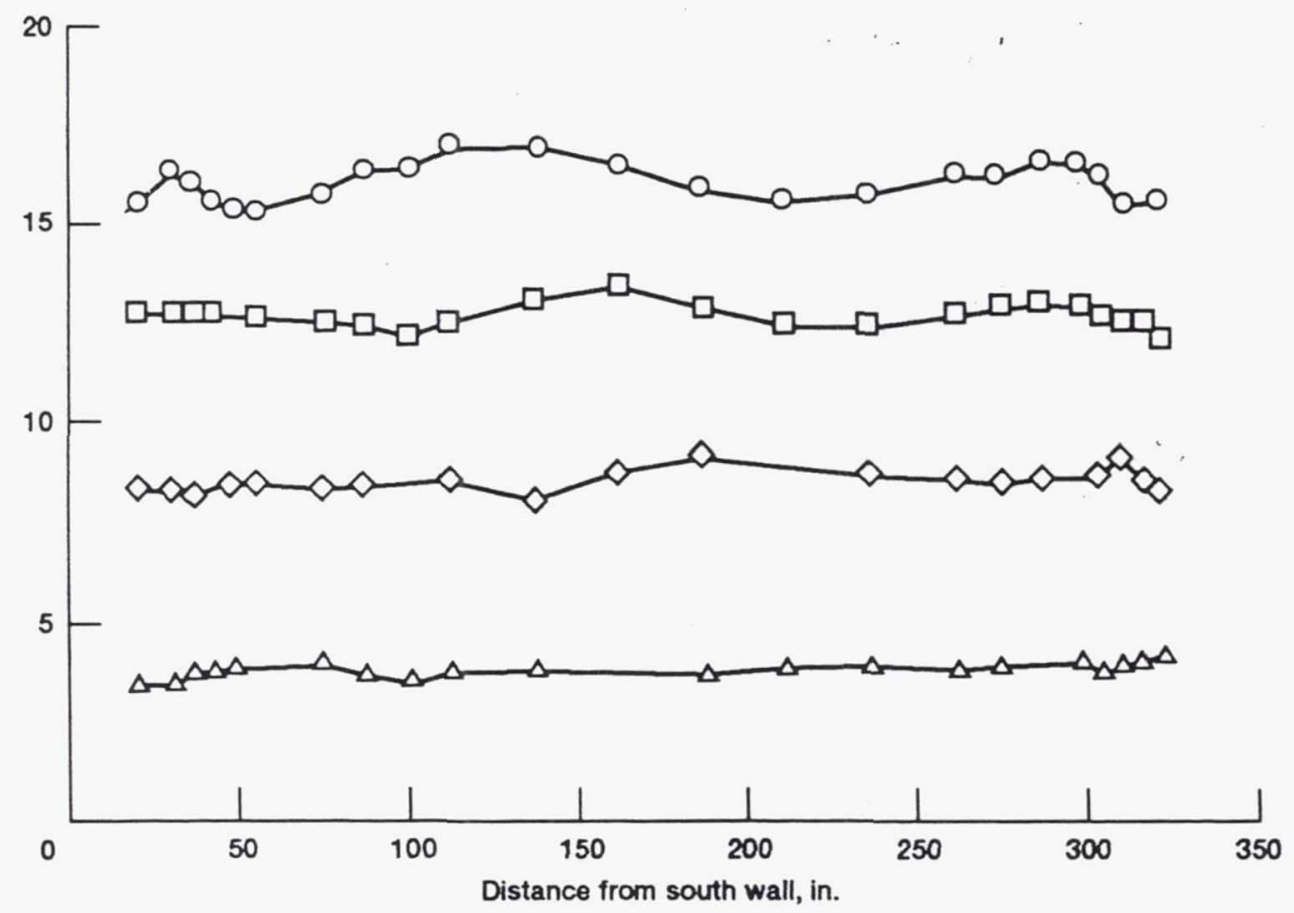

(b) Horizontal traverse.

Figure 41.-Velocity distributions from hot-film data in settling chamber upstream of 9- by 15-ft test section. 


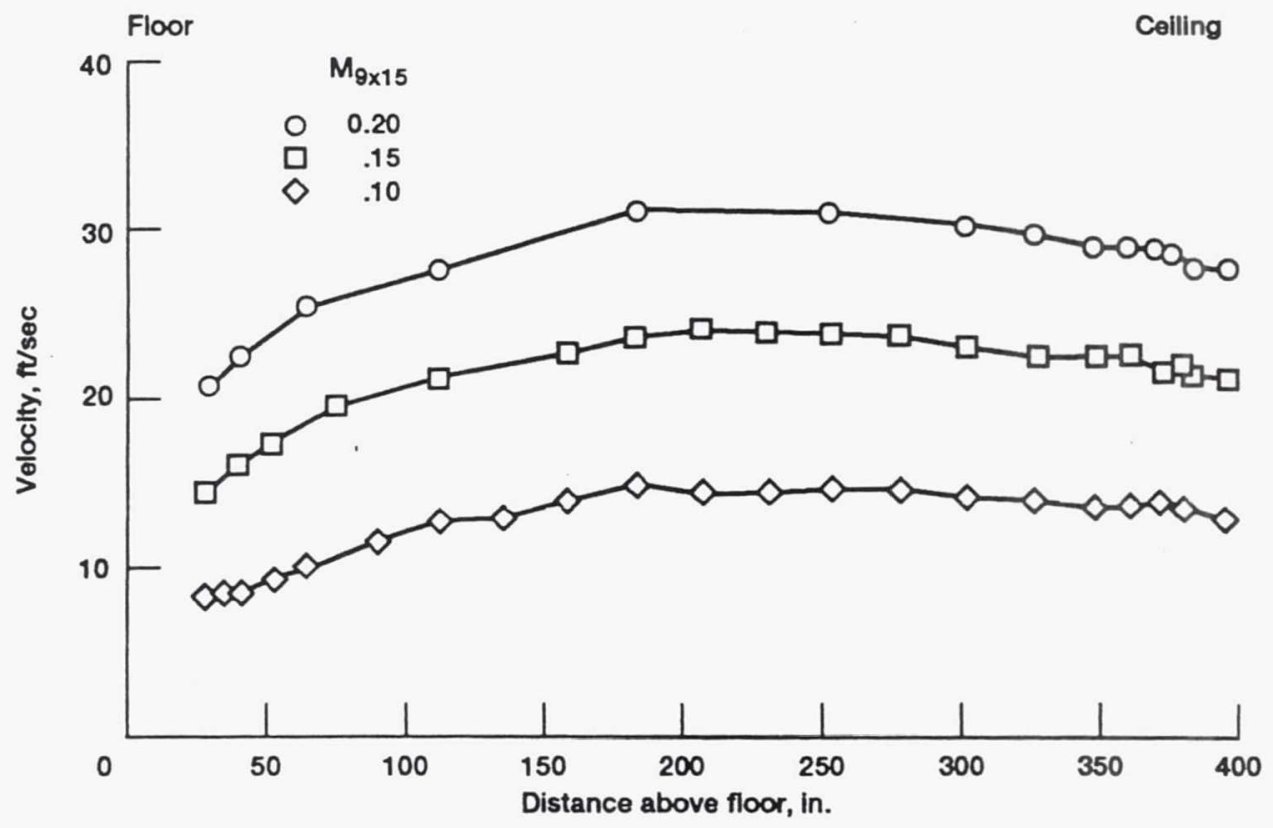

Figure 42.-Velocity distribution from wind anemometer data along vertical survey plane in settling chamber upstream of 9 - by 15 -ft test section.

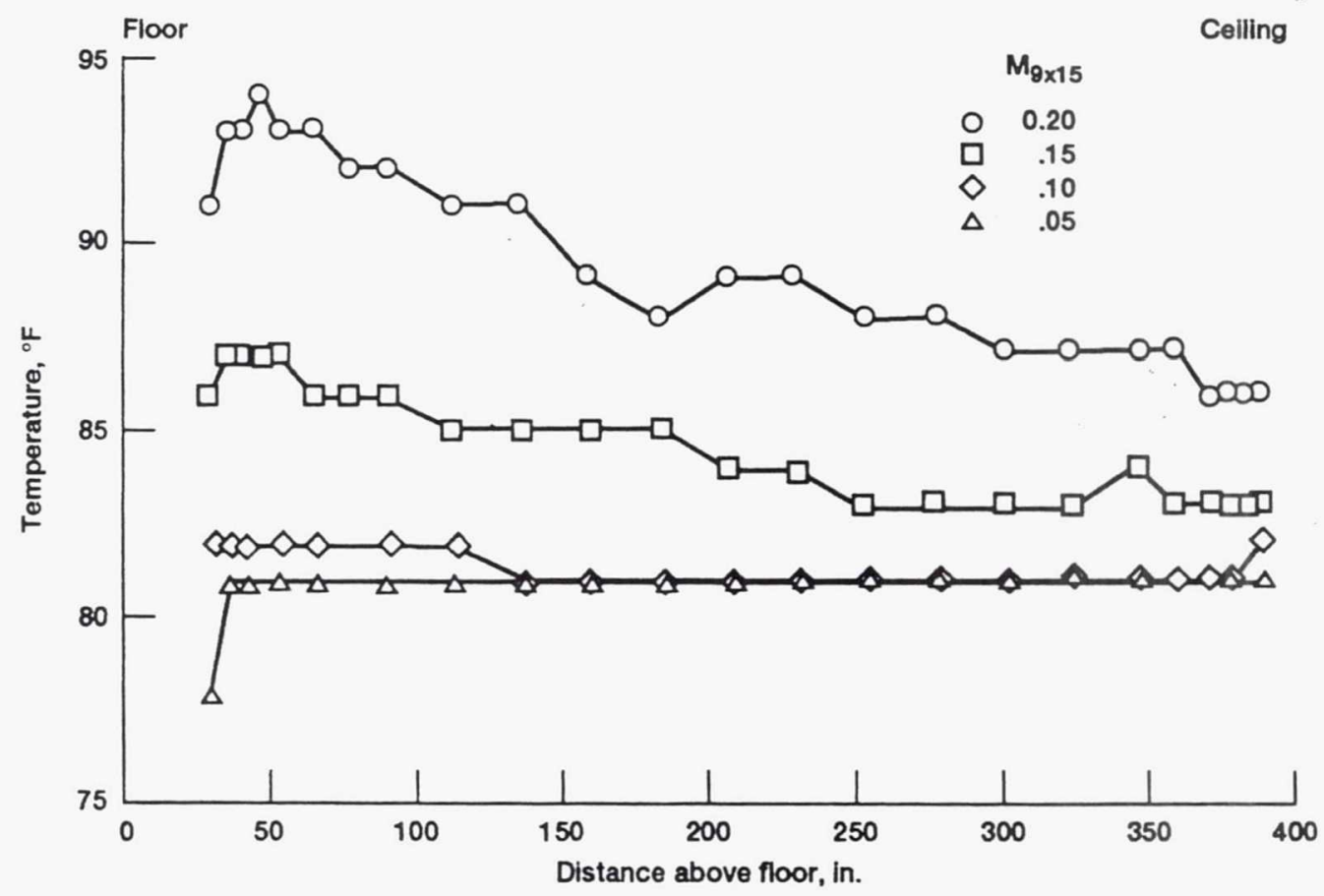

Figure 43.-Total temperature distribution along vertical survey plane in settling chamber upstream of 9 - by 15 -ft test section. 


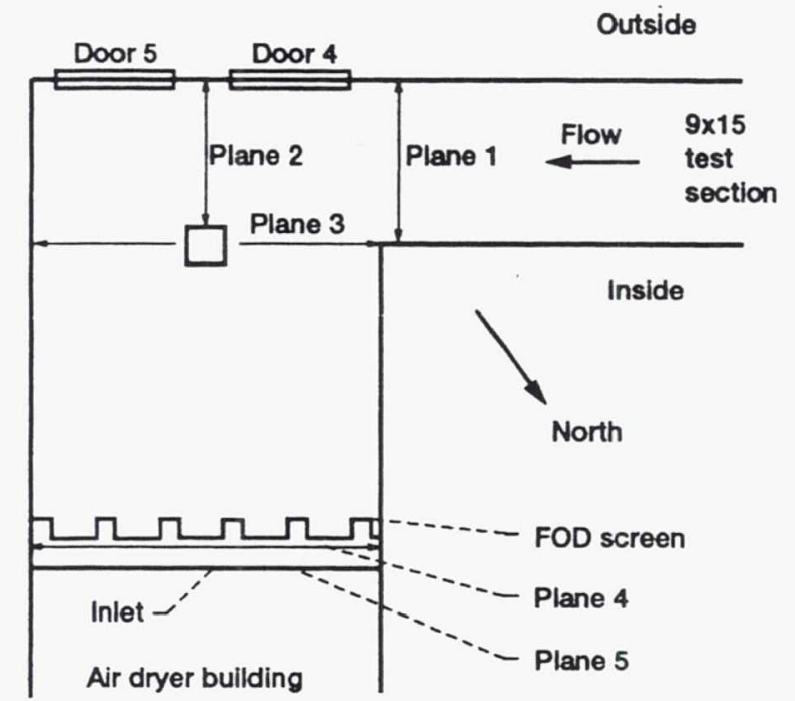

(a) Tum 3.

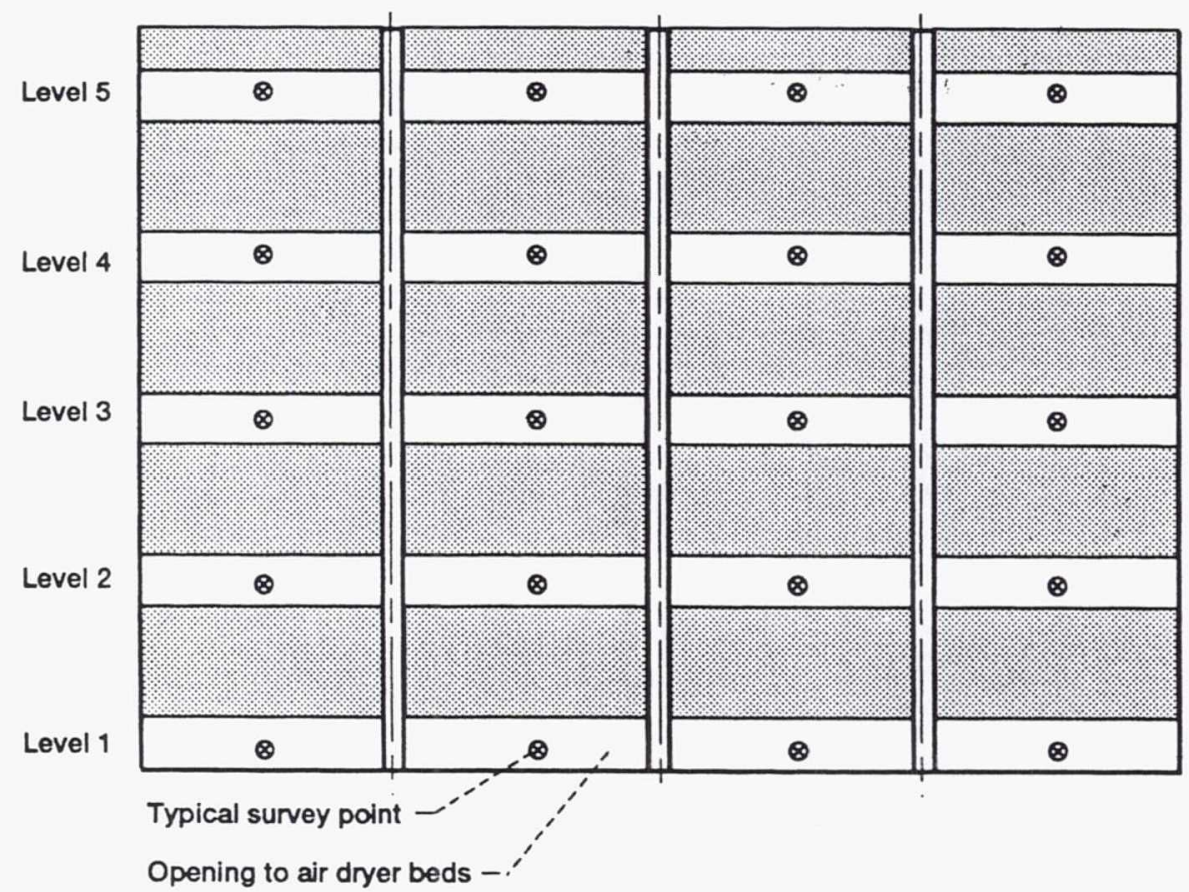

(b) Dryer bed entrance (survey plane 5).

Figure 44.-Anemometer survey locations in area 11 (air dryer inlet). 


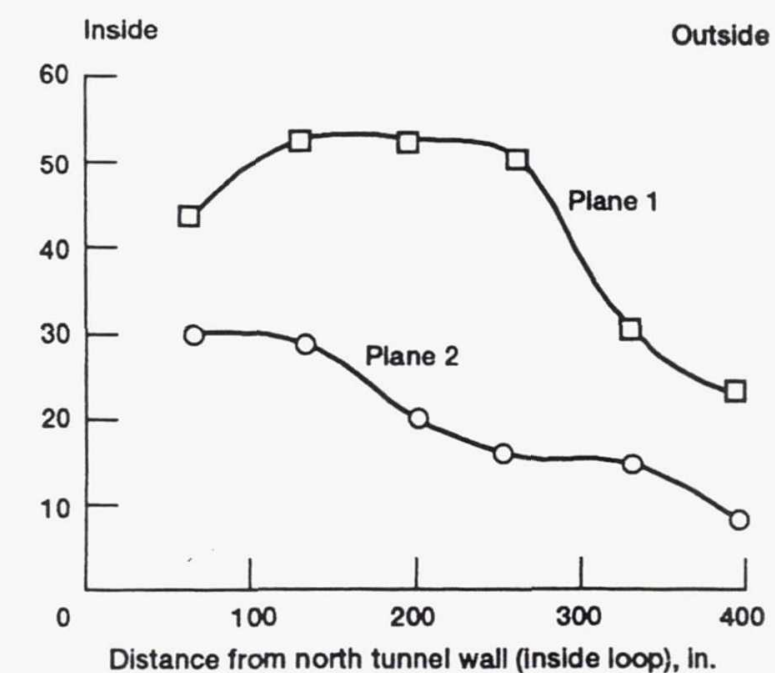

(a) Survey planes 1 (exit of hallway) and 2 (midway through tum 3).

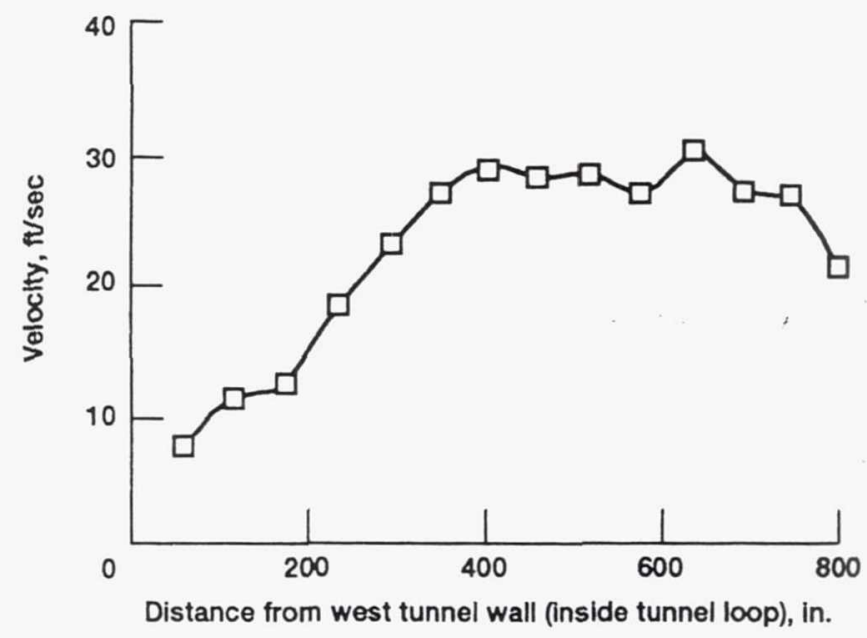

(b) Survey plane 3 (upstream of air dryer beds).

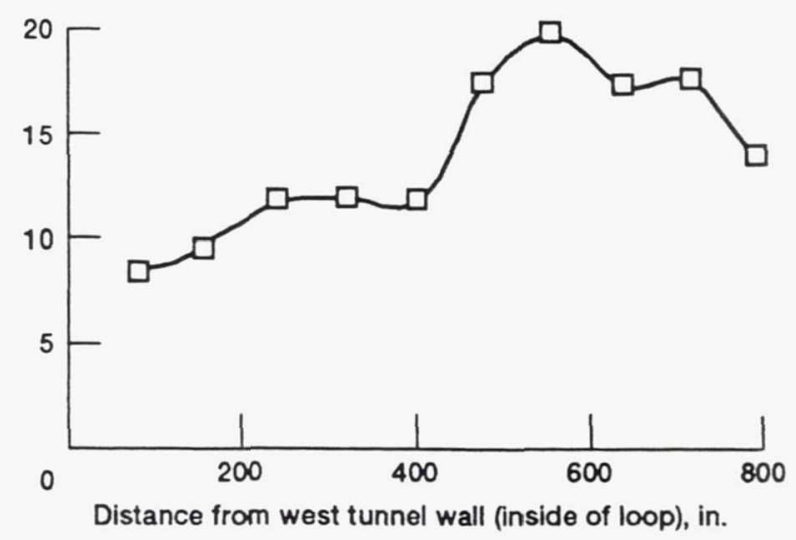

(c) Survey plane 4 (downstream of FOD screen).

Figure 45.-Velocity distributions in turn 3 from hand-held anemometer data at $M_{8 \times 6}=1.2$. 


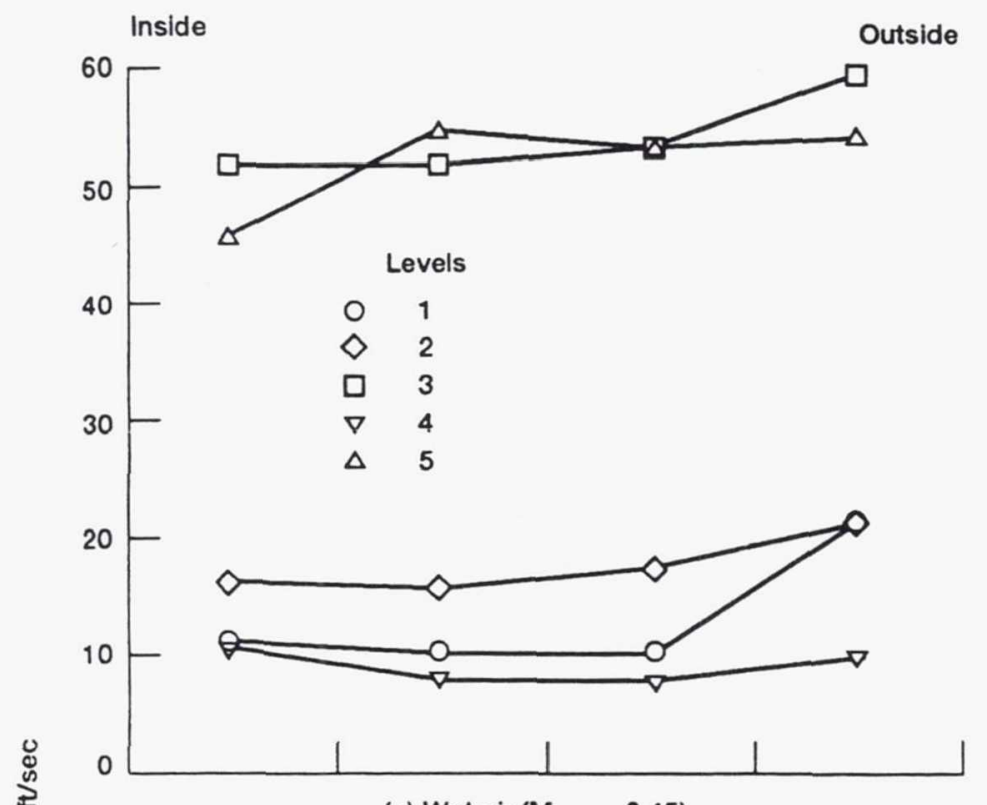

(a) Wet air $\left(M_{8 \times 6}=0.45\right)$.

$\frac{\frac{2}{0}}{3}$

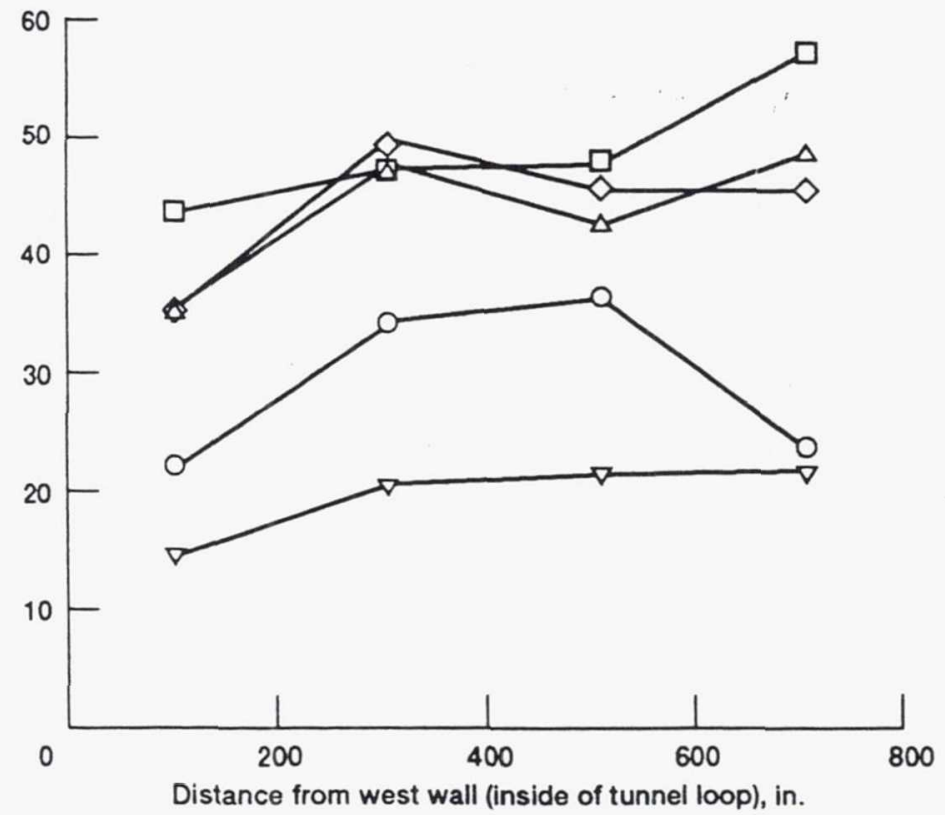

(b) Dry air $\left(M_{8 \times 6}=1.2\right)$.

Figure 46.-Velocity distributions at dryer bed inlet from hand-held anemometer data. 


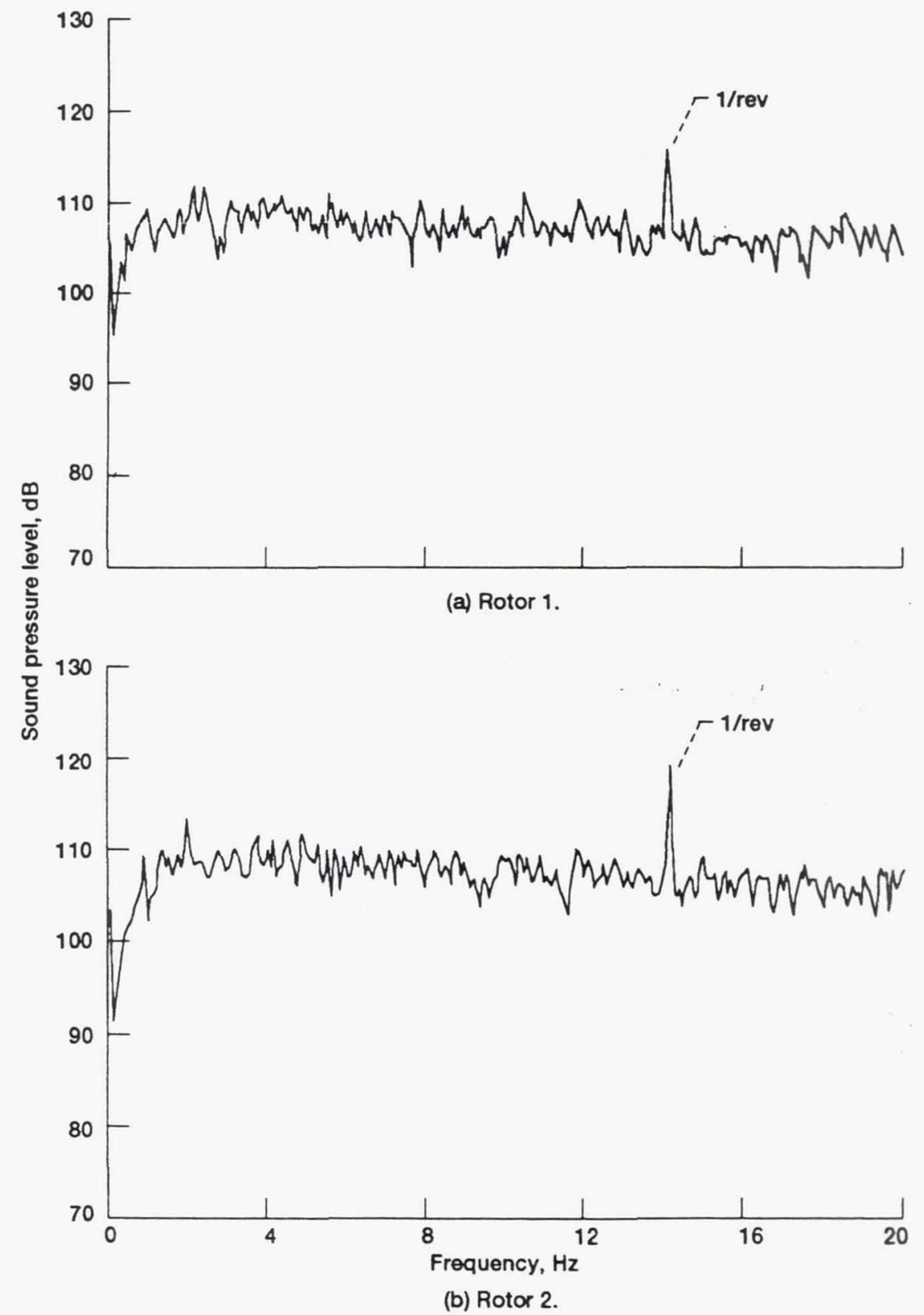

Figure 47.-Pressure spectra of compressor casing taps at first two rotors $(M=2.0$, resolution bandwidth $=0.8 \mathrm{~Hz}$ ). 
Public reporting burden for this collection of information is estimated to average 1 hour per response, including the time for reviewing instructions, searching existing data sources, gathering and maintaining the data needed, and completing and reviewing the collection of information. Send comments regarding this burden estimate or any other aspect of this collection of information, including suggestions for reducing this burden, to Washington Headquarters Services, Directorate for information Operations and Reports, 1215 Jefferson Davis Highway, Suite 1204, Arlington, VA 22202-4302, and to the Otfice of Management and Budget, Paperwork Reduction Project (0704-0188), Washington, DC 20503.
1. AGENCY USE ONLY (Leave blank)
2. REPORT DATE
July 1992
3. REPORT TYPE AND DATES COVERED
Technical Memorandum

\section{TITLE AND SUBTITLE}

Flow Quality Studies of the NASA Lewis Research Center 8- by 6-Foot

Supersonic/9- by 15-Foot Low Speed Wind Tunnel

6. AUTHOR(S)

E. Allen Arrington and Mark T. Pickett

WU-505-62-84

5. FUNDING NUMBERS

National Aeronautics and Space Administration

Lewis Research Center

Cleveland, Ohio 44135-3191

8. PERFORMING ORGANIZATION REPORT NUMBER

E-6827

9. SPONSORING/MONITORING AGENCY NAMES(S) AND ADDRESS(ES)

10. SPONSORING/MONITORING AGENCY REPORT NUMBER

National Aeronautics and Space Administration

Washington, D.C. 20546-0001

NASA TM-105417

AIAA-92-3916

11. SUPPLEMENTARY NOTES

Prepared for the 17th Aerospace Ground Testing Conference sponsored by the American Institute of Aeronautics and Astronautics, Nashville,

Tennessee, July 6-8, 1992. E. Allen Arrington, Sverdrup Technology, Inc., Lewis Research Center Group, 2001 Aerospace Parkway, Brook Park, Ohio 44142 (work funded by NASA Contract NAS3-25266), and Mark T. Pickett, Lewis Research Center. Responsible person, Mark T. Pickett, (216) 433-5721.

12a. DISTRIBUTION/AVAILABILITY STATEMENT

12b. DISTRIBUTION CODE

Unclassified - Unlimited

Subject Category 09

13. ABSTRACT (Maximum 200 words)

A series of studies has been conducted to determine the existing flow quality in the NASA Lewis 8- by 6-Foot Supersonic/ 9- by 15 -Foot Low Speed Wind Tunnel. The information gathered from these studies was used to determine the types and designs of flow manipulators which can be installed to improve overall tunnel flow quality and efficiency. Such manipulators include honeycomb flow straighteners, turbulence reduction screens, corner turning vanes, and acoustic treatments. This report describes the types of measurements, instrumentation, and results obtained from experiments conducted at several locations throughout the tunnel loop.

14. SUBJECT TERMS

Wind tunnel; Flow quality; Flow field measurement

15. NUMBER OF PAGES 46

16. PRICE CODE

$\mathrm{A03}$

\begin{tabular}{c|c}
\hline 17. SECURITY CLASSIFICATION & 18. SECURITY CLASSIFICATION \\
OF REPORT & OF THIS PAGE \\
Unclassified & Unclassified
\end{tabular}

19. SECURTYY CLASSIFICATION OF ABSTRACT

20. LIMITATION OF ABSTRACT

NSN 7540-01-280-5500 
National Aeronautics and

Space Administration

Lewis Research Center

Cleveland, Ohio 44135

Official Business

Penalty for Private Use $\$ 300$
FOURTH CLASS MAIL

ADDRESS CORRECTION REQUESTED
|||| $\mid$

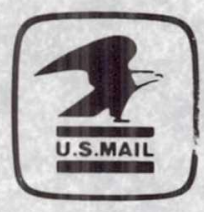

Postage and Fees Paid National Aeronautics and Space Administration

NASA 451 